CLAUDY MARCONDES DOS SANTOS JÚNIOR

METODOLOGIA PARA REPRESENTAÇÃO DETALHADA DOS CUSTOS DE AQUISIÇÃO DE ENERGIA E REPASSES TARIFÁRIOS

NO FLUXO DE CAIXA DAS EMPRESAS DISTRIBUIDORAS: UM ENFOQUE PROBABILÍSTICO 
CLAUDY MARCONDES DOS SANTOS JÚNIOR

\title{
METODOLOGIA PARA REPRESENTAÇÃO DETALHADA DOS CUSTOS DE AQUISIÇÃO DE ENERGIA E REPASSES TARIFÁRIOS NO FLUXO DE CAIXA DAS EMPRESAS DISTRIBUIDORAS: UM ENFOQUE PROBABILÍSTICO
}

\author{
Dissertação apresentada à Escola \\ Politécnica da Universidade de São \\ Paulo para a obtenção do título de \\ Mestre em Engenharia
}


CLAUDY MARCONDES DOS SANTOS JÚNIOR

\title{
METODOLOGIA PARA REPRESENTAÇÃO DETALHADA DOS CUSTOS DE AQUISIÇÃO DE ENERGIA E REPASSES TARIFÁRIOS NO FLUXO DE CAIXA DAS EMPRESAS DISTRIBUIDORAS: UM ENFOQUE PROBABILÍSTICO
}

\author{
Dissertação apresentada à Escola \\ Politécnica da Universidade de São \\ Paulo para a obtenção do título de \\ Mestre em Engenharia \\ Área de Concentração: \\ Sistemas de Potência \\ Orientador: \\ Prof. Dr. Dorel Soares Ramos
}


Este exemplar foi revisado e alterado em relação à versão original, sob responsabilidade única do autor e com a anuência de seu orientador.

São Paulo, de outubro de 2008.

Assinatura do autor

Assinatura do orientador

FICHA CATALOGRÁFICA

Santos Júnior, Claudy Marcondes dos

Metodologia para representação detalhada dos custos de aquisição de energia e repasses tarifários no fluxo de caixa das empresas distribuidoras: um enfoque probabilístico / C.M. dos Santos Júnior. -- ed.rev. -- São Paulo, 2008.

$120 \mathrm{p}$.

Dissertação (Mestrado) - Escola Politécnica da Universidade de São Paulo. Departamento de Engenharia de Energia e Automação Elétricas.

Distribuição de energia elétrica I. Universidade de São Paulo. Escola Politécnica. Departamento de Engenharia de Energia e Automação Elétricas II. t. 


\section{DEDICATÓRIA}

Dedico este trabalho ao meu Pai. Sem seu apoio e incentivo nada disso seria possível. 


\section{AGRADECIMENTOS}

Agradeço principalmente a Deus.

Ao meu orientador, Prof. Dorel Soares Ramos, pela confiança e valiosa ajuda durante todo trabalho.

A minha família, por tudo que eles representam pra mim e pelo amor incondicional, em especial a minha mãe Maria Aparecida, meu pai Claudy, minhas irmãs Elaine, Elisangela e Denise e meus sobrinhos Matheus e Maria Eduarda.

A minha namorada, Ana Catharina, pelo companheirismo e compreensão nas horas que tiveram que ser dedicadas a elaboração deste trabalho.

E a todos aqueles que, direta ou indiretamente, contribuíram para a realização deste trabalho. 


\section{RESUMO}

O gerenciamento dos custos com a compra de energia elétrica para atendimento do mercado consumidor é um assunto que assumiu, nos últimos anos, papel relevante nas distribuidoras. Este fenômeno pode ser explicado pela crescente participação dos custos de energia comprada, para suprimento do mercado cativo, no desempenho operacional dessas empresas, bem como pelas recentes alterações na regulamentação que agregaram ao processo da compra a necessidade de um altíssimo nível de assertividade.

Considerando a existência de uma lacuna na literatura da área, a despeito de trabalhos que tratam do entendimento e gerenciamento do repasse dos custos com a compra de energia elétrica pelas distribuidoras e da análise de riscos associados às incertezas pertinentes ao processo, propõe-se, neste trabalho, uma metodologia para representar os custos com a compra de energia elétrica no fluxo de caixa da distribuidora, assim como modelo que auxilie no gerenciamento dos riscos associados aos desvios das variáveis que compõem o processo, em relação a um cenário de referência.

Para tanto, são apresentadas, através de equações, as regras de repasse com a aquisição de energia elétrica para a tarifa de fornecimento do consumidor final e uma metodologia empírica para análise de risco baseada em modelagem estatística, com o suporte de modelos econométricos, permitindo uma varredura de cenários plausíveis via simulação Monte Carlo.

Com isso, para uma compra energia que atenda às necessidades de consumo de uma distribuidora ao longo de um ano, tal modelo deve ser capaz de informar a disponibilidade de caixa da empresa para fazer frente às despesas com a compra de energia em determinada data futura ou, ainda, deve ser capaz de permitir a avaliação do valor presente resultante dos desembolsos versus recebimentos ao final do período de repasse, aferidos através de metodologia com enfoque probabilístico. 


\begin{abstract}
The management of the costs related to electric energy purchase to supply the market is an issue that assumed, in the last years, a relevant role in the distribution companies. This phenomenon may be explained by the increasing participation of the quoted costs in the operational performance of such companies and by the recent changes in the rules which brought to the energy acquisition process a need of very high assertiveness.

Considering the existence of an important gap in the area literature, in despite of papers which approach the understanding and management of cost pass through with electric energy purchase by the distributors, and the risk analysis connected to the uncertainties relevant to the process, in this work it is developed a new methodology to represent the costs with electric energy purchase in the distributors cash flow, as well as a model that helps in the management of risks related to the variable changes in relation to a reference scenario for the whole process.

In this way, the energy supply costs pass through rules are presented with the aid of mathematical equations, as well as an empirical methodology is proposed, taking advantage of statistical and econometric models, in order to making feasible a Monte Carlo simulation aiming at screening the universe of scenarios that could happen in real life.

Furthermore, giving the energy supply costs throughout one year, the model should be capable to forecast the company cash available to face these costs in a certain future date and, besides that, the model should be capable to calculate the present value arising from the disbursement versus the receipts along the time, till the end of the pass through period, in a probabilistic focus.
\end{abstract}




\section{LISTA DE SIGLAS}

IRTITEM

IRTFIO

Valor1

Valoro

IVI

FATORX

$V R$

$V L 5$

Q5

VL3

Q3
Índice de Reajuste Tarifário específico para cada Item da "Parcela A"

Índice de Reajuste Tarifário da "Parcela B"

Valor associado a cada item das componentes da "Parcela A", considerando as condições vigentes na Data de Reajuste em Processamento

Valor associado a cada item das componentes da "Parcela A", considerando as condições vigentes na Data de Referência Anterior

Refere-se ao "número índice" obtido pela divisão dos índices do IGP-M da Fundação Getúlio Vargas, ou do índice que vier a sucedê-lo, do mês anterior à data do reajuste em processamento e o do mês anterior à Data de Referência Anterior

Refere-se ao "número índice" fixado pela Aneel, a cada revisão periódica, conforme definido no contrato de concessão, a ser subtraído ou adicionado ao IVI a cada reajuste tarifário anual. Destina-se à captura dos ganhos, para repartição com o consumidor, decorrentes de melhoras da produtividade associadas à escala do negócio, que aumenta na medida em que o mercado aumenta

Valor de Referência para repasse de preços, calculados e validos para o ano

valor médio de aquisição nos leilões de compra de energia elétrica proveniente de novos empreendimentos de geração realizados no ano "A - 5", ponderado pelas respectivas quantidades adquiridas

Quantidade total, expressa em MWh por ano, adquirida nos leilões de compra de energia elétrica proveniente de novos empreendimentos de geração, realizados no Ano "A - 5"

Valor médio de aquisição nos leilões de compra de energia elétrica proveniente de novos empreendimentos de geração realizados no ano "A - 3", ponderado pelas respectivas quantidades adquiridas

Quantidade total, expressa em MWh por ano, adquirida nos leilões de compra de energia elétrica proveniente de novos empreendimentos de geração, realizados no ano "A - 3" 


\section{ET}

$m$

a

$b$

Ea,m

$E_{b, m}$

Eltaipu,m

EProinfa,m

Creg

MrefCat

iPreg

$E^{100 \%} a, m$

Pmix

$\mathrm{Pa}$

$C 100 \%, m$

$P b$

Pltaipu

$E^{100 \%} b, m$

$\mathrm{C} 100 \%$
Energia total contratada habilitada para repasse no Período Tarifário

Mês pertencente ao Período Tarifário

Tipo de contrato composto por CCEAR e contratos de GD

Tipo de contrato composto por contratos bilaterais

Energia no mês " $m$ ", referente a cada contrato "a" pertencente à carteira da distribuidora na Data de Reajuste em Processamento para o Período Tarifário

Energia no mês "m", referente a cada contrato "b" considerado na carteira da distribuidora na Data de Reajuste em Processamento para o Período Tarifário

Energia referente à cota recebida de Itaipu

Energia no mês " $m$ ", referente à cota recebida do Proinfa

Carga Regulatória anual referente ao Período de Referência

Mercado de Referência de energia do Mercado cativo

Índice de perdas Regulatória

Energia no mês " $m$ " referente a cada contrato "a", já com ajuste que iguala o montante total contratado à Carga Regulatória em situação de sobra

Preço médio de repasse dos CCEARs e de GD na Data de Reajuste em Processamento

Preço de repasse do contrato "a" na Data de Reajuste em Processamento

"Repasse de 100\%" do custo da energia, referente ao mês " $m$ "

Preço do contrato "b" na Data de Reajuste em Processamento

Preço considerado para repasse na Data de reajuste em Processamento da energia de Itaipu

Energia no mês " $m$ ", referente a cada contrato " $b$ " considerado na carteira da distribuidora na Data de Reajuste em Processamento para o Período Tarifário, já com a redução, quando necessária, que iguala o montante total contratado à Carga Regulatória em situação de sobra

Custo total com o "Repasse de 100\%" na Data de reajuste em Processamento 
Mreg

n

Mreg,n

Creal, $n$

Mfat

iPreg,n

Ever,n

Evera,n

Everb,n

Everltaipu,n

EverProinfa, $n$

Sver

Sver, $n$

C3\%

$P a, n$

$P b, n$

Pspot,n

IPCAac

Acp, $n$

$E_{c p, n}$
Mercado Regulatório anual, referente ao Período de Apuração

Mês do ano civil (Período de Apuração) imediatamente anterior a Data de Reajuste em Processamento

Mercado Regulatório do mês " $n$ "

Carga real mensal do agente de distribuição medida pela CCEE no Centro de Gravidade no mês " $n$ "

Mercado de Energia faturado dos consumidores cativos pelo agente de distribuição no Período de Apuração

Índice de perdas Regulatória vigentes no mês " $n$ ", definida pela Aneel na revisão tarifária da distribuidora

Montante total de energia contratada, verificado no mês " $n$ "

Energia contratada pela distribuidora verificada no mês " $n$ ", referente ao contrato " $a$ "

Energia contratada pela distribuidora verificada no mês " $n$ ", referente ao contrato " $b$ "

Energia verificada no mês " $n$ ", referente à cota recebida de Itaipu

Energia verificada no mês " $n$ ", referente à cota recebida do Proinfa

Sobra Contratual verificada no Período de Apuração

Sobra Contratual verificada no mês " $n$ "

Custos com sobrecontratação repassáveis à tarifa do consumidor na Data de Reajuste em Processamento

Preço pago pelo contrato "a" no mês " $n$ "

Preço pago pelo contrato " $b$ " no mês " $n$ "

PLD médio ponderado pelas exposições da distribuidora no Mercado Spot no mês " $n$ "

Taxa de IPCA acumulada entre o mês de apuração da sobra e a Data de Reajuste em Processamento

Compra no Mercado Spot no mês " $n$ " considerada na apuração dos custos com Ajuste Financeiro

Energia comprada no Mercado Spot no mês " $n$ " 
$A a, n$

CAF

Tmédia,n

$E T^{100 \%}, m$

Ever $^{c v a} a, n$

Ever $^{\text {cva }}, n$

$\mathrm{Cuer}^{\text {cva }}, n$

CVAENERG, $n$

CVAENERG

MrefLiv

MrefDem

PTotal

iPreg

ECat

$\%$ ECat

PTec

iPTec

\%PTec

iPRB

$\%$ PRBcat
Energia no mês " $n$ ", do contrato "a" alocada para apuração dos custos com Ajuste Financeiro

Custos repassáveis a tarifa do consumidor com o Ajuste Financeiro na Data de Reajuste em Processamento

Preço médio dos contratos repassados à tarifa na Data de Reajuste em Processamento imediatamente anterior ao mês " $n$ "

Montante total de energia contratada considerado na Data de Reajuste em Processamento para o Período Tarifário que engloba o mês " $n$ "

Montante de Energia verificado no mês " $n$ ", referente ao contrato "a" com ajuste para apuração da CVAENERG

Montante total contratado verificado no mês " $n$ ", para apuração da CVAENERG

Custo total para o Montante total contratado verificado no mês "n", para apuração da CVAENERG

Custo com a CVAENeRG, no mês " $n$ "

Custo total com a CVAenerg na Data de Reajuste em Processamento

Mercado de Referência de energia do Mercado Livre

Mercado de Referência de Demanda

Perdas Totais (PTotal) ou Perdas Regulatória no Centro de Gravidade

Índice de perdas Regulatória

Compra de Energia Elétrica para revenda ao consumidor cativo

Participação da compra de energia elétrica para revenda em relação à Carga Regulatória

Perdas técnicas na distribuição

Índice de Perdas Técnicas

Participação das Perdas Técnicas na distribuição em relação à Carga Regulatória

Índice de perdas na Rede Básica

participação das perdas técnicas na distribuição referente à Energia comprada para revenda em relação à Carga Regulatória 
PCom

$\%$ PCom

PRBPdis

\%PRBPdis

TECat

TPTec

TPRBcat

TPCome

TPComD

$\% R D$

$\% R E$

f

RECat, $f$

MCat, $f$

RECL,f

MLiv,f

REDem, $f$

$M D e m, f$
Perdas Não Técnicas na Distribuição ou Perdas Comerciais

Participação das perdas não técnicas em relação à Carga Regulatória

Perdas na RB referente às Perdas na distribuição

Participação das perdas na RB referente às Perdas na distribuição em relação à Carga Regulatória

Tarifa da Compra de Energia Elétrica para revenda ao consumidor cativo

\section{Tarifa das Perdas Técnicas na Distribuição}

Tarifa das Perdas na Rede Básica referente à Energia comprada para revenda

Tarifas das Perdas não Técnicas na Distribuição em $\mathrm{R} \$ / M W h$

Tarifas das Perdas não Técnicas na Distribuição em R $\$ / k W$

Participação da Receita verificada de demanda no Período de Referência em relação à Receita Total verificada no mesmo período

Participação da Receita verificada de energia no Período de Referência em relação à Receita Total verificada no mesmo período

Mês referente a um determinado desembolso e/ou recebimento (faturamento)

Receita da distribuidora relacionada apenas à energia consumida por consumidores cativos no mês " $f$ "

Mercado de Energia referente ao consumo de energia dos consumidores cativos da distribuidora no mês " $f$ ".

Receita da distribuidora relacionada à energia consumida por consumidores cativos mais livres da distribuidora

Mercado de Energia referente ao consumo de energia dos consumidores livres da distribuidora no mês " $f$ ".

Receita da distribuidora relacionada à demanda faturada dos consumidores conectados a rede de distribuição

Mercado de Demanda referente à demanda faturada dos consumidores conectados à rede da distribuidora no mês " $f$ ". 


\begin{tabular}{|c|c|}
\hline RETotal,f & $\begin{array}{l}\text { Receita total provinda do faturamento dos custos relacionado à } \\
\text { Compra de energia elétrica no mês "f" }\end{array}$ \\
\hline$F$ & Mês futuro do Fluxo de Caixa da Compra \\
\hline$F C A, F$ & Caixa acumulado futuro em $R \$$ na data futura "F" \\
\hline j & Taxa de juros em \% \\
\hline Rf & Receita referente aos recebimentos no mês "f" \\
\hline$D f$ & Despesa referente ao desembolso no mês "f" \\
\hline$V P$ & Valor presente de um monte em determinada data futura " $F$ " \\
\hline K & Taxa de desconto em \% \\
\hline DRPo & $\begin{array}{l}\text { Data de Reajuste em Processamento imediatamente anterior ao } \\
\text { Período de Apuração }\end{array}$ \\
\hline DRP1 & $\begin{array}{l}\text { Data de Reajuste em Processamento contida no Período de } \\
\text { Apuração }\end{array}$ \\
\hline $\mathrm{DRP} 2$ & $\begin{array}{l}\text { Data de Reajuste em Processamento imediatamente posterior } \\
\text { ao Período de Apuração }\end{array}$ \\
\hline iGlosa & Índice de glosa regulatória \\
\hline MCat,f & Mercado Cativo faturado pela distribuidora no mês " $f$ " \\
\hline Cdist,$f$ & $\begin{array}{l}\text { Energia requerida pela distribuidora no Centro de Gravidade, no } \\
\text { mês "f" }\end{array}$ \\
\hline$M L i v, f$ & Mercado Livre faturado pela distribuidora no mês " $f$ " \\
\hline Perdas, $f$ & $\begin{array}{l}\text { Perdas Totais na distribuição, referenciada ao Centro de } \\
\text { Gravidade, no mês "f" }\end{array}$ \\
\hline$P I B, f$ & PIB no mês "f" \\
\hline Djf & $\begin{array}{l}\text { Variáveis simbólicas, dummies para o modelo de regressão da } \\
\text { Energia requerida pela distribuidora no Centro de Gravidade, no } \\
\text { mês "f" }\end{array}$ \\
\hline j & Mês do ano, variando de 1 (janeiro) a 12 (dezembro) \\
\hline$\beta \in \alpha$ & Coeficientes de regressão da equação \\
\hline$\Delta f$ & $\begin{array}{l}\text { Componente aleatória do modelo, suposta normalmente } \\
\text { distribuída de média zero e variância constante } \sigma^{2}-N(0, \sigma)\end{array}$ \\
\hline Previsão_se,f & Erro Padrão da Previsão \\
\hline
\end{tabular}




\begin{tabular}{|c|c|}
\hline$X f$ & $\begin{array}{l}\text { Vetor com os valores das variáveis explicativas para } \\
\text { determinada data " } f \text { ' futura }\end{array}$ \\
\hline$X f^{\prime}$ & Vetor transposto de $x f$ \\
\hline$T$ & Corresponde ao número de observações do histórico \\
\hline$K$ & Corresponde ao número de Coeficientes do Modelo \\
\hline$X$ & Matriz $T \times k$ dos valores das variáveis observadas \\
\hline$X^{\prime}$ & Matriz transposta de $X$ \\
\hline$s$ & Erro padrão da regressão \\
\hline$y i$ & $\begin{array}{l}\text { Corresponde ao valor observado da energia requerida pela } \\
\text { distribuidora no Centro de Gravidade para uma determinada } \\
\text { data "i" do histórico analisado }\end{array}$ \\
\hline yi' & $\begin{array}{l}\text { Corresponde ao valor calculado de energia requerida pela } \\
\text { distribuidora no Centro de Gravidade para uma determinada } \\
\text { data "i" do histórico analisado }\end{array}$ \\
\hline$x$ & $\begin{array}{l}\text { Corresponde ao mês que se deseja projetar o mercado livre e a } \\
\text { Perda na Rede Básica }\end{array}$ \\
\hline$i m$ & $\begin{array}{l}\text { Distribuição de Probabilidade do índice mensal de taxa SELIC } \\
\text { ou IPCA }\end{array}$ \\
\hline ia & $\begin{array}{l}\text { Distribuição de Probabilidade do índice anual de taxa SELIC ou } \\
\text { IPCA }\end{array}$ \\
\hline
\end{tabular}




\section{SUMÁRIO}

1. INTRODUÇÃO .....................................................................................................1

1.1. CUSTOS COM A COMPRA DE ENERGIA ELÉTRICA PELAS DISTRIBUIDORAS ...................... 1

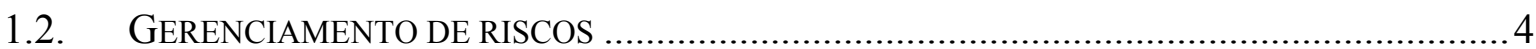

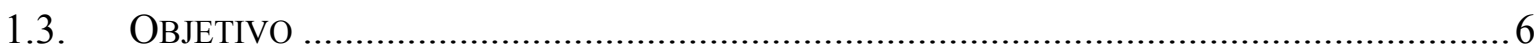

2. A ENERGIA ELÉTRICA NAS DISTRIBUIDORAS.................................................9

3. CONTRATAÇÃO DA ENERGIA ELÉTRICA PELAS DISTRIBUIDORAS .........11

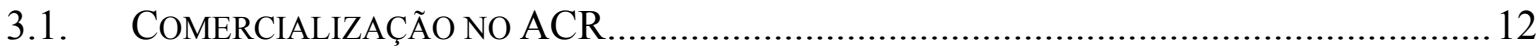

3.2. DESEMBOLSO DOS CUSTOS COM A CONTRATAÇ̃̃O...................................................... 15

3.3. SAZONALIDADE DOS CONTRATOS..................................................................... 16

4. REPASSE DOS CUSTOS COM ENERGIA ELÉTRICA.............................................18

4.1. A TARIFA DE FORNECIMENTO DE ENERGIA ELÉTRICA.................................................. 18

4.1.1. Evolução da tarifa de Fornecimento no Brasil .............................................. 18

4.1.2. Receita Requerida das Empresas de Distribuição ..........................................20

4.1.3. As Componentes da Tarifa de Fornecimento de Energia Elétrica.....................23

4.1.4. Mecanismos de atualização das Tarifas de Energia Elétrica ……...................22

4.2. CUSTOS COM A COMPRA DE ENERGIA ELÉTRICA REPASSÁVEIS À TARIFA ......................32

4.2.1. Repasse de 100\% dos Custos de Atendimento da Carga Regulatória ...............37

4.2.2. Repasse da Sobrecontratação ..................................................................4 43

4.2.3. Repasse do Ajuste Financeiro …………………....................................... 49

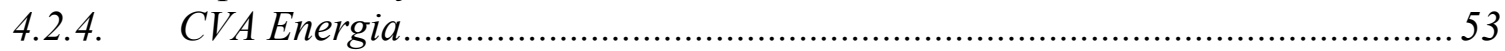

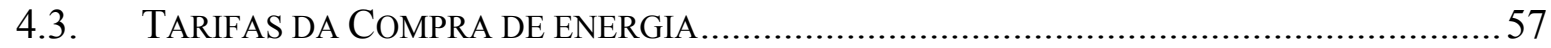

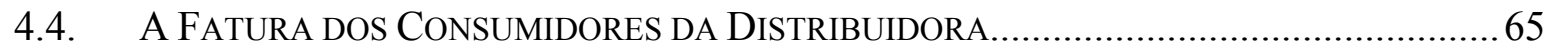

5. METODOLOGIA PARA REPRESENTAÇÃO DOS CUSTOS DE COMPRA DE ENERGIA ELÉTRICA NO FLUXO DE CAIXA DE UMA EMPRESA DISTRIBUIDORA .................................................................................................................67

5.1. VÉRTICE E HORIZONTE TEMPORAL DO FLUXO DE CAIXA EM ESTUDO............................69

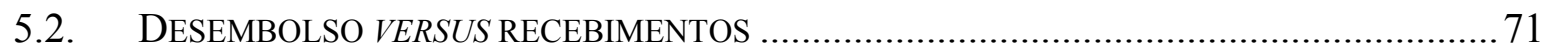

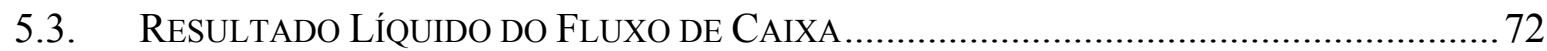

6. UM MODELO EMPÍRICO DE ANÁLISE DE RISCO PARA FLUXO DE CAIXA

DA COMPRA DE ENERGIA (CASHFLOW-AT-RISK) .................................................76

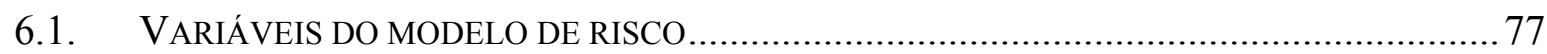

6.1.1. A escolha das Variáveis Independentes........................................................79

6.1.2. Variáveis de Interesse e Dependentes .........................................................79

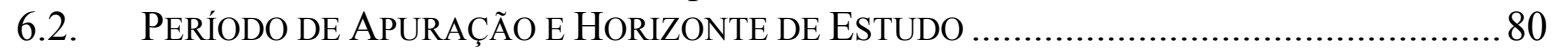

6.3. ElABORAÇÃO DE METODOLOGIA DE PREVISÃO PARA OS FATORES DE RISCO ………....80

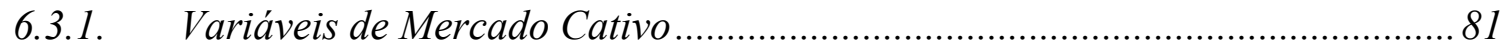

6.3.2. Variável de preço de curto prazo (PLD) ......................................................90

6.3.3. Tratamento para previsão dos fatores de risco macroeconômicos....................91

6.3.4. Outras Variáveis do Modelo de Previsão ....................................................93

6.4. MONTAR DISTRIBUIÇ̃̃o SIMULADA DAS VARIÁVEIS DE INTERESSE E DETERMINAR O

FLUXO DE CAIXA EM RISCO (CASHFLOW-AT-RISK) .......................................................... 94

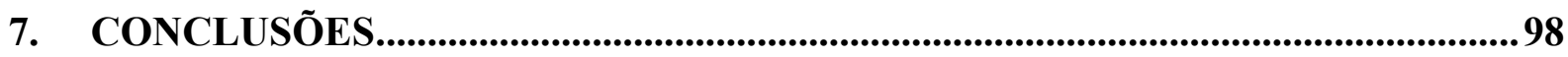

REFERÊNCIAS BIBLIOGRÁFICAS .......................................................................100 


\section{INTRODUÇÃO}

O trabalho de pesquisa reportado no que se segue, apresenta, através de equações matemáticas, as regras de repasse com a aquisição de energia elétrica para tarifa de fornecimento do consumidor final. Adicionalmente, desenvolve-se uma metodologia empírica para análise de risco baseada em modelagem estatística com o suporte de modelos econométricos para análise de séries temporais, permitindo uma varredura de cenários plausíveis via simulação Monte Carlo.

Nessa perspectiva, para uma compra energia que atenda às necessidades de consumo de uma distribuidora ao longo de um ano, deve-se dispor de um modelo capaz de permitir avaliar a disponibilidade de caixa da empresa para fazer frente às despesas com a compra de energia em determinada data futura. Mais ainda, o modelo deve ser capaz de permitir a avaliação do valor presente resultante dos desembolsos versus recebimentos ao final do período de repasse, aferidos através de metodologia com enfoque probabilístico, de modo a caracterizar o cumprimento da prerrogativa regulatória de repasse integral dos custos de compra de energia às tarifas.

\subsection{Custos com a compra de energia elétrica pelas distribuidoras}

Os custos com a compra de energia elétrica para atendimento do mercado consumidor têm participação relevante no desempenho operacional das empresas de distribuição de energia elétrica, contribuindo geralmente com mais da metade de seus custos operacionais. Uma administração inadequada destes custos resulta normalmente em relevantes prejuízos financeiros, podendo afetar severamente os resultados de uma distribuidora. Com isso, o planejamento e gerenciamento dos custos relacionados à compra de energia elétrica têm papel preponderante nas empresas de distribuição de energia elétrica.

Pode-se dizer que a compra de energia elétrica pelas distribuidoras começou a ganhar notoriedade no Brasil a partir 1993, com a Lei $n^{\circ} .8 .631$ (1993), onde foi 
instituída a obrigatoriedade às distribuidoras em estabelecerem compromissos de compra com os fornecedores, dos quais continham uma quantidade de energia elétrica pré-estabelecida pelas distribuidoras.

A partir daí, novas regras que regulamentam o processo da compra de energia elétrica foram criadas, até que, finalmente, em 2004, foi instituído através da Lei $n^{\circ}$. 10.848 (2004) um novo modelo para o setor elétrico brasileiro. Nesse novo esforço de modelagem institucional, as bases de contratação e repasse dos custos com energia elétrica foram modificadas para as regras vigentes no momento em que este trabalho é escrito.

A regulamentação desse novo modelo determina, entre outras coisas, que todos agentes de distribuição do Sistema Interligado Nacional: deverão contratar pelo menos $100 \%$ de suas necessidades de carga, sob risco de penalidades; repassarão à tarifa até $103 \%$ dos custos com a aquisição da energia elétrica; e deverão adquirir, por meio de leilões, realizados no Ambiente de Contratação Regulada (ACR), a energia necessária para atendimento de seu mercado com até cinco anos de antecedência. O intuito dessa regulamentação é garantir alguns dos objetivos principais do novo modelo, que são eles:

$\checkmark$ Garantir a expansão do sistema elétrico brasileiro;

$\checkmark$ Viabilizar comercialmente a entrada de novos geradores, atraindo investimentos e, dessa forma, contribuindo para a segurança do suprimento de energia elétrica e;

$\checkmark$ Promover a modicidade tarifária, através da contratação eficiente de energia para os consumidores cativos (consumo cativo da distribuidora, ou seja, consumidores residenciais, comerciais e industriais que não atendem aos requisitos para se tornarem livres $^{1}$ ou, ainda que atendam tais

\footnotetext{
${ }^{1}$ De acordo com a Lei $n^{\circ} .9 .074$ (1995), podem optar livremente pelo fornecedor de energia os consumidores cuja demanda seja maior ou igual $3 \mathrm{MW}$ e atendidos em nível e tensão a partir de 69 kV, se conectados antes de julho de 1995, ou em qualquer nível de tensão, se conectados após esta data. Consumidor responsável por unidade consumidora, ou conjunto de unidades consumidoras cuja carga seja maior ou igual a $500 \mathrm{~kW}$, do "Grupo A", também podem optar pela compra de fontes alternativas ou pequena centrais hidrelétricas $(\mathrm{PCH})$, de acordo com a Resolução $n^{\circ} .247$ (2006).
} 
requisitos, não tenham exercido essa opção. Estes últimos também são denominados consumidores potencialmente livres).

Esse sistema impõe à distribuidora de energia a necessidade de um altíssimo nível de assertividade de sua previsão de consumo, que tem por sua vez, incertezas pertinentes ao processo.

Susteras (2004), em sua dissertação de mestrado, analisa as regras definidas no Decreto $n^{\circ} .5 .163$ (2004) para o novo modelo do setor elétrico brasileiro, referente aos incentivos e penalidades nas declarações de necessidade de compra de energia pelas distribuidoras, com o objetivo de estabelecer metodologia que permita aos geradores elaboração de estratégias adequadas de oferta nos leilões de energia velha realizados pela Agência Nacional de Energia Elétrica (ANEEL).

Para tanto, foi desenvolvida uma metodologia de otimização, utilizando algoritmo genético, com intuito de tentar prever o comportamento das distribuidoras nos leilões de energia existente. A função objetivo proposta minimiza o valor presente dos prejuízos esperados para distribuidoras em função de: custo da energia contratada nos leilões; repasse considerado na tarifa de energia elétrica; penalidades de subcontratação e contratação acima dos 103\% do mercado cativo da distribuidora; recontratação de energia abaixo do Limite Inferior; e recontratação acima do Limite de Reposição.

É importante ressaltar que a metodologia apresentada, quando aferida, obteve resultados muito bons, posto que os valores apresentados no estudo de caso, a partir de dados reais de um processo de Leilão de Energia Existente, quando comparados com as saídas do modelo apresentaram variações menores que $1 \%$.

Em seu trabalho Cyrino e Campos (2005) também analisam as regras definidas no Decreto $n^{\circ} .5 .163$ (2004) referentes à comercialização de energia elétrica pelas distribuidoras, contudo, com foco na efetividade dos instrumentos disponíveis para mitigar os riscos relacionados à possibilidade de pagamento de penalidades, por parte das distribuidoras, decorrentes das incertezas com as variações do mercado consumidor e do preço da energia elétrica. 
No trabalho, é apresentada metodologia para projeção de mercado, que considera a projeção desagregada através da análise e modelagem do comportamento histórico do consumo de energia elétrica e sua relação com o contexto sócio-econômico para cada classe de consumo (residencial, industrial, comercial, etc.), e metodologia para projeção do preço de energia elétrica baseado na expansão do setor elétrico e nos preços gerados por simulações no Newave ${ }^{2}$.

Para mensurar o risco, o trabalho propõe um nível ótimo de contratação de energia por parte das distribuidoras associado ao menor custo total esperado. Com isso, através de projeções de cenários de preços e mercado, o modelo proposto apresenta o cálculo do Valor em Risco (VaR) em um determinado nível de confiança para um valor esperado do Preço de Liquidação das Diferenças - PLD³.

\subsection{Gerenciamento de riscos}

Diferentemente do apresentado no trabalho do Cyrino e Campos, poucos trabalhos analisam os riscos associados às incertezas inerentes ao processo de compra de energia elétrica e, não só isso, o gerenciamento de risco em instituições não financeiras tem sua prática ainda incipiente. Contudo, recentemente, esse tipo de abordagem vem ganhando espaço crescente no âmbito dessas instituições, particularmente no setor elétrico.

Se há três décadas os investidores aceitavam o movimento inesperado de preços ou flutuações macroeconômicas, como explicação para resultados financeiros ruins, nos dias de hoje espera-se que os gestores sejam capazes de identificar e controlar a exposição das empresas ao risco.

Entre os aspectos que contribuem para tal, destacam-se as recentes histórias de inúmeros casos de insucesso, entre os quais grandes instituições mundiais

\footnotetext{
${ }^{2}$ Newave, modelo utilizado no planejamento da operação de médio prazo (até cinco anos) de subsistemas hidrotérmicos interligados, ou seja, tem como objetivo determinar metas de geração para cada usina, a cada mês, que atendam a demanda e minimizem o valor esperado do custo total de operação ao longo do período de planejamento. Para tanto, adota a representação das usinas hidrelétricas pelo Modelo Equivalente de Energia e a resolução do problema de operação através da Programação Dinâmica Dual Estocástica - PDDE.

3 Preço de Liquidação das Diferenças (PLD), preço utilizado para valorar a compra e a venda de energia no Mercado de Curto Prazo.
} 
perderam bilhões de dólares, em geral, associados à falta de controles efetivos dos riscos envolvidos com seus investimentos e o respectivo impacto nas demonstrações financeiras quando da materialização desses riscos (Ferreira, 2005).

Segundo Castro (2002), no Brasil a abertura da economia e o controle da inflação obtidos na década de 90 , possibilitaram às empresas brasileiras uma inserção mais ampla no mercado internacional e a um planejamento de mais longo prazo, expondo-as a novas fontes de risco e conseqüentemente à necessidade de gerenciamento desses riscos.

Perobelli (2004) trata do gerenciamento de risco para empresas não financeiras em seu trabalho de doutorado, onde apresenta um modelo teórico para mensuração do fluxo de caixa em risco (CashFlow-at-Risk) das empresas, entendido como a probabilidade de a empresa não honrar seus compromissos em determinadas datas futuras, e o aplica a empresas pertencentes ao setor de distribuição de energia elétrica no Brasil.

Em seu modelo, Perobelli estima equações que relacionam as oscilações no fluxo de caixa livre ${ }^{4}$ (FCF) da empresa (variáveis dependentes) associadas a oscilações nos fatores de risco (variáveis independentes). Para tanto ela propõe a utilização de Dados em Painel ${ }^{5}$ para estimar as equações e a utilização do Modelo de Vetores Auto-regressivos (VARM) ${ }^{6}$ para estimar as oscilações dos fatores de risco.

Outro trabalho que propõe metodologia de análise de risco, é o elaborado pela RiskControl em pareceria com a Consultoria Tendências (LAROQUE et al.,

4 Fluxo de Caixa Livre (FCL), trata diretamente dos direitos dos proprietários do Patrimônio Líquido, dos preferencialistas e dos financiadores. O cálculo do FCL é realizado a partir do Lucro Operacional, incluindo Impostos, antes de qualquer remuneração aos donos de capital mencionados.

5 Dados em Painel, segundo Marques (2000), a modelagem utilizando dados em painel implica em maior quantidade de informação, e conseqüentemente maior eficiência na estimação, pois a amostra observa cada indivíduo sob uma perspectiva temporal, e não apenas como um corte no tempo.

6 Vector Autoregressive Model ou VARM, os modelos de vetores auto-regressivos, consistem em sistemas de equações simultâneas que procuram capturar a relação de interdependência entre variáveis e que permitem avaliar o impacto de choques aleatórios sobre uma dessas variáveis em particular. 
2003), que considera cenários probabilísticos para os fatores de risco a partir da integração de metodologias estatísticas e modelos macroeconômicos estruturais.

Para formulação de suas previsões a RiskControl -Tendências utiliza-se da estrutura sugerida pela teoria macroeconômica.

Como qualquer modelo estrutural, o modelo da RiskControl-Tendências divide-se em algumas variáveis exógenas e outras endógenas e a modelagem das relações entre essas variáveis é feita através de regressões econométricas. Para inserir incertezas ao modelo, o trabalho propõe a decomposição dos valores existentes das variáveis exógenas em tendência e resíduo e, através da utilização das diferenças entre estas duas componentes, é estimada a volatilidade condicional das variáveis. Para o cálculo das variáveis endógenas basta substituir os valores simulados para exógenas nas equações das endógenas. Neste sentido, é gerada uma gama maior de ocorrências estatísticas, permitindo calcular o risco.

\subsection{Objetivo}

Considerando a existência de uma "lacuna" na literatura da área, a despeito de trabalhos que tratam o entendimento e gerenciamento dos custos relacionados à compra de energia pelas distribuidoras, bem como análise de risco associadas às incertezas pertinentes ao processo, é proposto, neste trabalho, metodologia que combina as principais contribuições já dadas a respeito do assunto com pontos ainda não suficientemente explorados.

O objetivo principal é auxiliar as distribuidoras no entendimento e gerenciamento do repasse dos custos com a compra de energia elétrica através de metodologia que analisa as regras de repasse destes custos para a tarifa de fornecimento e seu impacto no fluxo de caixa das distribuidoras, bem como os riscos (CashFlow-at-Risk) agregados às incertezas pertinentes ao processo.

Para tanto, é apresentado estudo do repasse dos custos com a aquisição de energia elétrica para tarifa de fornecimento do consumidor final, interpretado através de equações. As principais referências para o desenvolvimento proposto são: 
$\checkmark$ Nota Técnica ANEEL 046 (2006), que define os critérios de repasse dos custos com aquisição de energia elétrica incorridos pelas concessionárias de distribuição;

$\checkmark$ Resolução 166 (2005), que estabelece as disposições consolidadas relativas ao cálculo da tarifa de uso dos sistemas de distribuição e da Tarifa de Energia Elétrica e;

Nota Técnica ANEEL 085 (2008), que define os critérios de repasse dos custos com sobrecontratação de energia elétrica.

Em conjunto, é apresentada também metodologia para construção de fluxo de caixa dos custos e receitas relacionadas à compra de energia elétrica para suprimento das necessidades de consumo das distribuidoras para o período analisado.

Por fim, propõe-se um modelo estocástico para análise de risco baseado na integração de metodologias estatísticas, modelos econométricos e simulações de Monte Carlo. Este modelo utiliza-se da estrutura sugerida pela teoria macroeconômica na formulação de suas previsões. As relações podem ser expressas por equações que se articulem, ou seja, assume-se a existência de variáveis independentes (ex: variáveis macroeconômicas e o mercado de consumo de energia) nas equações, estimadas por meio de dados históricos e regressões econométricas, e variáveis dependentes (desembolsos e receitas da distribuidora referentes à compra de energia elétrica), que são avaliadas em função das independentes. Para inserir incertezas ao modelo é proposta a utilização do "Erro Padrão da Previsão" das variáveis independentes, que considera os resíduos do modelo de regressão e as incertezas de seus coeficientes. Quanto às variáveis dependentes, basta substituir os valores simulados para independentes em suas equações. Neste sentido, são geradas amostras do espaço de estados das possíveis situações financeiras da distribuidora em análise, através de simulações de Monte Carlo, permitindo aferir qual o risco financeiro associado a eventuais não repasses de custos e/ou insuficiência de caixa para fazer frente aos desembolsos programados. 
Com isso, para uma compra de energia que atenda às necessidades de consumo de uma distribuidora ao longo de um ano, tal modelo deve ser capaz de informar valores prováveis que a empresa dispõe em caixa para honrar seus compromissos de custos em determinada data futura, ou ainda, qual o valor presente (VP) resultante dos desembolsos versus recebimentos ao final do período de repasse.

É importante ressaltar que, diferentemente dos trabalhos citados anteriormente, neste trabalho é estudado o repasse da compra de energia com um foco mensal, pressupondo-se que a compra de energia anual já foi definida pela distribuidora. 


\section{A ENERGIA ELÉTRICA NAS DISTRIBUIDORAS}

O primeiro passo para entender como a energia elétrica é tratada nas distribuidoras, é ter claro como é formado o processo desde a contratação até o fornecimento da energia aos consumidores. A Figura 2.1 ilustra, de forma simplificada, o ciclo no qual a distribuidora adquire energia de empresas supridoras (geradores e/ou comercializadores de energia), através de contratos, e a utiliza para suas necessidades de consumo com perdas e fornecimento aos seus consumidores cativos. Por outro lado, as empresas supridoras faturam da distribuidora os montantes vendidos em contratos e a distribuidora, por sua vez, fatura de seus consumidores a energia elétrica fornecida e a utilizada no consumo com as perdas, através da tarifa de fornecimento de energia elétrica.

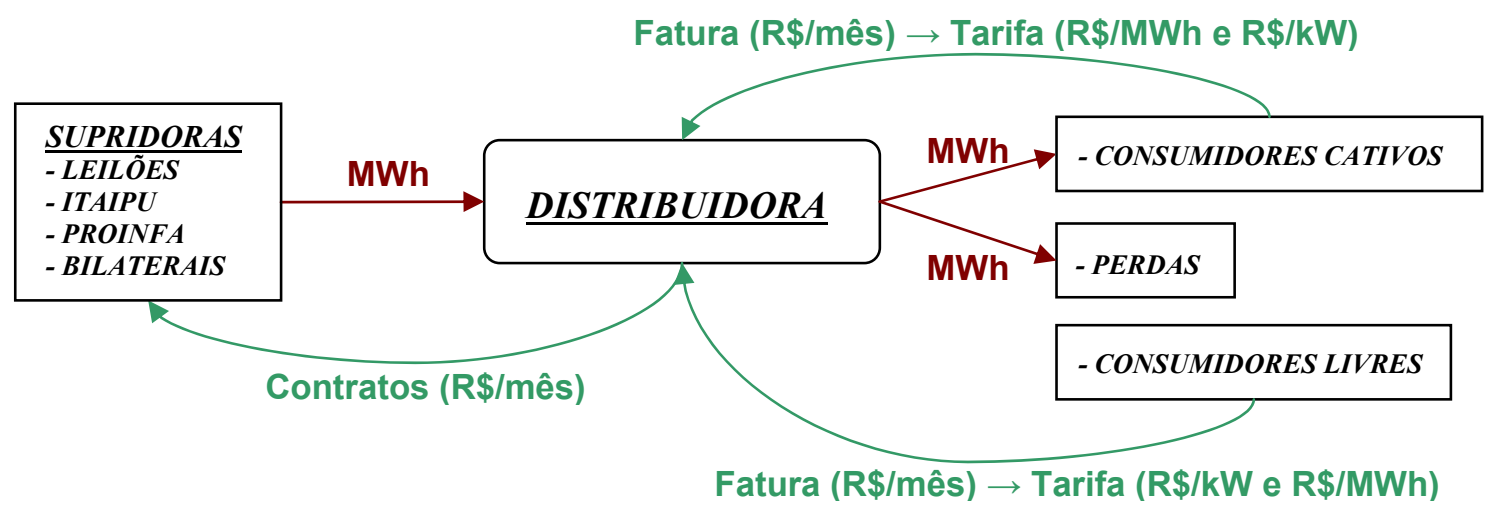

Figura 2.1 - Ciclo da Energia Elétrica nas Distribuidoras

De maneira mais detalhada, a Figura 2.2 ilustra o fluxograma da etapa de pagamentos e recebimentos do ciclo da energia elétrica nas distribuidoras, sendo esta o foco principal deste trabalho. Pode-se observar que o fluxo financeiro da compra é dividido em dois grandes blocos, o primeiro refere-se o desembolso pela distribuidora referente à energia comprada e o segundo bloco refere-se ao repasse dos custos com a energia comprada.

Entretanto, é importante ressaltar que a ordem cronológica não segue exatamente o fluxo apresentado, ou seja, como poderá ser observado no decorrer 
deste trabalho, a tarifa que está sendo aplicada ao consumidor final em determinada data e, conseqüentemente, gerando uma receita à distribuidora, contém, em sua formação, um custo de energia que ainda não foi fornecida pela distribuidora. Isto porque, a tarifa referente à energia comprada é formada, uma vez por ano, com o intuito de possibilitar à distribuidora arrecadar recursos para honrar seus compromissos contratuais para o próximo ano, ou seja, todos os custos esperados com a energia contratada para um ano estão embutidos em uma "única" tarifa, que por sua vez é aplicada ao consumidor mensalmente.

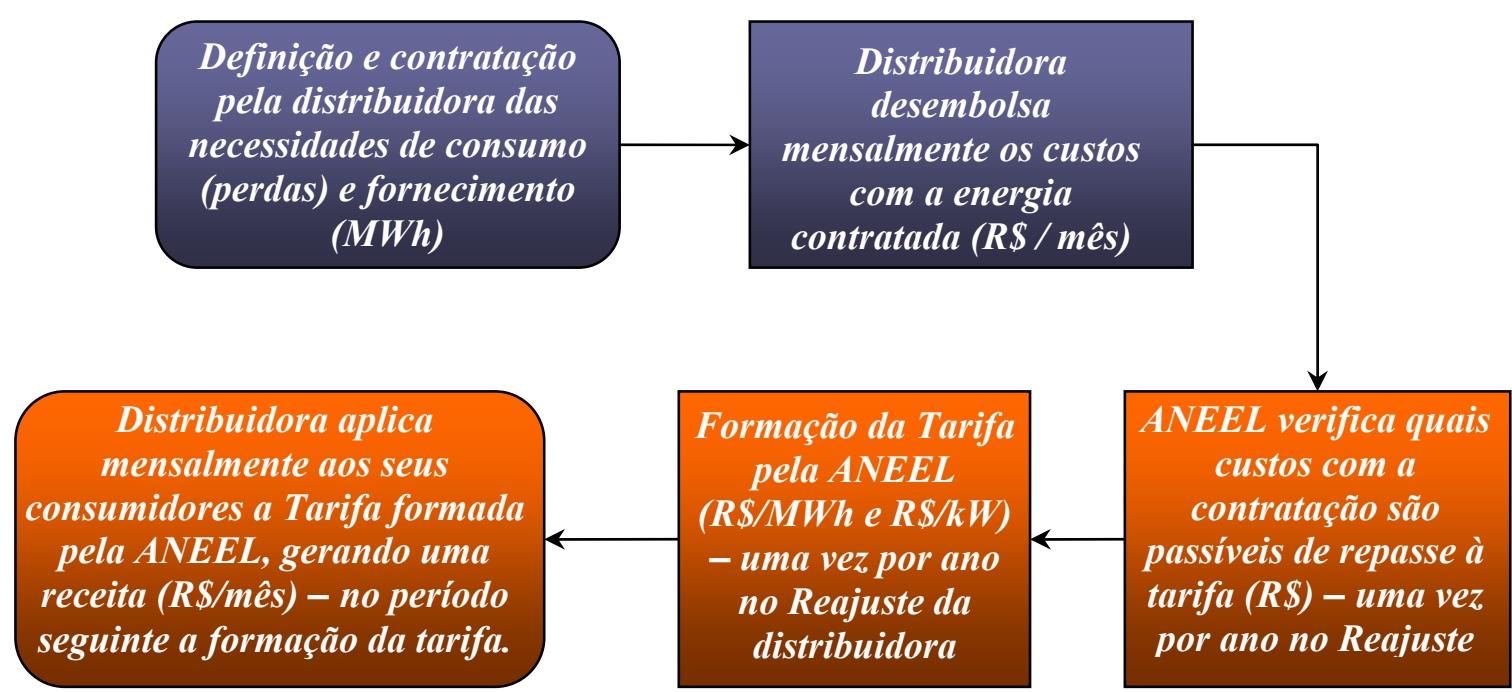

CONTRATAÇÃO DE ENERGIA ELÉTRICA PELA DISTRIBUDORA

REPASSE DOS CUSTOS À TARIFA DOS CONSUMIDORES

Figura 2.2 - Fluxograma Financeiro da energia comprada pela distribuidora para atendimento de suas necessidades de consumo e fornecimento ao consumidor cativo

Os capítulos seguintes detalham o processo apresentado na Figura 2.2, de forma a se obter, ao final, o equacionamento de todo fluxo financeiro da compra para atendimento da carga da distribuidora no decorrer de um ano civil, entendido como o período de janeiro a dezembro, e do repasse dos custos com a aquisição dessa energia ao longo do tempo. 


\section{CONTRATAÇÃO DA ENERGIA ELÉTRICA PELAS DISTRIBUIDORAS}

Conforme já mencionado no Capitulo 1 , desde a Lei $\mathrm{n}^{\circ} .8 .631$ (1993), as concessionárias de distribuição são obrigadas a estabelecer contratos de compra de uma quantidade pré-estabelecida de energia elétrica. A partir do Novo Modelo Institucional do Setor Elétrico (2004), uma nova filosofia de atração de investimentos foi desenhada, trazendo uma grande alteração na regulamentação da contratação de energia elétrica.

Através da Lei $n^{\circ} .10 .848$ (2004), como também já mencionado no Capitulo 1 , impõe-se às empresas de distribuição a obrigatoriedade de que os montantes de energia elétrica contratada garantam o atendimento à totalidade de suas cargas (consumidores cativos + perdas), mediante a contratação regulada, por meio de leilões públicos. Para tanto, foram criados dois diferentes ambientes de contratação de energia elétrica: o Ambiente de Contratação Regulada (ACR) e o Ambiente de Contratação Livre (ACL), conforme segue:

$\S 2^{\circ}$ Para fins de comercialização de energia elétrica, entende-se como:

I - Ambiente de Contratação Regulada - ACR o segmento do mercado no qual se realizam as operações de compra e venda de energia elétrica entre agentes vendedores e agentes de distribuição, precedidas de licitação, ressalvados os casos previstos em lei, conforme regras e procedimentos de comercialização específicos;

II - Ambiente de Contratação Livre - ACL o segmento do mercado no qual se realizam as operações de compra e venda de energia elétrica, objeto de contratos bilaterais livremente negociados, conforme regras e procedimentos de comercialização específicos; (DECRETO $n^{\circ} .5 .163,2004$, art. $1^{\circ}$, parágrafo $2^{\circ}$, grifo nosso)

A Figura 3.1, ilustra de forma simplificada a comercialização de energia envolvendo os dois ambientes de contratação definidos no novo modelo. 


\section{Vendedores}

Geradores de Serviço Público, Autoprodutores,

Produtores Independentes e Comercilaizadores

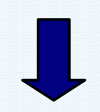

Ambiente de

Contratação Regulada (ACR)

Distribuidores (Consumidores Cativos)

Contratos Resultantes de Leilão

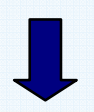

Ambiente de Contratação Livre (ACL)

Consumidores Livres, Comercializadores

Contratos Livremente Negociados

Figura 3.1 - Visão Geral da Comercialização de Energia Elétrica no Novo Modelo.

\subsection{Comercialização no ACR}

Do ACR participam como agentes compradores todas as concessionárias, permissionárias e autorizadas do serviço público de distribuição de energia elétrica. Toda contratação de energia elétrica é feita por meio de contratos bilaterais, denominados "Contrato de Comercialização de Energia no Ambiente Regulado (CCEAR)" (Lei $n^{\circ}$. 10.848, 2004, artigo $2^{\circ}$, parágrafo $2^{\circ}$ ), formalizados através de leilões públicos, onde todos os agentes vendedores ${ }^{7}$ assinam contratos com todas as distribuidoras que participaram do leilão em questão (Pool de Compra).

Os Leilões realizados no ACR são divididos em dois blocos de geração: leilões de novos empreendimentos de geração e; leilões de empreendimentos de geração existente, como seguem:

Art. 11. Para atendimento à obrigação prevista no inciso II do art. $2^{\circ}$, cada agente de distribuição do SIN deverá adquirir, por meio de leilões realizados no ACR, energia elétrica proveniente de:

I - empreendimentos de geração existentes; e

II - novos empreendimentos de geração.

\footnotetext{
7 Agente Vendedor - Agente titular de concessão, permissão ou autorização do poder concedente para gerar, importar ou comercializar energia elétrica (Decreto n. ${ }^{\circ} 5.163,2004$ ).
} 
$\S 1^{\circ}$ Entendem-se como novos empreendimentos de geração aqueles que até a data de publicação do respectivo edital de leilão:

I - não sejam detentores de concessão, permissão ou autorização; ou

II - sejam parte de empreendimento existente que venha a ser objeto de ampliação, restrito ao acréscimo da sua capacidade instalada.

$\S 2^{\circ} \mathrm{A}$ energia elétrica decorrente de importação e a gerada por meio de fontes alternativas, salvo o disposto no $\S 4^{\circ}$, serão consideradas como provenientes de empreendimentos de geração novos ou existentes, conforme previsto no $\S 1$ o deste artigo. (DECRETO $\mathrm{n}^{\circ}$. 5.163, 2004, art. $\left.11^{\circ}\right)$

A idéia contida nesta segmentação é a de que a energia gerada por usinas existentes (energia "velha") e, teoricamente, já financiadas e amortizadas, pode ser comercializada por preços menores do que aquela gerada pelas novas usinas.

Anualmente as distribuidoras têm que realizar declarações de compra de energia elétrica nos leilões, para o ano em questão (Leilões de Ajuste) e para os anos subseqüentes (A-1, A-3 e A-5). A Figura 3.2 ilustra, de forma esquemática, as possíveis contratações de energia elétrica pelas distribuidoras para inicio de suprimento no ano-base "A", onde:

Ano-base "A" representa o ano de previsão para o início do suprimento da energia elétrica adquirida pelos agentes de distribuição por meio dos leilões;

$\checkmark$ Ano "A - 1" representa o ano anterior ao ano-base "A" em que se realizam compras de energia elétrica;

$\checkmark$ Ano "A - 3" representa o terceiro ano anterior ao ano-base "A" em que se realizam os leilões de compra de energia elétrica, para garantir o atendimento do mercado projetado para o ano alvo "A"; e

Ano "A - 5" representa o quinto ano anterior ao ano-base " $A$ " em que se realizam os leilões de compra de energia elétrica, para garantir o atendimento do mercado projetado para o ano alvo "A". 


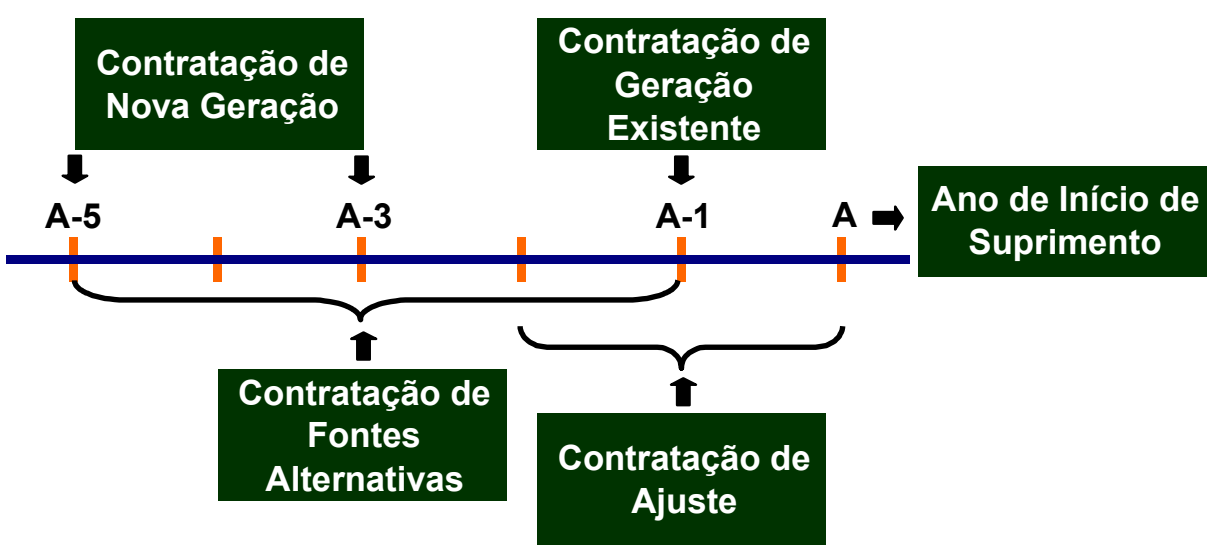

Figura 3.2 - Cronograma para realização de Leilões de compra de energia elétrica.

O Ministério de Minas e Energia (MME) deverá definir o preço máximo de aquisição nos leilões de energia proveniente de empreendimentos existentes "A-1", sendo que, a partir de 2009 , o preço máximo não poderá superar o valor médio resultante dos leilões de compra de energia elétrica provenientes de novos empreendimentos realizados no ano "A-5".

Adicionalmente, está estabelecido o seguinte:

$\checkmark$ A ANEEL promoverá, direta ou indiretamente, leilões específicos para a contratação de ajuste pelos agentes de distribuição, com prazo de suprimento de até dois anos, para fins de possibilitar a complementação, pelos referidos agentes, do montante de energia elétrica necessário para o atendimento à totalidade de suas cargas. O montante total de energia contratada em leilões de ajuste não poderá exceder a um por cento da carga total contratada da distribuidora ${ }^{8}$;

$\checkmark$ O CCEAR deverá prever os seguintes prazos:

$\rightarrow$ No mínimo quinze e no máximo trinta anos, para os contratos de energia provenientes de novos empreendimentos;

$\rightarrow$ No mínimo cinco e no máximo quinze anos, para os contratos de energia provenientes de empreendimentos existentes; e

${ }^{8}$ Exceto nos anos de 2008 e 2009, quando este limite de contratação será de cinco por cento (Decreto $\left.n^{\circ} 6.210,2007\right)$. 
$\rightarrow$ No mínimo dez e no máximo trinta anos, para os contratos de energia provenientes de fontes alternativas.

$\checkmark$ A partir de 2009, nos leilões de energia provenientes de empreendimentos existentes ("A - 1"), cada agente de distribuição poderá contratar até cento e cinco por cento da energia elétrica correspondente ao seu montante de reposição ${ }^{9}$; e

$\checkmark$ Os CEEAR decorrentes dos leilões de energia elétrica provenientes de empreendimentos existentes deverão possibilitar a redução dos montantes contratados, a critério exclusivo do agente de distribuição, em razão:

$\rightarrow$ Saída de consumidor Potencialmente Livre para o ACL;

$\rightarrow$ Variações de mercado, limitado a redução de até quatro por cento do montante inicial contratado; e

$\rightarrow$ Acréscimo na aquisição de energia elétrica decorrentes de contratos celebrados até 16 de março de 2004.

\subsection{Desembolso dos custos com a contratação}

Os leilões no ACR são os principais instrumentos de contratação de energia elétrica pelas distribuidoras. Adicionalmente, as distribuidoras podem ter contratos de energia elétrica provenientes de geração distribuída $(G D)^{10}$, porém com restrição de montante adquirido de até dez por cento de sua carga; Itaipu Binacional e do Programa de incentivo às fontes alternativas de energia elétrica (Proinfa), de forma compulsória, na qual as distribuidoras apenas recebem o valor que têm obrigação a contratar; e contratos bilaterais firmados anteriores à Lei $n^{\circ} 10.848$ (2004), ou seja, firmados antes de 16 de março de 2004, que serão referenciados neste trabalho apenas como contratos bilaterais. (RESOLUÇÃO n. 5.163, 2004, art. $3^{\circ}$ )

\footnotetext{
${ }^{9}$ Entende-se por montante de reposição a quantidade de energia elétrica objeto de contratos que forem extintos, ou tiverem previsão de redução da quantidade contratada.

${ }^{10}$ Geração Distribuída são as fontes de geração conectadas diretamente ao sistema elétrico da distribuidora.
} 
A soma de todos os montantes contratados deve garantir o atendimento de, pelo menos, $100 \%$ da carga da distribuidora, sob o risco de penalidade.

Neste trabalho considera-se que os montantes contratados para o ano de análise (ano civil) e sua sazonalidade já foram definidos pela distribuidora, com isso, pressupõe-se que os custos com aquisição e o montante desembolsado mensalmente são conhecidos.

\subsection{Sazonalidade dos Contratos}

Sazonalidade dos contratos refere-se à alocação mensal do montante anual de energia contratada, conforme exemplo ilustrado na Figura 3.3.

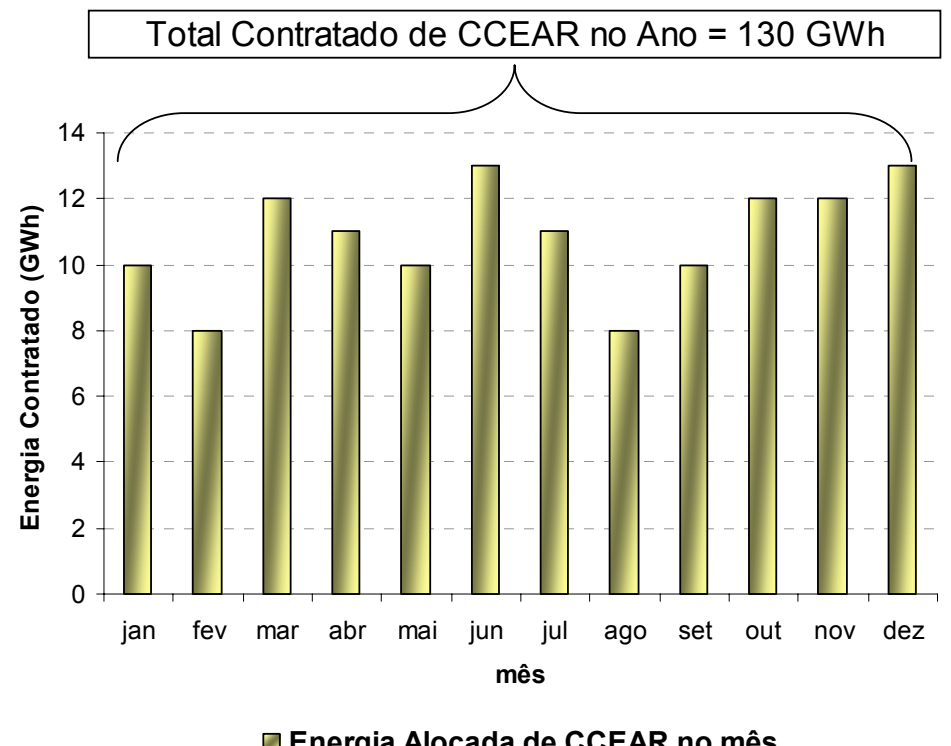

Figura 3.3- Exemplo de sazonalidade da energia contratada de CCEAR para um ano.

A Sazonalização dos contratos é realizada anualmente em dezembro e tem início com a disponibilização pela ANEEL dos montantes referentes às cotas mensais de Itaipu e Proinfa para o próximo ano civil.

Existem duas modalidades de CCEARs, os CCEARs de Quantidade ${ }^{11}$ e os CCEARs de Disponibilidade ${ }^{12}$ e suas sazonalização diferem como segue:

${ }^{11}$ CCEARs de Quantidade, são aqueles nos quais os riscos hidrológicos da operação energética integrada são assumidos totalmente pelos Geradores, cabendo a eles todos os custos referentes 
1. A sazonalização de CCEARs de Quantidade segue o disposto abaixo (PdC CO.11 Sazonalização de CCEAR, 2006):

$\rightarrow$ Os Agentes de Distribuição poderão sazonalizar seus CCEARs de Quantidade mediante negociações bilaterais com $\mathrm{O}$ agente vendedor;

$\rightarrow$ O limite máximo de alocação no mês não pode ultrapassar a Potência Associada ${ }^{13}$ a energia contratada;

$\rightarrow$ Caso não ocorra acordo entres as partes (distribuidora e vendedor), os CCEARs de Quantidade serão sazonalizados por contingência, ou seja, para sazonalizar os CCEARs será aplicado o perfil de Carga declarado pelo Agente de Distribuição, consolidado pelo Sistema SIMPLES ${ }^{14}$, sobre a energia, expressa em MW médio, do referido CCEAR, respeitados os limites de Potência Associada e mais ou menos quinze por cento da energia anual, em MW médio, do referido CCEAR. Nos casos em que a aplicação da curva do Sistema SIMPLES ultrapassar os limites estabelecidos, este valor será apurado e rateado proporcionalmente entre os meses que tiverem folga.

2. Os CCEARs de Disponibilidade terão sazonalização Flat, ou seja, divisão proporcional do total de energia anual pelo número de horas do mês.

Para os demais contratos a sazonalização é realizada mediante negociação entre as partes, respeitando o limite máximo da potência associada, e caso não haja acordo a sazonalização será realizada de maneira Flat, conforme definido acima.

ao fornecimento da energia contratada. Os riscos financeiros são decorrentes de diferenças de preços entre submercados assumidos pelo comprador.

${ }^{12}$ CCEARs de Disponibilidade, são aqueles nos quais tanto os riscos, como os ônus e os benefícios da variação de produção em relação à energia assegurada, são alocados ao pool e repassados aos consumidores regulados.

${ }^{13}$ Potência Associada, refere-se à quantidade de potência associada à energia contratada, definida em cláusula contratual, em qualquer mês contratual, que o Agente Vendedor deverá colocar à disposição do Agente de Distribuição no centro de gravidade do Agente Vendedor (PdC CO.11 Sazonalização de CCEAR, 2006).

${ }^{14}$ Sistema SIMPLES é o Sistema de Informações de Mercado para o Planejamento do Setor Elétrico. 


\section{REPASSE DOS CUSTOS COM ENERGIA ELÉTRICA}

Como já exposto no capitulo 2 através da Figura 2.2, o repasse dos custos com a compra de energia ocorre em três etapas:

$\checkmark$ Verificação dos custos com a compra de energia, do período analisado, passíveis de repasse à tarifa $(R \$)$;

$\checkmark$ Repasse dos custos habilitados à tarifa $(\mathrm{R} \$ / \mathrm{MWh}$ e $\mathrm{R} \$ / \mathrm{kW})$;

$\checkmark$ Fatura dos consumidores o volume correspondente a esses custos (R\$/mês).

Entretanto, para representar estas etapas em equações desagregando o que do valor faturado do consumidor é referente exclusivamente a energia elétrica comprada, é necessário entender antes como é formada a tarifa de fornecimento das distribuidoras.

\subsection{A tarifa de fornecimento de energia elétrica}

Mensalmente os consumidores conectados à rede de distribuição de energia elétrica são faturados, por suas distribuidoras, montantes, em $\mathrm{R} \$$, correspondente à utilização da rede elétrica $(\mathrm{kW})$ e à quantidade consumida de energia elétrica $(\mathrm{MWh})$, esse processo é feito através da tarifa de fornecimento de energia elétrica.

Neste item será abordado, de forma simplificada, como é composta a tarifa de fornecimento de energia elétrica, o seu reajuste e como através dela as empresas de distribuição faturam de seus consumidores.

\subsubsection{Evolução da tarifa de Fornecimento no Brasil}

Até 1993 as tarifas de energia elétrica eram equalizadas em todo Brasil e seu cálculo era baseado nos custos do serviço do fornecimento com remuneração garantida às empresas de energia elétrica. O Ministério de Minas e Energia, através 
do Departamento Nacional de Águas e Energia Elétrica (Dnaee) calculava o que as concessionárias haviam investido para levar a energia elétrica até o consumidor, acrescido da taxa de remuneração, sendo que o total era rateado entre os diversos consumidores do país, sem distinção área de concessão (território geográfico onde cada empresa é contratualmente obrigada a fornecer energia elétrica) ou ponto da conexão. É importante ressaltar que essa modalidade de tarifa não incentivava as empresas à eficiência, pois todo o custo era repassado ao consumidor.

Através da Lei $n^{\circ} .8 .631$ (1993), regulamentada pelo Decreto $n^{\circ} .774$ (1993), foi extinto o regime de remuneração garantida e posto um fim na equalização tarifária para o serviço publico de energia elétrica, ou seja, as tarifas seriam fixadas por empresa concessionária e baseadas nos custos marginais ${ }^{15}$ de fornecimento, conforme segue:

Art. $7^{\circ}$ - As tarifas de fornecimento de energia elétrica deverão ser apresentadas pelos concessionários de acordo com a estrutura de grupo, subgrupos e classe de consumidores definida pelo DNAAE, tendo como referência a estrutura de custo marginal. (PORTARIA $n^{\circ}$. 176, 1993, art. $7^{\circ}$ )

Os defensores dessa medida a justificavam pela necessidade das concessionárias adequarem suas tarifas ao mercado que atendiam de modo a atingir um patamar satisfatório de rentabilidade numa perspectiva de longo prazo, o que tornou a questão tarifária bastante complexa (DOMICIANO, 2002).

Em fevereiro de 1995, foi aprovada a Lei $n^{\circ} .8 .987$ (1995), denominada Lei de Concessões. A regulamentação para o caso específico do setor elétrico se deu no mesmo ano através da Lei $n^{\circ} .9 .074$ (1995). Com isso uma série de implementações de cunho institucional para viabilizar mudanças no setor elétrico foram necessárias, destacando-se (SILVA, 2001):

A criação da Agência Nacional de Energia Elétrica (ANEEL), responsável pela regulação tarifária e estabelecimento das condições gerais de contratação do acesso e do uso dos sistemas de transmissão e de distribuição e;

15 Custo marginal corresponde ao aumento do custo total decorrente da produção de mais uma unidade. É o custo extra necessário para a produção de uma unidade adicional. (Holanda, 1980, p.301) 
$\checkmark$ A forma de participação dos agentes de produção e consumo no Mercado Atacadista de Energia (MAE), atual Câmara de Comercialização de Energia Elétrica (CCEE).

Em 2002, a ANEEL, através das Resoluções $n^{\circ} .790$ (2002) e $n^{\circ} .666$ (2002), estabeleceu procedimentos para a determinação das tarifas de fornecimento de energia elétrica e metodologia para o cálculo do reajuste das tarifas de uso do sistema de distribuição de energia elétrica aplicáveis a unidades consumidoras.

Com a Resolução $n^{\circ}$. 166 (2005), a ANEEL consolida o cálculo da tarifa de uso dos sistemas de distribuição (Tusd) e da tarifa de energia elétrica (TE) e define a atual composição tarifária.

\subsubsection{Receita Requerida das Empresas de Distribuição}

Cabe à ANEEL estabelecer tarifas que assegurem ao consumidor 0 pagamento de um valor justo, como também garantir o equilíbrio econômicofinanceiro da empresa de distribuição de energia elétrica, para que esta possa oferecer um serviço com a qualidade, confiabilidade e continuidade necessárias.

A Receita Requerida das distribuidoras é composta por duas parcelas: a "Parcela A" (PA) e a "Parcela B" (PB): A "Parcela A" refere-se ao repasse de custos não gerenciáveis, ou seja, são custos necessários para o serviço de distribuição, mas seus valores, bem como sua variação no tempo, independem de controle da empresa. Já a "Parcela B" refere-se ao repasse de custos gerenciáveis, como, por exemplo, a cobertura de custos de pessoal, de material e outras atividades vinculadas diretamente à operação e manutenção dos serviços de distribuição. A Tabela 4.1 contém a composição da Receita Requerida da distribuidora.

Além da Receita Requerida, a ANEEL considera na composição da receita da distribuidora, outra parcela denomina "Outras Receitas", que compreende as receitas que não decorrem exclusivamente das tarifas, mas que mantém relação, mesmo indireta, com o serviço público prestado ou com os bens afetos a sua prestação (Nota Técnica ANEEL nº 184, 2007). 
Tabela 4.1 - Composição da Receita Requerida da distribuidora.

\begin{tabular}{|c|c|}
\hline $\begin{array}{c}\text { PARCELA A } \\
\text { (custos não-gerenciáveis) }\end{array}$ & $\begin{array}{c}\text { PARCELA B } \\
\text { (custos gerenciáveis) }\end{array}$ \\
\hline Encargos Setoriais & Custos Operacionais \\
\hline $\begin{array}{l}\text { Cotas da Reserva Global de Reversão } \\
\text { (RGR) }\end{array}$ & $\begin{array}{l}\text { Recursos Humanos (administrativo e de } \\
\text { operação e manutenção) }\end{array}$ \\
\hline $\begin{array}{l}\text { Cotas da Conta de Consumo de } \\
\text { Combustível (CCC) }\end{array}$ & $\begin{array}{c}\text { Infra-estrutura física, envolvendo edificações } \\
\text { móveis e informática }\end{array}$ \\
\hline $\begin{array}{c}\text { Taxa de Fiscalização de Serviços de Energia } \\
\text { Elétrica (TFSEE) }\end{array}$ & Materiais e Serviços de Terceiros \\
\hline Rateio de custos do Proinfa & Transporte \\
\hline \multicolumn{2}{|l|}{$\begin{array}{l}\text { Conta de Desenvolvimento Energético } \\
\text { (CDE) }\end{array}$} \\
\hline $\begin{array}{c}\text { Compensação Financeira pela Utilização de } \\
\text { Recursos Hídricos (CFURH) }\end{array}$ & Remuneração do Capital \\
\hline $\begin{array}{c}\text { Taxa de Fiscalização de serviços de Energia } \\
\text { Elétrica (TFSEE) }\end{array}$ & $\begin{array}{c}\text { Taxa de retorno (WACC) aplicada a Base de } \\
\text { Remuneração }\end{array}$ \\
\hline \multicolumn{2}{|l|}{ Encargos de Serviços do Sistema (ESS) } \\
\hline $\begin{array}{l}\text { Pesquisa e Desenvolvimento Energético } \\
\text { (P\&D) }\end{array}$ & Quota de Reintegração Regulatória \\
\hline \multirow[t]{2}{*}{$\begin{array}{l}\text { Custeio das Atividades do Operador } \\
\text { Nacional do Sistema (ONS) }\end{array}$} & Quota de Depreciação \\
\hline & Quota de Amortização \\
\hline \multicolumn{2}{|l|}{ Custos com Transporte de Energia } \\
\hline \multicolumn{2}{|l|}{$\begin{array}{l}\text { Uso das Instalações da Rede Básica de } \\
\text { Transmissão de Energia Elétrica }\end{array}$} \\
\hline \multicolumn{2}{|l|}{ Uso das Instalações de Conexão } \\
\hline \multicolumn{2}{|l|}{ Uso das Instalações de Distribuição } \\
\hline \multicolumn{2}{|l|}{$\begin{array}{c}\text { Transporte da Energia Elétrica Proveniente } \\
\text { de Itaipu }\end{array}$} \\
\hline \multicolumn{2}{|l|}{ Compra de Energia Elétrica para Revenda } \\
\hline \multicolumn{2}{|l|}{ Energia de Itaipu } \\
\hline $\begin{array}{c}\text { Contratos Bilaterais de Longo Prazo ou } \\
\text { Leilões }\end{array}$ & \\
\hline
\end{tabular}

FONTE: Agência Nacional de Energia Elétrica. Nota Técnica n. 184 - Segunda Revisão Tarifária Periódica da Eletropaulo, 2007.

Como o foco deste trabalho é a compra de Energia Elétrica para revenda, componente pertencente a "Parcela A", explicações sobre os custos referentes à "Parcela B" e a "Outras receitas" não serão aprofundados neste trabalho, valendo 
como referência a Nota Técnica Aneel $\mathrm{n}^{\circ} 184$ (2007) e o Cadernos Temáticos ANEEL 4 - Tarifas de Fornecimento de Energia Elétrica (2005).

Porém, vale ressaltar que a ANEEL, quando na consideração de repasse dos custos da "Parcela B", considera:

1. Empresa de Referência - empresa com custos operacionais eficientes e que sejam aderentes às reais condições geoeconômicas do ambiente no qual a distribuidora desenvolve sua atividade de prestação dos serviços de distribuição de energia elétrica. Esta é a forma na qual a Aneel utiliza para que a distribuidora seja eficiente nos seus gastos operacionais, pois só são considerados na tarifa os custos operacionais calculados para Empresa de Referência;

2. Remuneração do Capital - Para remunerar o capital investido pela empresa detentora da concessão de distribuição de energia elétrica, a Aneel aplica à base de remuneração (valor dos ativos necessários para prestar o serviço de distribuição, no termos da Resolução n. 234 (2006)) a taxa de retorno adequada, que é calculada através da participação ótima do capital próprio e de terceiros no capital total (estrutura ótima de capital), utilizando como base o Custo Médio ponderado do Capital (WACC) e;

3. Taxa média de depreciação e amortização dos ativos da distribuidora aplicada sobre o valor do Ativo Imobilizado ${ }^{16}$. Representa a forma de recomposição dos investimentos realizados para prestação do serviço ao longo da vida útil desses bens.

\footnotetext{
${ }^{16}$ Ativo Imobilizado, conceito empregado em contabilidade para definir, dentro de uma determinada empresa, quais são os bens e direitos desta empresa que não sofrem movimentação constante. Fazem parte do patrimônio desta empresa.
} 


\title{
4.1.3. As Componentes da Tarifa de Fornecimento de Energia Elétrica
}

As tarifas de fornecimento de energia elétrica são definidas com base na receita requerida da concessionária de distribuição. Segundo Bitu e Born (1993), tem-se que:

\begin{abstract}
A tarifa deve satisfazer às necessidades financeiras das distribuidoras (nível tarifário) e, ao mesmo tempo, atender aos objetivos de alocação eficientes de recursos, igualdade e justiça social, estabilidade relativa ao preço, simplicidade e uso racional de energia elétrica (estrutura tarifária).
\end{abstract}

O nível tarifário é valor geral dos preços, este define o volume total da receita da distribuidora (Receita Requerida da Distribuidora) e o preço médio é o parâmetro que define os níveis das tarifas (Bitu; Born, 1993, p. 38). Separando a Receita Requerida da distribuidora em duas componentes, uma relacionada à energia e outra relacionada a potência, e dividindo estas componentes pelo mercado de energia e demanda da distribuidora, respectivamente, é possível calcular a tarifa média (preço médio) de energia e de demanda da distribuidora. E é partindo do nível tarifário, que a Aneel compõe as tarifas, diferenciando-as pela estrutura tarifária.

A estrutura tarifária define a relatividade dos preços. No Brasil é calculada com base nos custos marginais de fornecimento. A estrutura compreende a diferenciação das tarifas, segundo os componentes de consumo e demanda, nível de tensão de fornecimento, classe de consumo, estação do ano, período do dia, localização do consumidor, etc. (Bitu; Born, 1993, p. 38).

Como um dos objetivos deste trabalho é o de calcular a receita provinda da tarifa referente aos custos com a compra de energia e não o de entender como cada consumidor é faturado, a aplicação da tarifa média ao mercado total da distribuidora parece ser uma suposição adequada, já que, a somatória das receitas provindas da aplicação de tarifas especifica a cada consumidor deve ser, em tese, igual à receita total provinda da aplicação da tarifa média ao mercado total de consumo da distribuidora (nível tarifário). 
Com isso, neste trabalho, é suposto, de forma simplificada, a utilização direta da tarifa média para aplicação ao mercado consumidor da distribuidora como um todo.

Detalhes de faturamento dos consumidores segundo a estrutura tarifária, ou seja, segundo sua classe de consumo, nível de tensão (ponto de entrega), posto tarifário (horo-sazonal, convencional), tipo de tarifa (monômia, binômia), etc., podem ser encontrados na Resolução n. ${ }^{\circ} 456$ (2000).

Conforme Resolução ANEEL n. 166 (2005) as duas componentes definidas acima para a Receita Requerida da distribuidora são representadas nas tarifas de fornecimento através da Tarifa de Uso do Sistema de Distribuição (Tusd) e da Tarifa de Energia (TE).

\subsubsection{TARIFA DE USO DO SISTEMA DE DISTRIBUIÇÃO (TUSD)}

A Tusd é destinada a todos os consumidores ligados a rede de distribuição da concessionária e tem como objetivo cobrir os custos com o uso do sistema de distribuição, custos com o uso da Rede Básica ${ }^{17}$ e encargos destinados aos consumidores de energia elétrica. A Tusd é segregada, como segue (RESOLUÇÃO ANEEL $n^{\circ}$. 166, 2005):

a) Serviço de transmissão de energia elétrica, na forma da Tusd Fio A, que por sua vez é composta:

$\checkmark$ Custos com uso da Rede Básica (TUSTRB);

$\checkmark$ Custos com o uso das instalações de Fronteiras (TUSTFR);

$\checkmark$ Custos de Conexão aos sistemas de transmissão;

$\checkmark$ Custo com o uso da rede de distribuição de outras concessionárias e;

$\checkmark$ Compra de energia para cobrir perdas técnicas na rede básica referente às perdas técnicas e não técnicas da Distribuição;

17 Rede Básica, conjunto de linhas de transmissão, barramentos, transformadores de potência e equipamentos com tensão igual ou superior a $230 \mathrm{kV}$ e instalações definidas pela Aneel. 
b) Serviço de distribuição de energia elétrica, na forma da Tusd Fio B, que por sua vez é composta:

$\checkmark$ Remuneração dos ativos de distribuição de energia elétrica;

$\checkmark$ Cota de reintegração dos ativos em decorrência da depreciação e;

$\checkmark$ Custos Operação e Manutenção;

c) Encargos do próprio sistema de distribuição, na forma da Tusd Encargos do Serviço de Distribuição;

d) Perdas elétricas técnicas e não técnicas, respectivamente, na forma Tusd Perdas Técnicas e Tusd Perdas Não Técnicas;

e) Conta de Consumo de Combustíveis (CCC), na forma Tusd $\mathrm{CCC}_{\text {ISOLADos; }}$

f) Conta de Desenvolvimento Energético (CDE), na forma Tusd $\mathrm{CDE}_{\mathrm{S} / \mathrm{SE} / \mathrm{CO}}$ ou Tusd $\mathrm{CDE}_{\mathrm{N} / \mathrm{NE}}$, conforme o caso e;

g) Programa de Incentivo às Fontes Alternativas de Energia Elétrica (Proinfa), na forma de Tusd Proinfa.

Como objetivo deste trabalho visa o repasse da compra de energia elétrica por parte das distribuidoras, a seguir são detalhadas apenas as componentes da Tusd referentes à Compra de Energia Elétrica pelas distribuidoras. As definições das outras componentes podem ser encontradas no Caderno Temático ANEEL 4, Tarifas de Fornecimento de Energia Elétrica (2005) e na Resolução ANEEL nº 166 (2005).

\section{TUSD PERDAS TÉCNICAS (TUSDPT)}

Tarifa, em $\mathrm{R} \$ / \mathrm{kW}$ com preços em ponta e fora de ponta, referente ao repasse dos custos com aquisição de energia pela distribuidora para as perdas técnicas na distribuição. As Perdas Técnicas são definidas, como segue:

a) perdas técnicas: constituem a quantidade de energia elétrica, expressa em megawatt-hora por ano (MWh/ano), dissipada entre os suprimentos de energia da distribuidora e os pontos de entrega nas instalações das unidades consumidoras ou distribuidoras supridas. Essa perda é decorrente das leis da Física relativas aos processos de transporte, transformação de 
tensão e das perdas inerentes aos equipamentos de medição (NOTA TÉCNICA ANEEL n026, 2006).

\section{TUSD PERDAS NÃO TÉCNICAS}

A Tusd Perdas não Técnicas tem sua componente da tarifa subdividida em duas parcelas, uma em R $\$ / K W$ (TUSDPNTD) e outra na forma de encargo em $\mathrm{R} \$ / \mathrm{MWh}$ (TUSDPNTE). A Tusd perdas não técnicas refere-se ao repasse dos custos da distribuidora com a aquisição de energia para as perdas não técnicas, expressa em MWh, que são definidas como segue:

b) perdas não técnicas: apuradas pela diferença entre as perdas totais e as perdas técnicas, considerando, portanto, todas as demais perdas associadas à distribuição de energia elétrica, tais como furtos de energia, erros de medição, erros no processo de faturamento, unidades consumidoras sem equipamento de medição, etc. Esse tipo de perda está diretamente associado à gestão comercial da distribuidora (NOTA TÉCNICA ANEEL n026, 2006).

\section{TUSD FIO A - COMPRA DE ENERGIA PARA COBRIR PERDAS TÉCNICAS NA REDE BÁSICA REFERENTES À CARGA E ÀS PERDAS TÉCNICAS E NÃO TÉCNICAS DA DISTRIBUIÇÃO (TUSDPRB)}

Tarifa em $\mathrm{R} \$ / \mathrm{kW}$, refere-se, como o título já diz, aos custos da energia adquirida pela distribuidora para atender as perdas técnicas na Rede Básica causada pela energia consumida pela distribuidora com suas perdas técnica e perdas não técnicas na rede de distribuição.

As perdas técnicas na rede básica da distribuidora constituem a quantidade de energia elétrica, expressa em MWh, dissipada entre centro de gravidade do sistema de transmissão (CG) e os pontos de medição de fronteira da distribuidora, ou seja, de forma simplificada, nos limites entre o sistema de transmissão e de distribuição de energia da distribuidora. 


\subsubsection{TARIFA DE ENERGIA (TE)}

A TE é destinada apenas aos consumidores cativos ligados à rede de distribuição da concessionária e tem como objetivo principal cobrir os custos com a energia elétrica comprada para revenda e encargos destinados apenas a esse tipo de consumidor. A TE é expressa em $R \$ / M W h$ e é definida basicamente como a soma dos seguintes custos (RESOLUÇÃO ANEEL $n^{\circ}$. 166, 2005):

$\checkmark$ Compra de Energia Elétrica para revenda;

$\checkmark$ Encargos de Serviços do Sistema (ESS);

$\checkmark$ Perdas Técnicas de energia na Rede Básica relativas ao consumo do mercado cativo;

$\checkmark$ P\&D - Pesquisa e Desenvolvimento e Eficiência Energética e;

$\checkmark$ TFSEE - Taxa de Fiscalização de Serviços de Energia Elétrica.

Conforme no item 4.1.3.1, a seguir são detalhadas apenas as componentes da TE relacionadas à compra de energia elétrica pelas distribuidoras.

\section{TE - COMPRA DE ENERGIA PARA REVENDA (TEENERG)}

A TE referente à compra de energia elétrica para revenda aos consumidores cativos é entendida, neste trabalho, como o repasse dos custos que a distribuída teve ao adquirir o montante de energia consumido pelos consumidores cativos, e isso engloba o custo total proveniente da compra de energia da usina hidrelétrica de Itaipu, ou seja, custos com a potência, transporte e transmissão proporcionais a parcela de energia adquirida de Itaipu.

\section{TE - PERDAS TÉCNICAS NA REDE BÁSICA (TEPRB)}

A TEPRB refere-se ao repasse dos custos com energia comprada para atender às perdas técnicas na Rede Básica (conforme definido anteriormente) 
causada pela energia adquirida pela distribuidora para atendimento do consumo dos consumidores cativos.

A Figura 4.1 ilustra a composição da Tarifa de Fornecimento repassada para o consumidor onde as componentes referentes à compra de energia estão destacadas com letras em vermelho.

\begin{tabular}{|c|c|c|}
\hline \multicolumn{3}{|c|}{ RECEITA REQUERIDA DA DISTRIBUIDORA (R\$) } \\
\hline \multicolumn{2}{|c|}{ RECEITA DA TUSD } & RECEITA DA TE \\
\hline $\begin{array}{l}\text { MERCADO DE REFERÊNCIA } \\
\text { DE DEMANDA }\end{array}$ & $\begin{array}{l}\text { MERCADO DE REFERÊNCIA } \\
\text { DE CONSUMO }\end{array}$ & $\begin{array}{l}\text { MERCADO DE REFERÊNCIA } \\
\text { DE CONSUMO }\end{array}$ \\
\hline \multicolumn{3}{|l|}{$\begin{array}{c}\text { TUSD - FIO A (serviços de terceiros) } \\
\text { (R\$/kW) - PA }\end{array}$} \\
\hline $\begin{array}{l}\text { - TUST RB } \\
\text { - TUST FR } \\
\text { - CONEXÃO RB } \\
\text { - TUSD de outras distribuidoras } \\
\text { - Perdas na RB das Perdas da } \\
\text { Distribuicão } \\
\end{array}$ & \multirow{2}{*}{\begin{tabular}{|l} 
TUSD - ENCARGOS (R\$/kWh) - PA \\
- RGR \\
- TFSEE (ANEEL) \\
- P\&D e PEE \\
- ONS \\
- CCC/CDE/PROINFA \\
- Perdas não Técnicas na \\
distribuição
\end{tabular}} & \multirow{2}{*}{$\begin{array}{l}\text { TE (RS/MWh) - PA } \\
\text { - Compra de Energia para } \\
\text { revenda (cativo) } \\
\text { - Transporte de ITAIPU } \\
\text { - ESS } \\
\text { - Perdas na RB } \\
\text { - P\&D e PEE } \\
\text {-TFSEE (Aneel) }\end{array}$} \\
\hline $\begin{array}{l}\text { TUSD - PERDAS (R\$/kW) - PA } \\
\text { - Perdas Técnicas na Distribuição } \\
\text { - Perdas Não Técnicas na Distribuição }\end{array}$ & & \\
\hline \multicolumn{3}{|l|}{$\begin{array}{l}\text { TUSD - FIO B (serviços da distribuidora) } \\
\text { (R\$/kW) - PB } \\
\text { - Remuneração de Ativos } \\
\text { - Depreciação } \\
\text { - Custo de O \& M }\end{array}$} \\
\hline & & 10 \\
\hline
\end{tabular}

Figura 4.1 - Configuração das Componentes da TUSD e da TE.

\subsubsection{Mecanismos de atualização das Tarifas de Energia Elétrica}

As empresas concessionárias fornecem energia elétrica a seus consumidores com base em obrigações e direitos estabelecidos em um Contrato de Concessão, celebrado com a União, para a exploração do serviço público de distribuição de energia elétrica em sua área de concessão.

No momento da assinatura do Contrato, a empresa concessionária reconhece que o nível tarifário vigente, ou seja, as tarifas definidas na estrutura tarifária da empresa são suficientes para a manutenção do seu equilíbrio econômico-financeiro. 
Além disso, os contratos de concessão estabelecem que as tarifas de fornecimento possam ser atualizadas por meio de três mecanismos, quais sejam: reajuste tarifário anual; revisão tarifária periódica e; revisão tarifária extraordinária.

\subsubsection{REAJUSTE TARIFÁRIO ANUAL}

O objetivo do Reajuste Tarifário Anual (IRT) é restabelecer anualmente o poder de compra da receita obtida pelo concessionário. Conforme já citado, a receita da concessionária é composta por duas parcelas. A "Parcela A" representada pelos "custos não-gerenciáveis" da empresa, e a "Parcela B" que compreende o valor remanescente da receita, representado pelos "custos gerenciáveis".

Em cada reajuste anual de um novo período tarifário - Data de Reajuste em Processamento (DRP) - a distribuidora tem consolidada, com base na estrutura e níveis tarifários então vigentes, a sua Receita Anual referente aos últimos doze meses (RA0). Tem também consolidado, o valor da "Parcela A", considerando os valores e condições vigentes na Data de Referência Anterior (DRA). A Figura 4.2 ilustra o período considerado como referência na DRP, denominado aqui de Período de Referência.

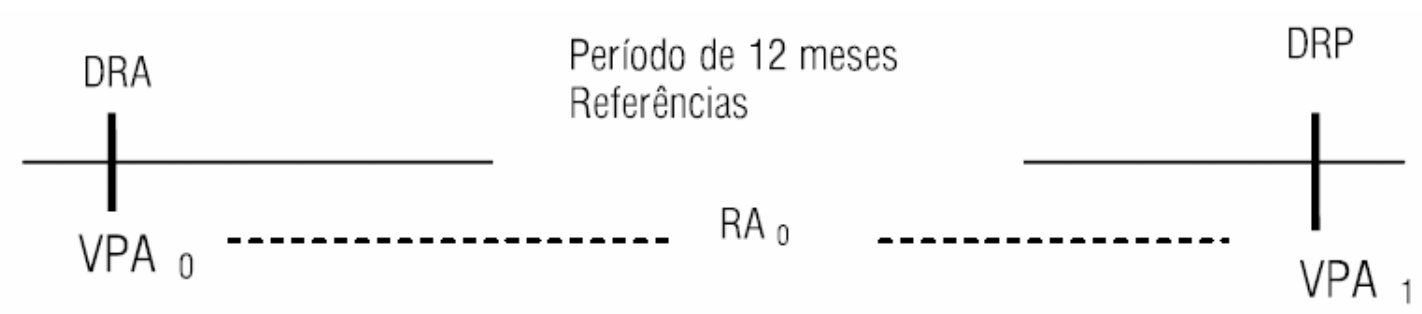

Figura 4.2 - Período de referência do Reajuste Tarifário Anual

O novo valor da "Parcela A" (VPA1) na Data de Reajuste em Processamento é obtido pelo somatório dos valores então vigentes para cada um de seus itens, conforme apresentado na Tabela 4.1. O valor da "Parcela B" (VPB0), na Data de Referência Anterior - DRA, é obtido pela diferença entre RAo e VPA0. O novo valor 
da "Parcela B" (VPB1) é resultante da VPB0, corrigido pela variação do IGP-M observada nos 12 meses anteriores à DRP.

Desta forma, o reajuste tarifário anual das componentes da "Parcela A" é calculado mediante a aplicação do Índice de Reajuste Tarifário específico do respectivo item (IRTITEM), sobre cada item que a compõe em DRA, conforme eq.(1). O reajuste da "Parcela B" é calculado mediante a aplicação Índice de Reajuste Tarifário da PB (IRTFIO), conforme eq. (2).

$$
\begin{gathered}
\text { IRTITEM }=\frac{\text { Valor } 1}{\text { Valor } 0} \\
\text { IRTFIO }=I V I \pm F A T O R X
\end{gathered}
$$

Onde:

Valor1 - valor associado a cada item das componentes da PA, considerando as condições vigentes em DRP e o mercado de referência; e

Valoro - valor associado a cada item das componentes da PA, considerando as condições vigentes em DRA e o mercado de referência.

IVI - Refere-se ao "número índice" obtido pela divisão dos índices do IGP-M da Fundação Getúlio Vargas, ou do índice que vier a sucedê-lo, do mês anterior à data do reajuste em processamento e o do mês anterior à Data de Referência Anterior.

FATOR "X" - É um "número índice" fixado pela Aneel, a cada revisão periódica, conforme definido no contrato de concessão, a ser subtraído ou adicionado ao IVI a cada reajuste tarifário anual. Destina-se à captura dos ganhos, para repartição com o consumidor, decorrentes de melhoras da produtividade associadas à escala do negócio, que aumenta na medida em que o mercado aumenta. 


\subsubsection{REVISÃO TARIFÁRIA PERIÓDICA}

O processo de Revisão tarifária periódica tem como principal objetivo analisar, após um período previamente definido no contrato de concessão (geralmente de 4 anos), o equilíbrio econômico-financeiro da concessão.

Destaca-se que enquanto nos reajustes tarifários anuais a "Parcela B" da Receita é atualizada monetariamente pelo IGP-M, no momento da revisão tarifária periódica há um recalculo de todos os custos gerenciáveis, aferindo-se do ponto de vista regulatório ("price-cap") a receita necessária para cobertura dos custos operacionais eficientes e a remuneração adequada sobre os investimentos realizados com prudência.

A revisão tarifária periódica é realizada mediante $\mathrm{o}$ cálculo do reposicionamento tarifário e do estabelecimento do Fator $\mathrm{X}$.

\section{REPOSICIONAMENTO TARIFÁRIO}

O cálculo do reposicionamento tarifário se baseia na definição da receita requerida para prestação do serviço, o que inclui os custos não gerenciáveis, e parcela da receita necessária para cobertura dos custos operacionais eficientes para um dado nível de qualidade do serviço - assim como uma remuneração adequada sobre investimentos realizados com prudência.

\section{CÁLCULO DO FATOR X}

Por meio do Fator $X$, são estabelecidas as metas de eficiência para o próximo período tarifário que são expressas na tarifa. $O$ Fator $X$ é resultante da composição dos seguintes elementos:

I. componente Xe - reflete, por meio de um índice, os ganhos de produtividade esperados pelo natural incremento do consumo de energia elétrica na área de concessão da distribuidora, em função do maior consumo dos consumidores 
existentes, como pela incorporação de novos consumidores, no período entre revisões tarifárias;

III. componente Xa - reflete um índice de ajuste ao reajuste do componente "pessoal" da "Parcela B", quando dos reajustes tarifários anuais, que reflita adequadamente o valor da remuneração da mão de obra do setor formal da economia brasileira.

\subsubsection{REVISÃO TARIFÁRIA EXTRAORDINÁRIA}

Além dos processos de Reajuste Tarifário Anual (IRT) e Revisão Tarifária Periódica (RTP), o contrato de concessão estabelece também o mecanismo da Revisão Tarifária Extraordinária (RTE), por meio do qual, a ANEEL, pode, a qualquer tempo, por solicitação da empresa de distribuição e quando devidamente comprovada, proceder à revisão das tarifas, visando manter o equilíbrio econômicofinanceiro do contrato, caso subsistam alterações significativas nos custos da empresa de distribuição, incluindo as modificações de tarifas de compra de energia, encargos setoriais ou encargos de uso das redes elétricas que possam ser estabelecidos durante o período.

A criação, alteração ou extinção de quaisquer tributos ou encargos legais, após a assinatura do contrato de concessão, quando comprovado seu impacto, implicará também na revisão das tarifas, para mais ou para menos, conforme o caso, ressalvado os impostos sobre a renda, a Contribuição Social sobre o Lucro Líquido (CSLL) e quaisquer outros que venham a ser criados, tendo como base de cálculo o resultado da atividade econômica.

\subsection{Custos com a compra de energia elétrica repassáveis à tarifa}

Os custos com aquisição de energia elétrica são enquadrados no "Parcela A" da tarifa de distribuição, conseqüentemente devem ser integralmente repassados ao consumidor. Porém, isto não é totalmente verdade, posto que o Regulador com o 
intuito de atender aos principais objetivos do novo modelo, conforme já exposto no capitulo 0 , incentivando a contratação eficiente das distribuidoras, definiu limites de repasse à tarifa dos custos com a compra de energia elétrica.

Com isso, para regular o repasse dos custos de aquisições de energia elétrica por parte das distribuidoras às tarifas dos consumidores finais, a Aneel calcula anualmente o Valor de Referência (VR), mediante aplicação da eq.(3), como segue:

$$
V R=\frac{V L 5 \times Q 5+V L 3 \times Q 3}{Q 5+Q 3}
$$

Onde:

VR - Valor de Referência para repasse de preços, calculado e válido para o ano "A"; VL5 - valor médio de aquisição nos leilões de compra de energia elétrica proveniente de novos empreendimentos de geração realizados no ano "A - 5", ponderado pelas respectivas quantidades adquiridas;

Q5 - quantidade total, expressa em MWh por ano, adquirida nos leilões de compra de energia elétrica proveniente de novos empreendimentos de geração, realizados no Ano "A - 5";

VL3 - valor médio de aquisição nos leilões de compra de energia elétrica proveniente de novos empreendimentos de geração realizados no ano "A - 3", ponderado pelas respectivas quantidades adquiridas; $\mathrm{e}$

Q3 - quantidade total, expressa em MWh por ano, adquirida nos leilões de compra de energia elétrica proveniente de novos empreendimentos de geração, realizados no ano "A - 3".

Os critérios de repasse a serem autorizados pela a ANEEL, dos custos de aquisição de energia elétrica, variam de acordo com cada tipo de contrato, como descrito a seguir: 
$\checkmark$ Nos leilões de compra de energia elétrica proveniente de novos empreendimentos realizados no ano "A - 5":

a. Repasse do VR durante os três primeiros anos de suprimento da energia elétrica adquirida e;

b. Repasse integral do valor de aquisição da energia elétrica, a partir do quarto ano de sua entrega.

$\checkmark$ Nos leilões de compra de energia elétrica proveniente de novos empreendimentos realizados no ano "A - 3":

a. Repasse do VR durante os três primeiros anos de entrega da energia elétrica adquirida, limitado ao montante correspondente a dois por cento da carga do agente de distribuição comprador verificada no ano "A - 5";

b. Repasse integral do valor de aquisição da energia elétrica a partir do quarto ano de sua entrega, limitado ao montante correspondente a dois por cento da carga do agente de distribuição comprador verificada no ano "A - 5" e;

c. Repasse ao menor valor entre o $V L 5$ e o $V L 3$ da parcela adquirida que exceder os montantes referidos nos itens "a" e "b" acima.

Nos leilões de energia elétrica proveniente de empreendimentos existentes "A - 1" repasse integral dos respectivos valores de sua aquisição;

$\rightarrow$ A partir de 2009, nos leilões de energia proveniente de empreendimentos existentes, cada agente de distribuição deverá contratar energia elétrica correspondente a no mínimo noventa e seis por cento do seu montante de reposição ${ }^{18} \mathrm{e}$, havendo disponibilidade, até cinco por cento acima do montante de reposição referido e (DECRETO n. $\left.{ }^{\circ} 5.163,2004\right)$;

${ }^{18}$ Montante de Reposição, quantidade de energia elétrica dos contratos que se extinguirem no ano dos leilões (Decreto . $^{\circ} 5.163,2004$ ) 
$\checkmark$ Nos leilões de ajustes, repasse integral até o limite do $V R$;

$\checkmark \mathrm{Na}$ contratação de energia elétrica proveniente de geração distribuída repasse integral até o limite do $V R$, porém com restrição de montante adquirido de até dez por cento da carga da distribuidora;

$\checkmark$ Nos leilões de compra de energia elétrica proveniente de fontes alternativas, repasse integral dos respectivos valores de aquisição; e

$\checkmark \mathrm{Na}$ contratação de energia elétrica proveniente de Itaipu Binacional e Proinfa, repasse integral.

Além disso, no repasse dos custos totais com a aquisição de energia elétrica, considera-se até cento e três por cento do montante total de energia elétrica contratada em relação à carga anual de fornecimento do agente de distribuição. $E$ em caso de insuficiência de contratação de energia elétrica (Subcontratação), para suprimento do mercado de consumo da distribuidora, verificado no decorrer de um ano (janeiro a dezembro), a distribuidora sofrerá penalidade e possível não repasse de custos à tarifa caso o PLD seja menor que o $V R$, que serão calculados como seguem:

$1^{0}$ Penalidade: quantidade de energia elétrica, resultante da diferença entre o mercado de consumo da distribuidora verificado e o montante total contratado, multiplicada pelo maior valor entre o Preço de Liquidação de Diferença $(P L D)$ e o Valor de referência $(V R)$ e;

$2^{\circ}$ Não Repasse à tarifa: quantidade de energia elétrica, resultante da diferença entre o mercado de consumo da distribuidora verificado e o montante total contratado, multiplicada pela diferença do Preço de Liquidação de Diferença $(P L D)$ e o Valor de referência $(V R)$. Caso o $P L D$ seja menor que o VR não há ônus adicional a distribuidora.

Para tanto, a ANEEL, na Data de Reajuste em Processamento (DRP) (conforme definida no item 4.1.4.1), leva em consideração quatro etapas de repasse da compra de energia às tarifas dos consumidores: 
1. "Repasse de $100 \%$ " dos custos de atendimento da Carga Regulatória ${ }^{19}$ da distribuidora;

2. Repasse dos custos da "Sobrecontratação";

3. Repasse dos custos com o "Ajuste Financeiro" dos resultados da liquidação no mercado de curto prazo (Mercado "Spot") e;

\section{CVA Energia.}

Na primeira e na quarta etapa, são definidos os custos relacionados a $100 \%$ (cem por cento) da carga de fornecimento anual regulatória, enquanto que, na segunda e na terceira etapa, são verificadas as sobras de energia.

Vale ressaltar, que as equações desenvolvidas a seguir são de origem própria e são baseadas nos procedimentos de reajuste tarifário realizado pela ANEEL, porém, adaptadas para o objetivo principal deste trabalho, que é o de representação da compra de energia, referente a um ano civil, em fluxo de caixa, ou seja, o que difere, em alguns casos, do período analisado pela ANEEL. Outra importante consideração é de que o procedimento adotado pela ANEEL sofreu diversas alterações ao longo dos últimos anos e discussões a respeito do assunto, no momento em que escrito este trabalho, ainda estão sendo realizadas.

Além disso, com o intuito de facilitar o entendimento e a aplicação de algumas dessas equações, apresenta-se no decorrer deste trabalho um exemplo hipotético para uma distribuidora de energia elétrica com data do aniversário de reajuste tarifário no inicio de julho de cada ano. Vale ressaltar que, as escolhas das datas de reajustes tarifários, utilizadas na aplicação das equações apresentadas a seguir, estão condicionadas a se obter, ao final, a representação do repasse dos custos com compra de energia elétrica para o ano de 2006 em fluxo de caixa. É considerado ainda, apenas quatro momentos de avaliação (ao invés de doze, simulando que as avaliações mensais pudessem ser realizadas por trimestre), facilitando assim a apresentação dos resultados obtidos com o exemplo.

\footnotetext{
${ }^{19}$ Carga Regulatória, carga anual de fornecimento do agente de distribuição, calculada no Centro de Gravidade da Rede Básica, que serve como referência para Aneel no cálculo de repasse dos custos de contratação de energia. A equação que calcula a Carga Regulatória será apresentada mais adiante neste trabalho.
} 


\subsubsection{Repasse de $100 \%$ dos Custos de Atendimento da Carga Regulatória}

O primeiro passo do cálculo do repasse dos custos com aquisição de energia elétrica é o levantamento de toda carteira de contratos de energia da distribuidora, vigentes na Data de Reajuste em Processamento (DRP), que servirá como base para o atendimento de $100 \%$ da Carga Regulatória até a próxima DRP, obedecendo às seguintes regras:

$\checkmark$ Para a energia elétrica comprada através de contratos bilaterais é considerado o montante de energia elétrica que poderá ser atendido pelos contratos nos 12 meses subseqüentes à DRP, entendido aqui como o Período Tarifário, limitado ao montante de energia elétrica do mesmo contrato verificado no Período de Referência (conforme item 4.1.4.1) e;

$\checkmark$ Para a energia elétrica comprada para os demais contratos será considerado o montante de energia elétrica de cada contrato para entrega no Período Tarifário.

A soma dos montantes contratados resulta na energia total contratada $(E T)$, em MWh, vigente na DRP, apto para repasse à tarifa de fornecimento do consumidor final, conforme eq. (4) a seguir:

$$
E T=\sum_{m}\left[\sum_{a}(E a, m)+\sum_{b}(E b, m)+E l t a i p u, m+E \text { Proinf } a, m\right]
$$

Onde:

m Mês pertencente ao Período Tarifário;

a Tipo de contrato composto por CCEAR e contratos de GD;

b Tipo de contrato composto por contratos bilaterais; 
Ea,m Energia em MWh, no mês " $m$ ", referente a cada contrato " $a$ " pertencente à carteira da distribuidora na DRP para o Período Tarifário;

Eb,m Energia em MWh, no mês " $m$ ", referente a cada contrato " $b$ " considerado na carteira da distribuidora na DRP para o Período Tarifário;

Eltaipu,m Energia em MWh, no mês $m$, referente à cota recebida de Itaipu e;

EProinfa, $m$ Energia em MWh, no mês $m$, referente à cota recebida do Proinfa.

As Tabela 4.2 e Tabela 4.3 a seguir apresentam exemplo de aplicação da eq. (4) às DRPs de 2005 e 2006 de uma distribuidora hipotética.

Tabela 4.2 - Energia elétrica comprada (MWh) - DRP 2005.

\begin{tabular}{|c|c|c|c|c|c|c|}
\hline & \multirow{2}{*}{\multicolumn{2}{|c|}{$3^{\circ} \mathrm{T} / 2005(\mathrm{~m}=1)$}} & \multirow{2}{*}{\multicolumn{2}{|c|}{\begin{tabular}{|l|l|}
$1^{\circ} \mathrm{T} / 2006(\mathrm{~m}=3)$ & $2^{\circ} \mathrm{T} / 2006(\mathrm{~m}=4)$ \\
\end{tabular}}} & \multirow[b]{2}{*}{ TOTAL } \\
\hline & & & & & & \\
\hline$E a, m$ & CCEAR Existente & 1.027 .902 & 1.034 .893 & 1.467 .759 & 1.513 .314 & 5.043 .869 \\
\hline$E a, m$ & CCEAR Nova & - & - & - & - & - \\
\hline$E b, m$ & Bilaterais & 1.108 .154 & 1.113 .640 & 936.908 & 967.411 & 4.126 .113 \\
\hline E Itaipu,m & Itaipu & 1.027 .285 & 1.027 .285 & 998.108 & 1.016 .119 & 4.068 .796 \\
\hline E Proinfa,m & Proinfa & - & - & - & - & - \\
\hline TOTAL & & 3.163 .341 & 3.175 .818 & 3.402 .775 & 3.496 .844 & $E T=13.238 .778$ \\
\hline
\end{tabular}

Tabela 4.3 - Energía elétrica comprada (MWh) - DRP 2006.

\begin{tabular}{|c|c|c|c|c|c|c|}
\hline & & $3^{\circ} \mathrm{T} / 2006(\mathrm{~m}=5)$ & $4^{\circ} T / 2006(m=6)$ & $1^{\circ} \mathrm{T} / 2007(\mathrm{~m}=7)$ & $2^{\circ} T / 2007(m=8)$ & Total \\
\hline$E a, m$ & CCEAR Existente & 1.149 .363 & 1.128 .177 & 1.080 .747 & 1.114 .767 & 4.473 .054 \\
\hline$E a, m$ & CCEAR Nova & - & - & - & - & - \\
\hline$E b, m$ & Bilaterais & 992.916 & 996.507 & 968.758 & 970.436 & 3.928 .616 \\
\hline E Itaipu,m & Itaipu & 1.035 .763 & 1.032 .205 & 1.006 .195 & 1.027 .306 & 4.101 .469 \\
\hline E Proinfa,m & Proinfa & 18.663 & 21.572 & 109.233 & 110.395 & 259.863 \\
\hline TOTAL & & 3.196 .705 & 3.178 .461 & 3.164 .933 & 3.222 .904 & $E T=12.763 .003$ \\
\hline
\end{tabular}

Após a definição dos montantes contratados de energia, deve-se estabelecer qual a carga anual de fornecimento do agente de distribuição que servirá como base de cálculo para o limite de repasse. Para tanto, utiliza-se da Carga Regulatória calculada no Centro de Gravidade (Creg) da distribuidora conforme eq. (5) a seguir:

$$
\text { Creg }=\text { MrefCat } \times(1+i \text { Preg })
$$

Onde: 
MrefCat Mercado de Referência, composto pela quantidade total de energia faturada pela distribuidora de seus consumidores cativos, expresso em MWh, no Período de Referência e;

iPreg Índice de perdas Regulatória, em \%, esta entendida como as perdas elétricas da distribuidora referenciadas no Centro de Gravidade, as quais se dividem em perdas técnicas e comerciais, calculado conforme percentual estabelecido na revisão tarifária periódica de cada distribuidora.

Paraexemplificar a eq. (5) considera-se os seguintes valores, também para as DRPs de 2005 e 2006 :

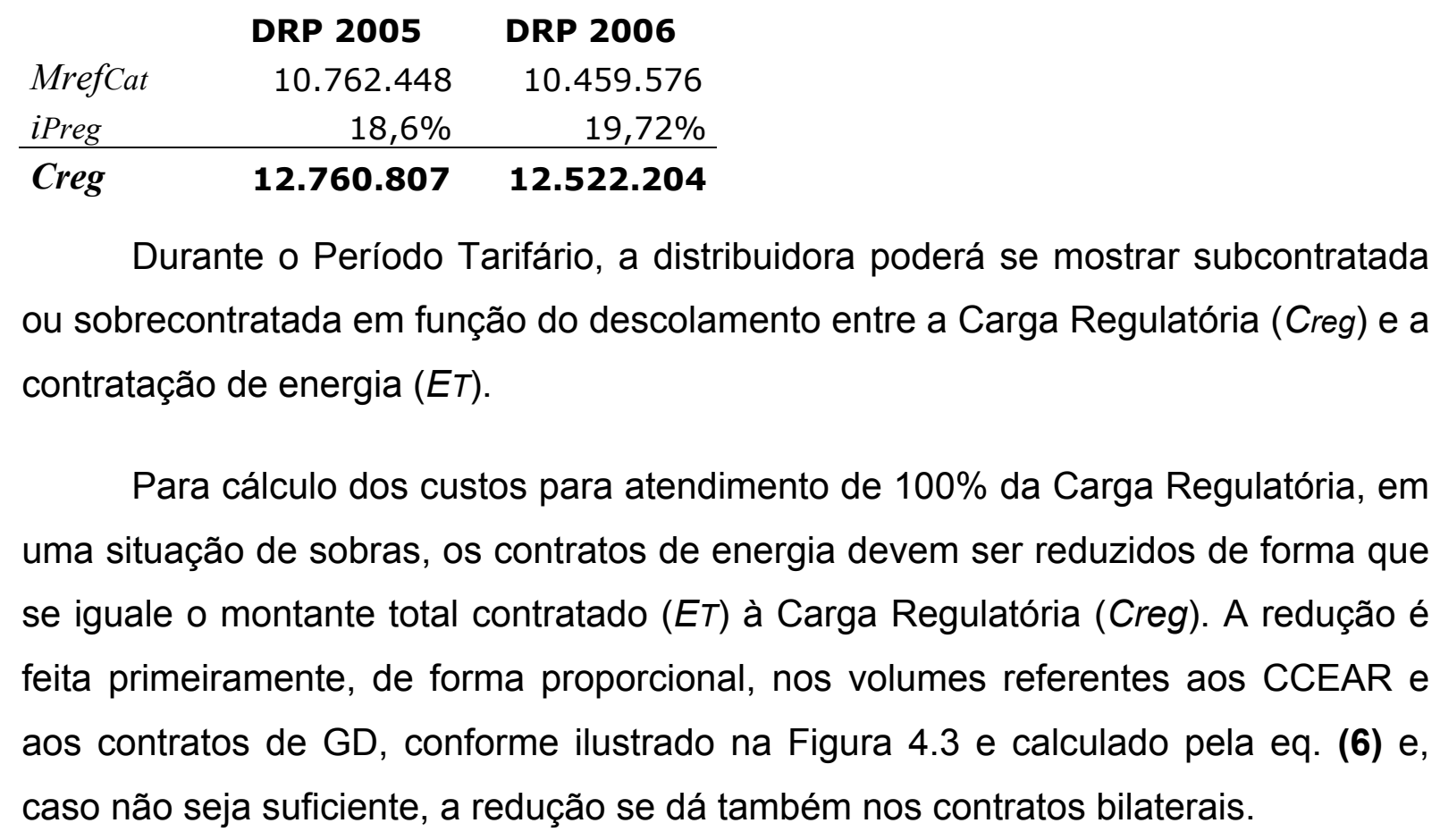




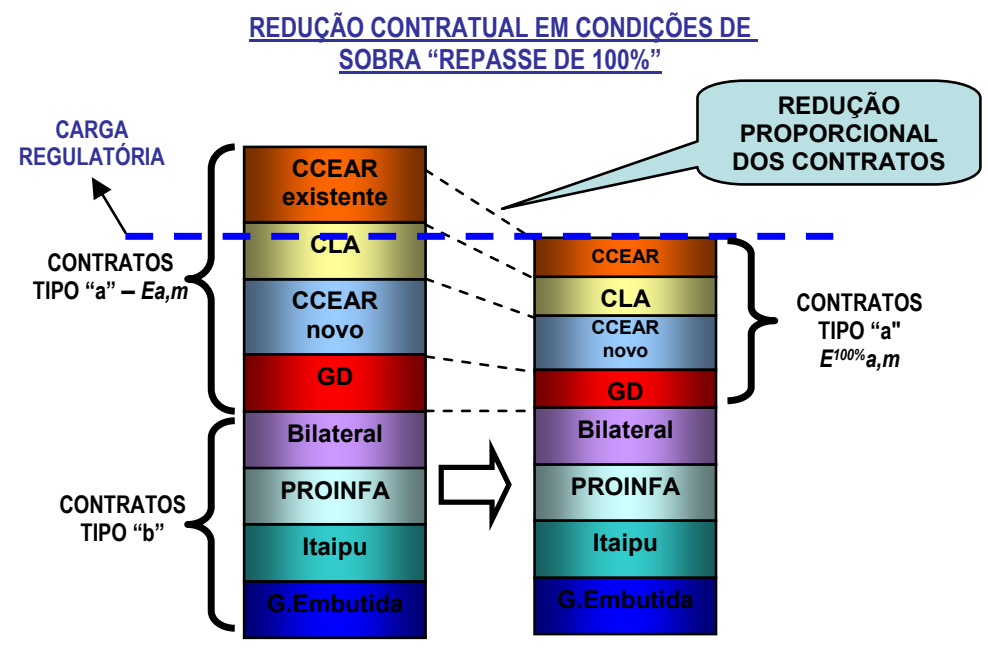

Figura 4.3 - Redução Contratual em condições de sobra

$E^{100 \%} a, m=$ Mínimo $\left(E a, m \times \frac{C r e g-\left[E T-\sum_{m a} \sum_{m}(E a, m)\right]}{\sum_{m} \sum_{a}(E a, m)} ; E a, m\right) \geq 0$

Onde:

$E^{100 \%}$ a,m Energia em MWh, no mês " $m$ " referente a cada contrato "a", já com ajuste que iguala o montante total contratado à Carga Regulatória em situação de sobra;

Verifica-se no Exemplo que ET maior que Creg tanto para 2005 quanto para 2006. Desta forma, a distribuidora analisada mostra-se sobrecontratada para fins de reajuste tarifário.

As Tabela 4.4 e Tabela 4.5 apresentam a aplicação da eq. (6) ao Exemplo Hipotético, de forma a ajustar os contratos tipo "a" e obter $E T=C r e g$.

Tabela 4.4 - Energia elétrica comprada ajustada para cálculo do IRT (MWh) - DRP 2005.

\begin{tabular}{|c|c|c|c|c|c|c|}
\hline & $3^{\circ} \mathrm{T} / 2005(\mathrm{~m}=1)$ & $4^{\circ} \mathrm{T} / 2005(\mathrm{~m}=2)$ & $1^{\circ} \mathrm{T} / 2006(\mathrm{~m}=3)$ & $2^{\circ} \mathrm{T} / 2006(\mathrm{~m}=4)$ & TOTAL \\
\hline$E_{a, n}^{100 \%}$ & CCEAR Existente & 930.495 & 936.824 & 1.328 .671 & 1.369 .909 & 4.565 .899 \\
\hline$E_{a, m}^{100 \%}$ & CCEAR Nova & & - & - & - & - \\
\hline$E^{100 \%} b, m$ & Bilaterais & 1.108 .154 & 1.113 .640 & 936.908 & 967.411 & 4.126 .113 \\
\hline E Itaipu,m & Itaipu & 1.027 .285 & 1.027 .285 & 998.108 & 1.016 .119 & 4.068 .796 \\
\hline E Proinfa, & Proinfa & & - & - & - & - \\
\hline TOTAL & & 3.065 .934 & 3.077 .749 & 3.263 .687 & 3.353 .438 & $E T=12.760 .807$ \\
\hline
\end{tabular}


Tabela 4.5 - Energia elétrica comprada ajustada para cálculo do IRT (MWh) - DRP 2006.

\begin{tabular}{|c|c|c|c|c|c|c|}
\hline & $3^{\circ} \mathrm{T} / 2006(\mathrm{~m}=5)$ & $4^{\circ} \mathrm{T} / 2006(\mathrm{~m}=6)$ & $1^{\circ} \mathrm{T} / 2007(\mathrm{~m}=7)$ & $2^{\circ} \mathrm{T} / 2007(\mathrm{~m}=8)$ & Total \\
\hline$E_{a, m}^{100 \%}$ & CCEAR Existente & 1.087 .489 & 1.067 .444 & 1.022 .567 & 1.054 .756 & 4.232 .256 \\
\hline$E_{a, m}^{100 \%}$ & CCEAR Nova & - & - & - & - & - \\
\hline$E^{100 \%} b, m$ & Bilaterais & 992.916 & 996.507 & 968.758 & 970.436 & 3.928 .616 \\
\hline E Itaipu,m & Itaipu & 1.035 .763 & 1.032 .205 & 1.006 .195 & 1.027 .306 & 4.101 .469 \\
\hline E Proinfa,m & Proinfa & 18.663 & 21.572 & 109.233 & 110.395 & 259.863 \\
\hline TOTAL & & 3.134 .831 & 3.117 .728 & 3.106 .753 & 3.162 .892 & $E T=12.522 .204$ \\
\hline
\end{tabular}

Além disso, é possível verificar que tanto para a DRP 2005 quanto para a DRP 2006 houve apenas a necessidade de ajuste nos contratos tipo "a".

Já em uma situação de déficit, além do montante total contratado $(E T)$, considera-se também a aquisição de energia pela distribuidora no mercado de curto prazo com o objetivo de cobrir o déficit (Figura 4.4). Neste sentido, a energia liquidada na CCEE é tratada como um contrato de curto prazo e seu montante $\left(E_{c p}\right)$ é valorado ao Preço médio de repasse dos contratos de leilões regulados (CCEAR) e de GD na DRP (Pmix), em R\$/MWh, calculado conforme a eq.(7).

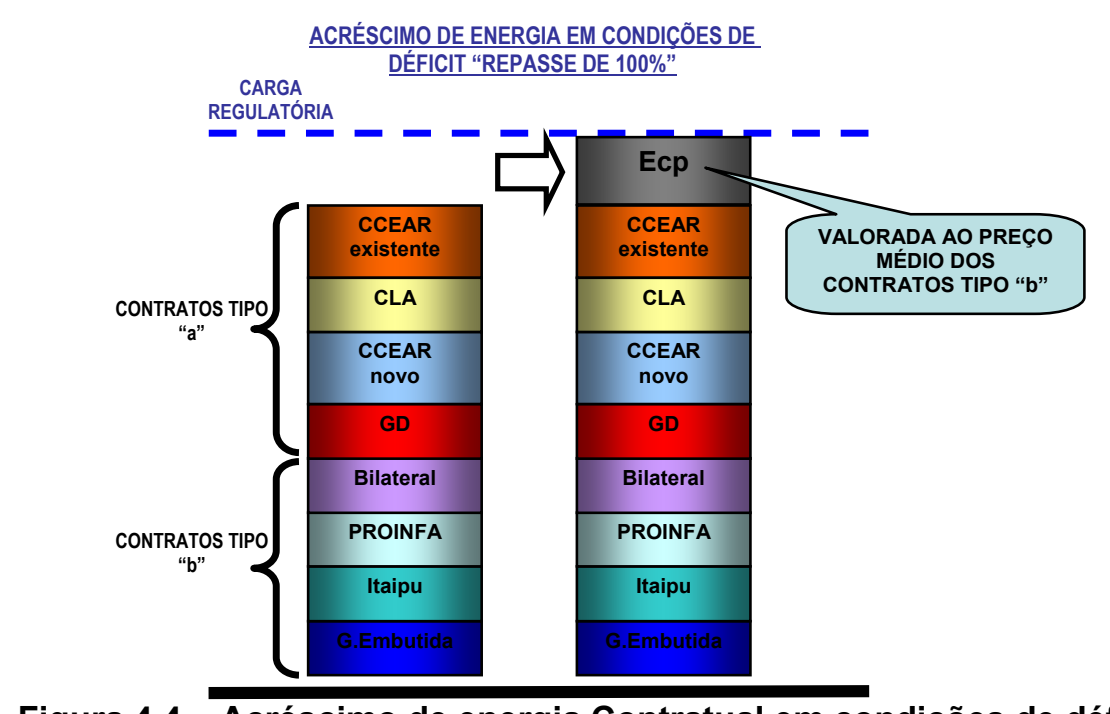

Figura 4.4 - Acréscimo de energia Contratual em condições de déficit 


$$
P_{\text {mix }}=\frac{\sum_{m} \sum_{a}(P a \times E a, m)}{\sum_{m} \sum_{a}(E a, m)}
$$

Onde:

Pa Preço de repasse do contrato "a" na DRP, em $\mathrm{R} \$ / \mathrm{MWh}$, que obedece aos limites descritos no início do item 4.2.

Seguindo o exposto acima, o "Repasse de 100\%" do custo da energia, referente ao mês " $m$ " (C100\%,m), é dado pela eq. (8), como segue:

$$
C 100 \%, m=\sum_{b}\left(P_{b} \times E_{b, m}^{100 \%}\right)+\sum_{a}\left(P_{m i x} \times E_{a, m}^{100 \%}\right)+P_{\text {Itaipu }} \times E_{\text {Itaipu }, m}+E_{c p} \times \text { Pmix }
$$

Onde:

$P b \quad$ Preço do contrato "b" na DRP, em R\$/MWh;

Pltaipu Preço, em $\mathrm{R} \$ / \mathrm{MWh}$, considerado para repasse na DRP da energia de Itaipu e;

$E^{100 \%} b, m$ Energia em MWh, no mês " $m$ ", referente a cada contrato " $b$ " considerado na carteira da distribuidora na DRP para o Período Tarifário, já com a redução, quando necessária, que iguala o montante total contratado à Carga Regulatória em situação de sobra, conforme descrito anteriormente.

Finalmente para o calculo do custo total com o "Repasse de 100\%" na DRP, considera-se a eq. (9), conforme segue: 


$$
C 100 \%=\sum_{m} C 100 \%, m
$$

No exemplo consideram-se os seguintes preços para os contratos:

$\operatorname{Preço~}(R \$ / M W h)$

$P a$ CCEAR Existente

Pa CCEAR Nova

$\mathrm{Pb} \quad$ Bilaterais

PItaipu Itaipu
DRP 2005 DRP 2006

$\begin{array}{cc}59,49 & 66,30 \\ 114,60 & 135,39 \\ 83,52 & 91,58\end{array}$

Sendo que, para o exemplo, a aplicação da eq. (7) implica em $P$ mix $=P_{a}=$ 59,49 R\$/MWh na DRP 2005 e Pmix $=P_{a}=66,30$ R\$/MWh na DRP 2006.

Aplicando os dados do exemplo hipotético as equações (8) e (9) obtêm-se os resultados apresentados nas Tabela 4.6 e Tabela 4.7 a seguir:

Tabela 4.6 - Custo com o Repasse de 100\% (R\$ mil) - DRP 2005.

\begin{tabular}{|l|r|r|r|r|r|}
\multicolumn{1}{c|}{} & $\mathbf{3}^{\circ} \mathbf{T} / \mathbf{2 0 0 5}(\mathbf{m}=\mathbf{1})$ & $\mathbf{4}^{\circ} \mathbf{T} / \mathbf{2 0 0 5}(\mathbf{m}=\mathbf{2})$ & $\mathbf{1}^{\circ} \mathbf{T} / \mathbf{2 0 0 6}(\mathbf{m}=\mathbf{3})$ & $\mathbf{2}^{\circ} \mathbf{T} / \mathbf{2 0 0 6}(\mathbf{m}=\mathbf{4})$ & \multicolumn{1}{c|}{ TOTAL } \\
\hline CCEAR Existente & 55.355 & 55.732 & 79.043 & 81.496 & 271.625 \\
CCEAR Nova & - & - & - & - & - \\
Bilaterais & 126.994 & 127.623 & 107.370 & 110.865 & 472.853 \\
Itaipu & 85.799 & 85.799 & 83.362 & 84.866 & 339.826 \\
\hline $\boldsymbol{C 1 0 0 \%}, \boldsymbol{m}$ & 268.148 & 269.154 & 269.774 & 277.227 & $\mathbf{C 1 0 0 \%}=\mathbf{1 . 0 8 4 . 3 0 4}$ \\
\hline
\end{tabular}

Tabela 4.7 - Custo com o Repasse de 100\% (R\$ mil) - DRP 2006.

\begin{tabular}{|c|c|c|c|c|c|}
\hline & $3^{\circ} \mathrm{T} / 2006(\mathrm{~m}=5)$ & $4^{\circ} \mathrm{T} / 2006(\mathrm{~m}=6)$ & $1^{\circ} \mathrm{T} / 2007(\mathrm{~m}=7)$ & $2^{\circ} \mathrm{T} / 2007(\mathrm{~m}=8)$ & Total \\
\hline CCEAR Existente & 72.101 & 70.772 & 67.796 & 69.930 & 280.599 \\
\hline CCEAR Nova & - & - & - & - & - \\
\hline Bilaterais & 134.431 & 134.917 & 131.160 & 131.387 & 531.895 \\
\hline Itaipu & 94.855 & 94.529 & 92.147 & 94.081 & 375.613 \\
\hline $\mathrm{C100 \% , \textrm {m }}$ & 301.387 & 300.218 & 291.104 & 295.398 & $\mathrm{C} 100 \%=1.188 .106$ \\
\hline
\end{tabular}

\subsubsection{Repasse da Sobrecontratação}

O artigo 38 do Decreto Aneel $n^{\circ} 5.163$ (2004) estabelece que no repasse dos custos com aquisição de energia elétrica às tarifas dos consumidores finais, deverá ser considerado até cento e três por cento do montante total de energia elétrica contratada em relação à carga anual de fornecimento do agente de distribuição. 
Para tanto devem ser observados:

$\checkmark$ Apuração das sobras contratuais será realizada para um ano civil (janeiro a dezembro), denominado aqui como Período de Apuração, e seu cálculo será efetuado na DRP do ano seguinte à apuração;

$\checkmark$ O repasse das sobras contratuais será limitado a 3\% do Mercado Regulatório (Mreg);

$\checkmark$ Custo da sobrecontratação será incluído nas tarifas mediante a componente financeira, atualizada pelo IPCA; e

$\checkmark$ Empilhamento conforme Figura 4.5, para definição dos contratos utilizados para valoração dos custos com sobrecontratação.

\section{CCEAR existente \\ CCEAR Ajuste \\ CCEAR novo \\ Geração Distribuida \\ Contratos Bilaterais \\ PROINFA / ITAIPU}

Figura 4.5 - Pilha de Contratos em ordem de mérito de consideração para repasse

Porém, antes de calcular os custos com sobrecontratação, é necessário calcular os seguintes itens:

a. Mercado Regulatório do mês " $n$ " (Mreg,n), expresso em MWh, calculado para o Centro de Gravidade conforme eq. (10) a seguir: 


$$
\text { Mreg, } n=\frac{\text { Creal }, n}{\sum_{n} \text { Creal }, n} \times \text { Mfat } \times(1+i \text { Pr eg, } n)
$$

Onde:

Mês do ano civil (Período de Apuração) imediatamente anterior a DRP;

Creal,n Carga real mensal do agente de distribuição medida pela CCEE no Centro de Gravidade (CG) da Rede Básica em MWh, no mês " $n$ ”;

Mfat Mercado de Energia faturado dos consumidores cativos em MWh pelo agente de distribuição no Período de Apuração; e

iPreg,n Índice de perdas Regulatória vigentes no mês " $n$ ", definida pela Aneel na revisão tarifária da distribuidora.

Para exemplificar a eq. (10) e as equações a seguir, utiliza-se como base o reajuste tarifário de 2007, lembrando que a escolha da data do reajuste tarifária está condicionada a exemplificar a representação dos custos de compra de energia elétrica para o ano de 2006, de uma distribuidora hipotética, em fluxo de caixa.

Desta forma, a Tabela 4.8 apresenta o Mercado Regulatório do mês " $n$ " (Mreg,n) da distribuidora do exemplo para o ano de 2006, assumindo que o Mfat em 2006 foi de 10.503.701 MWh.

Tabela 4.8 - Mercado regulatório mensal, verificado em 2006 (MWh)

\begin{tabular}{|l|r|r|r|r|}
\cline { 2 - 5 } \multicolumn{1}{c|}{} & $\mathbf{1}^{\circ} \mathbf{T} / \mathbf{2 0 0 6}(\mathbf{n}=\mathbf{3})$ & $\mathbf{2}^{\circ} \mathbf{T} / \mathbf{2 0 0 6}(\mathbf{n}=\mathbf{4})$ & $\mathbf{3}^{\circ} \mathbf{T} / \mathbf{2 0 0 6}(\mathbf{n}=\mathbf{5})$ & $\mathbf{4}^{\circ} \mathbf{T} / \mathbf{2 0 0 6}(\mathbf{n}=\mathbf{6})$ \\
\hline Creal, $\boldsymbol{i}$ Preg, $\boldsymbol{n}$ & 3.141 .485 & 3.107 .572 & 3.159 .790 & 3.191 .390 \\
\hline Mreg, $\boldsymbol{n}$ & $18,60 \%$ & $18,60 \%$ & $19,72 \%$ & $19,72 \%$ \\
\hline
\end{tabular}

b. Montante total de energia contratada, verificado no mês " $n$ ", em MWh, (Ever,n), calculado conforme eq. (11) a seguir: 


$$
\text { Ever }, n=\sum_{a}(\text { Evera }, n)+\sum_{b}(\text { Everb }, n)+\text { Everltaipu }, n+\text { Ever Pro inf } a, n
$$

Onde:

$a, b \quad$ Conforme definidos no Item 4.2.1;

Evera, $n$ Energia contratada pela distribuidora, em MWh, verificada no mês " $n$ ", referente ao contrato "a";

Everb, $n$ Energia contratada pela distribuidora, em MWh, verificada no mês " $n$ ", referente ao contrato " $b$ ";

Everltaipu,n Energia em MWh verificada no mês " $n$ ", referente à cota recebida de Itaipu e;

EverProinfa, $n$ Energia em MWh verificada no mês " $n$ ", referente à cota recebida do Proinfa.

$\mathrm{Na}$ Tabela 4.9 encontra-se os resultados obtidos com a aplicação da eq. (11) ao exemplo estudado.

Tabela 4.9 - Montante total de energia contratada, verificado em 2006 (MWh)

\begin{tabular}{|c|c|c|c|c|c|}
\hline & $1^{\circ} \mathrm{T} / 2006(\mathrm{n}=3)$ & $2^{\circ} \mathrm{T} / 2006(\mathrm{n}=4)$ & $3^{\circ} T / 2006(n=5)$ & $4^{\circ} T / 2006(n=6)$ \\
\hline Ever $a, n$ & CCEAR Existente & 1.130 .814 & 1.151 .450 & 1.182 .769 & 1.172 .969 \\
\hline Ever $a, n$ & CCEAR Nova & - & - & - & - \\
\hline Ever $b, n$ & Bilaterais & 960.711 & 1.004 .845 & 999.518 & 996.030 \\
\hline Ever Itaipu,n & Itaipu & 1.008 .116 & 1.023 .196 & 1.037 .178 & 1.037 .234 \\
\hline Ever Proinfa,n & Proinfa & 2.175 & 7.965 & 17.900 & 20.593 \\
\hline Ever, $n$ & Total & 3.101 .815 & 3.187 .456 & 3.237 .364 & 3.226 .825 \\
\hline
\end{tabular}

c. Sobra Contratual (Sver) verificada no Período de Apuração, em MWh, limitada a $3 \%$ do Mercado Regulatório, calculada conforme eq. (12) a seguir: 
Sver = Mínimo $\left[\left(3 \% \times \sum_{n} \operatorname{Mreg}, n\right) ; \operatorname{Máximo}\left(0 ; \sum_{n} E v e r, n-\sum_{n}\right.\right.$ Creal,$\left.\left.n\right)\right]$

Aplicando a eq. (12) aos valores das Tabela 4.8 e Tabela 4.9 obtém-se Sver = 236.773 MWh.

d. Sobra Contratual verificada no mês "n", em MWh, para repasse da sobrecontratação (Sver,n), calculada conforme eq. (13) a seguir:

$$
\text { Sver }, n=\frac{\text { Máximo }(\text { Ever }, n-\text { Creal }, n ; 0)}{\sum_{n}(\text { Máximo }(\text { Ever }, n-\text { Creal }, n ; 0))} \times \text { Sver }
$$

A Sobra Contratual verificada no mês " $\mathrm{n}$ " é apresentada na Tabela 4.10, conforme segue:

Tabela 4.10 - Sobra mensal Contratual verificada em 2006 (MWh)

\begin{tabular}{|l|r|r|r|r|r|}
\multicolumn{1}{c|}{} & $\mathbf{1}^{\circ} \mathrm{T} / \mathbf{2 0 0 6}(\mathbf{n}=\mathbf{3})$ & $\mathbf{2}^{\circ} \mathrm{T} / \mathbf{2 0 0 6}(\mathbf{n}=\mathbf{4})$ & $\mathbf{3}^{\circ} \mathrm{T} / \mathbf{2 0 0 6}(\mathbf{n}=5)$ & $\mathbf{4}^{\circ} \mathrm{T} / \mathbf{2 0 0 6}(\mathbf{n}=\mathbf{6})$ & \multicolumn{1}{c|}{ Total (Sver) } \\
\hline Sver, $n$ & - & 63.455 & 61.620 & 28.148 & $\mathbf{1 5 3 . 2 2 3}$ \\
\hline
\end{tabular}

Calculadas as sobras contratuais mensais, é necessário definir quais contratos serão utilizados no cálculo dos custos de sobrecontratação, para tanto, se utiliza da ordem de mérito contratual, conforme Figura 4.5, onde CCEAR de energia existente é o primeiro a ser considerado e assim sucessivamente de cima para baixo na pilha, até que toda Sobra Contratual verificada no mês seja alocada. Desta forma, obtém-se para cada contrato a energia em MWh alocada para sobra (Svera,n e Sverb,n), conforme eq. (14) e eq. (15) abaixo:

$$
\text { SverCCEA Re, } n=\text { Mínimo }(\text { Sver }, n ; \text { EverCCEARe, } n)
$$

Onde: 
SverCCEARe,n Energia em MWh, no mês " $n$ ", do contrato CCEAR de energia existente alocada para sobra.

E se $($ Sver, $n-$ SverCCEARe,n) $\geq 0$, então:

$$
\text { SvercCEARa, } n=\text { Mínimo }[(\text { Sver }, n-\text { SvercCEA Re, } n) ; \text { EvercCEARa }, n]
$$

Onde:

SverCCEARa,n Energia em MWh, no mês $m$, do contrato CCEAR de ajuste alocada para sobra.

E assim sucessivamente até que toda sobra contratual no mês seja alocada.

No exemplo, verifica-se que a aplicação da eq. (14) é suficiente para cobrir a sobra contratual mensal, ou seja, toda sobra contratual mensal verificada no mês e apresentada pela Tabela 4.10 é composta por contratos de CCEAR de energia existente.

Por fim, o cálculo dos custos com sobrecontratação, repassáveis à tarifa do consumidor na DRP (C3\%), é dado pela soma dos custos dos respectivos montantes sobrecontratados descontados da receita adquirida com a venda desses montantes no mercado de curto prazo (Mercado Spot) ao PLD, conforme eq. (16) a seguir:

$$
\begin{aligned}
& C 3 \%=\sum_{n}\left[\left(\sum_{a}(\text { Svera, } n \times\left(P_{a, n}-P_{\text {spot }, n)}\right)+\underbrace{\sum_{b}\left(\text { Sverb }, n \times\left(P_{b, n}-P_{\text {spot }, n)}\right)\right)}_{b}) \times I P C A a c\right]\right. \\
& \text { Esta parcela só é necessária quando não houver } \\
& \text { contratos suficientes do tipo "a" pra alocar à sobra. }
\end{aligned}
$$

Onde:

Pa,n Preço pago pelo contrato "a" no mês " $n$ ”, em R\$/MWh; 
$P b, n \quad$ Preço pago pelo contrato " $b$ " no mês " $n$ ", em R $\$ / M W h$;

Pspot,n PLD médio ponderado pelas exposições da distribuidora no Mercado Spot em R\$/MWh, no mês " $n$ "; e

IPCAac Taxa de IPCA acumulada entre o mês de apuração da sobra e a DRP.

A Tabela 4.11 apresenta, para o exemplo, o cálculo dos custos com sobrecontratação, repassáveis à tarifa do consumidor na DRP 2007(C3\%).

Tabela 4.11 - Custos com sobrecontratação verificada em 2006 para DRP 2007

\begin{tabular}{|c|c|c|c|c|c|}
\hline & $1^{\circ} \mathrm{T} / 2006(\mathrm{n}=3)$ & $2^{\circ} T / 2006(n=4)$ & $3^{\circ} T / 2006(n=5)$ & $4^{\circ} T / 2006(n=6)$ & TOTAL \\
\hline Sver CCEARe,n (MWh) & - & 63.455 & 61.620 & 28.148 & 153.223 \\
\hline P CCEARe,n (R\$/MWh) & 61,27 & 61,27 & 65,61 & 65,76 & \\
\hline$P$ spot, $n(R \$ / M W h)$ & 29,44 & 46,51 & 107,20 & 65,26 & \\
\hline IPCA ac & $103,8 \%$ & $103,7 \%$ & $103,2 \%$ & $102,1 \%$ & \\
\hline Total (R\$ mil) & 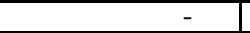 & 971 & (2.646) & 14 & $C 3 \%=-1.660$ \\
\hline
\end{tabular}

\subsubsection{Repasse do Ajuste Financeiro}

Mesmo que a distribuidora esteja contratada exatamente $100 \%$ de sua Carga Real no decorrer de um ano civil, ou seja, total contratado no ano exatamente igual às necessidades de consumo da distribuidora para o mesmo ano, poderão ocorrer sobras e déficits mensais em função da sazonalização dos contratos. Com o intuito de dar tratamento isonômico para essas sobras e déficits, é proposto que, até o limite de $100 \%$ do Mercado Regulatório anual (Mreg), seja apurado o resultado financeiro com o "descasamento" entre a sazonalização dos contratos e a Carga Real mensal (Creal, $n)$ da distribuidora.

Para apuração do repasse dos custos com o Ajuste Financeiro é utilizado como base neste trabalho, entendimento da Nota Técnica $n^{\circ} 085$ SEM/SER/ANEEL de 05 de março de 2008.

Sendo assim, ressalta-se que:

A apuração do Ajuste Financeiro é feita para um ano civil (Período de Apuração) e seu resultado é repassado à tarifa na DRP do ano seguinte à apuração; 
$\checkmark$ Os custos decorrentes do Ajuste financeiro serão incluídos nas tarifas mediante a componente financeira, atualizada pelo IPCA; e

$\checkmark$ Será considerada a proporção da sobra de energia no mês, utilizada para o cálculo do Ajuste Financeiro, em relação à soma da energia verificada dos contratos, no mesmo mês, de CCEARs e GD, já descontados os montantes utilizados no repasse da Sobrecontratação. Assim, multiplicando essa proporção pela energia verificada de cada CCEAR e contrato de GD, obtém-se o montante de cada contrato utilizado para valoração dos custos decorrentes do Ajuste Financeiro. A Figura 4.6 ajuda no entendimento deste processo.

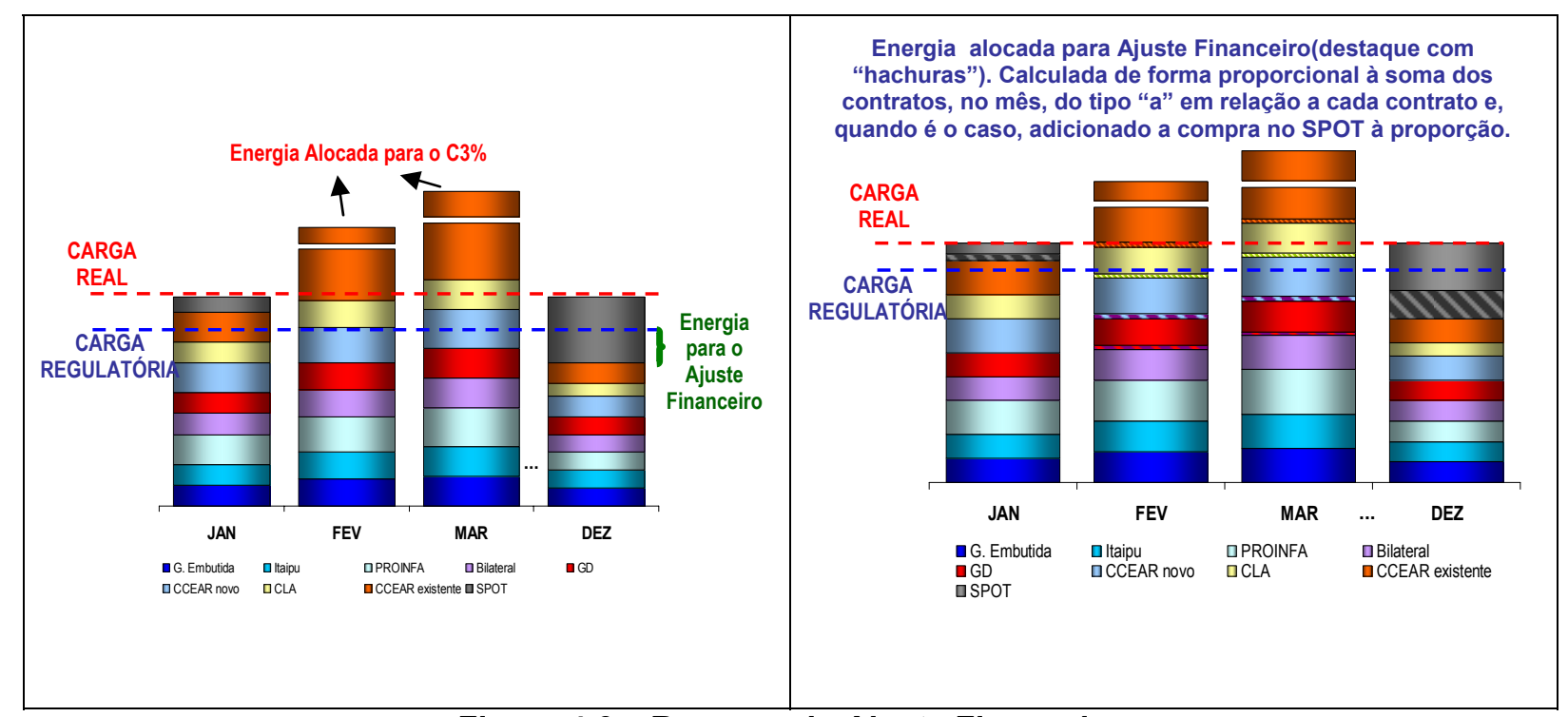

Figura 4.6 - Repasse do Ajuste Financeiro

Antes de propor equação para o cálculo do resultado do Ajuste Financeiro, é necessário definir a quantidade de energia comprada no Mercado Spot (déficit) que será considerada para o cálculo e quais contratos servirão para cobrir tal déficit, como segue:

a. O montante de Energia em MWh, comprada no Mercado Spot no mês " $n$ " considerada na apuração dos custos com Ajuste Financeiro (Acp,n) é calculado conforme eq. (17) a seguir: 


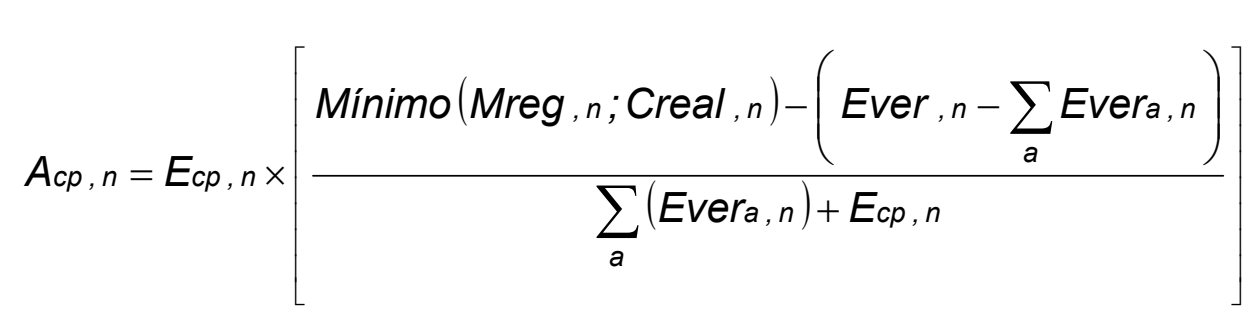

Onde:

Ecp,n Energia em MWh, comprada no mercado de curto prazo (Mercado Spot) no mês "n".

Aplicando a eq. (17) aos Valores das Tabela 4.8 e Tabela 4.9 obtém-se, para o exemplo, os resultados apresentados na Tabela 4.12 a seguir:

Tabela 4.12 -Energia comprada no Mercado Spot ajustada para o Ajuste Financeiro (MWh)

\begin{tabular}{|c|c|c|c|c|c|}
\hline & $1^{\circ} T / 2006(n=3)$ & $2^{\circ} \mathrm{T} / 2006(n=4)$ & $3^{\circ} T / 2006(n=5)$ & $4^{\circ} T / 2006(n=6)$ & TOTAL (EAcp,n) \\
\hline$E_{c p, n}=($ Creal,$n-$ Ever,$n)$ & 39.670 & - & - & - & \\
\hline$A_{c p, n}$ & 38.463 & - & - & - & 38.463 \\
\hline
\end{tabular}

b. O montante de Energia em MWh, no mês " $n$ ", do contrato "a" alocada para apuração dos custos com Ajuste Financeiro $(A a, n)$, é calculada conforme eq. (18) a seguir:

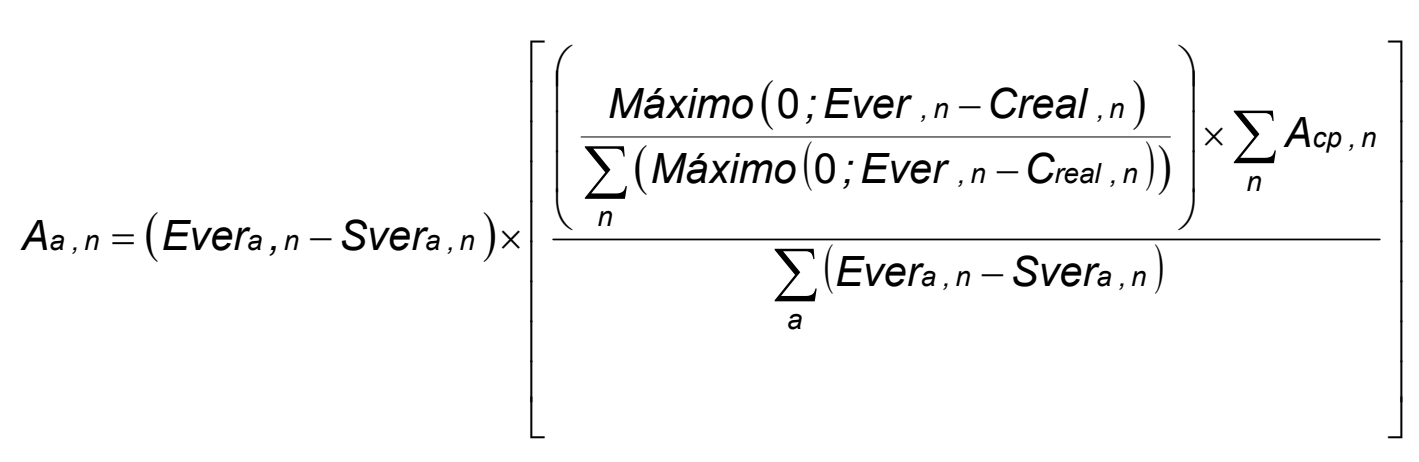

No exemplo, a utilização da eq. (18) implica nos resultados apresentados na Tabela 4.13 a seguir: 
Tabela 4.13 - Energia do contrato "a" alocada para o Ajuste Financeiro (MWh)

\begin{tabular}{|c|c|c|c|c|c|}
\hline & $1^{\circ} T / 2006(n=3)$ & $2^{\circ} T / 2006(n=4)$ & $3^{\circ} \mathrm{T} / 2006(\mathrm{n}=5)$ & $4^{\circ} T / 2006(n=6)$ & 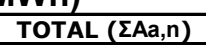 \\
\hline Máximo [0;(Ever,n-Creal,n)] & - & 79.884 & 77.573 & 35.436 & \\
\hline $\begin{array}{|ll|}A a, n & \text { CCEAR Existente } \\
\end{array}$ & - & 15.929 & 15.468 & 7.066 & 463 \\
\hline
\end{tabular}

Por fim é proposto para o cálculo dos custos repassáveis a tarifa do consumidor com o Ajuste Financeiro na DRP $(C A F)$ a eq. (19), como segue:

$$
C A F=\sum_{n}\left[\left(\sum_{a}[A a, n \times(P a, n-P s p o t, n)]+A c p, n \times(P s p o t, n-T m e d i a, n)\right) \times I P C A a c\right]
$$

Onde:

Tmédia, $n \quad$ Preço médio dos contratos repassados à tarifa na DRP imediatamente anterior ao mês " $n$ ", em $R \$ / M W h$, calculada conforme eq. (20) a seguir:

$$
\text { Tmédia, } n=\frac{\sum_{m} C 100 \%, m}{\text { Creg }}
$$

Onde:

C100\%,m e Creg Conforme definido no item 4.2.1.

A Tabela 4.14 apresenta, para o exemplo, o resultado dos custos repassáveis a tarifa do consumidor com o Ajuste Financeiro na DRP.

\begin{tabular}{|c|c|c|c|c|c|}
\hline Tmédia & DRP 2005 & DRP 2006 & \\
\hline \multirow[t]{2}{*}{ Tmédia } & 76,67 & 78,13 & & & \\
\hline & $1^{\circ} T / 2006(n=3)$ & $2^{\circ} \mathrm{T} / 2006(n=4)$ & $3^{\circ} T / 2006(n=5)$ & $4^{\circ} T / 2006(n=6)$ & TOTAL \\
\hline P CCEARe,n (R\$/MWh) & 61,27 & 61,27 & 65,61 & 65,76 & \\
\hline P CCEARn, n (R\$/MWh) & - & - & - & - & \\
\hline P spot,n (R\$/MWh) & 29,44 & 46,51 & 107,20 & 65,26 & \\
\hline Tmédia, $n$ & 76,67 & 76,67 & 78,13 & 78,13 & \\
\hline IPCA ac & $103,8 \%$ & $103,7 \%$ & $103,2 \%$ & $102,1 \%$ & \\
\hline Total (R\$ mil) & $(1.886)$ & 244 & (664) & 4 & CAF $=-2.302$ \\
\hline
\end{tabular}

Tabela 4.14 - Custos com Ajuste Financeiro em 2006 para DRP 2007 


\subsection{4. $\quad$ CVA Energia}

Em linhas gerais, o mecanismo da Conta de Compensação de Variação de Valores do Custo de Aquisição de Energia Elétrica (CVAENERG) apura diferenças entre o valor desembolsado pela distribuidora com a compra de energia para atendimento de $100 \%$ de suas necessidades de consumo e a receita considerada na Data de Reajuste Anterior (DRA). Esta diferença é verificada observando a data do desembolso e, a partir de então, é remunerada pela taxa SELIC, em duas etapas. A primeira corrige os valores de CVA Energia até $05^{\circ}$ dia útil anterior a DRP, utilizando-se da SELIC divulgada pelo Banco Central e a segunda etapa corrige o valor de CVA Energia calculado na primeira etapa para os 12 meses subseqüentes a DRP, utilizando-se de projeção da taxa SELIC.

Para apuração da CVA Energia é utilizado como base neste trabalho, entendimento da Nota Técnica ${ }^{\circ} 085$ SEM/SER/ANEEL de 05 de março de 2008, de que a apuração da CVA Energia:

$\checkmark$ Tem como referência as variações ocorridas em um ano civil (Período de Apuração) e seu cálculo é realizado na DRP do ano seguinte a apuração;

$\checkmark$ Apenas será realizada após definidos quais contratos compõem as sobras contratuais (Item 0) e;

$\checkmark$ Considera como base o menor valor entre a Carga Real e o Mercado Regulatório e em caso de Carga Real maior que do que o Mercado Regulatório os contratos são ajustados de forma que a glosa regulatória (diferença entre a Carga Real e o Mercado Regulatório) seja valorada pelo preço médio dos contratos firmados após a Lei $\mathrm{n}^{\circ} 10.848$ (2004) descontados dos montantes utilizados no repasse da Sobrecontratação.

Para tanto, é necessário definir os seguintes itens:

a) Montante total de energia contratada, em MWh, considerado na DRP para o Período Tarifário que engloba o mês "n" (ET100\%,m), calculado conforme eq. (21) a seguir: 


$$
E T^{100 \%}, m=\left(\sum_{a}\left(E^{100 \%} a, m\right)+\sum_{b}\left(E^{100 \%} b, m\right)+\text { Eltaipu, } m+\text { EProinf } a, m\right) \Rightarrow m=n
$$

Agrupando os valores apresentados na Tabela 4.2 e Tabela 4.3 e aplicando a eq. (21) obtém-se os valores da Tabela 4.15 a seguir:

Tabela 4.15 - Energia contratada para 2006 considerada na DRP 2005 e DRP 2007 (MWh)

\begin{tabular}{|c|c|c|c|c|c|c|}
\hline & \multirow{2}{*}{\multicolumn{2}{|c|}{ DRP 2005}} & \multirow{2}{*}{\multicolumn{2}{|c|}{ DRP 2006}} & \multirow{3}{*}{ TOTAL } \\
\hline & & & & & & \\
\hline & & $\begin{array}{c}1^{\circ} \mathrm{T} / 2006 \\
(\mathrm{~m}=\mathrm{n}=3)\end{array}$ & $\begin{array}{c}2^{\circ} \mathrm{T} / 2006 \\
(\mathrm{~m}=\mathrm{n}=4)\end{array}$ & $\begin{array}{c}3^{\circ} \mathrm{T} / 2006 \\
(m=n=5)\end{array}$ & $\begin{array}{c}4^{\circ} \mathrm{T} / 2006 \\
(\mathrm{~m}=\mathrm{n}=6)\end{array}$ & \\
\hline$E_{a, m}^{100 \%}$ & CCEAR Existente & 1.467 .759 & 1.513 .314 & 1.087 .489 & 1.067 .444 & 5.136 .007 \\
\hline$E_{a, m}^{100 \%}$ & CCEAR Nova & - & - & - & - & - \\
\hline$E^{100 \%} b, m$ & Bilaterais & 998.108 & 1.016 .119 & 992.916 & 996.507 & 4.003 .650 \\
\hline E Itaipu,m & Itaipu & 998.108 & 1.016 .119 & 1.035 .763 & 1.032 .205 & 4.082 .194 \\
\hline E Proinfa,m & Proinfa & - & - & 18.663 & 21.572 & 40.235 \\
\hline$E T^{100 \%}, m$ & & 3.463 .976 & 3.545 .551 & 3.134 .831 & 3.117 .728 & ET $=13.262 .086$ \\
\hline
\end{tabular}

b) Montante de Energia em MWh, verificado no mês " $n$ ", referente ao contrato "a" com ajuste para apuração da CVAENERG $\left(\right.$ Ever $\left.^{c v a} a, n\right)$, calculado conforme eq. (22) a seguir:

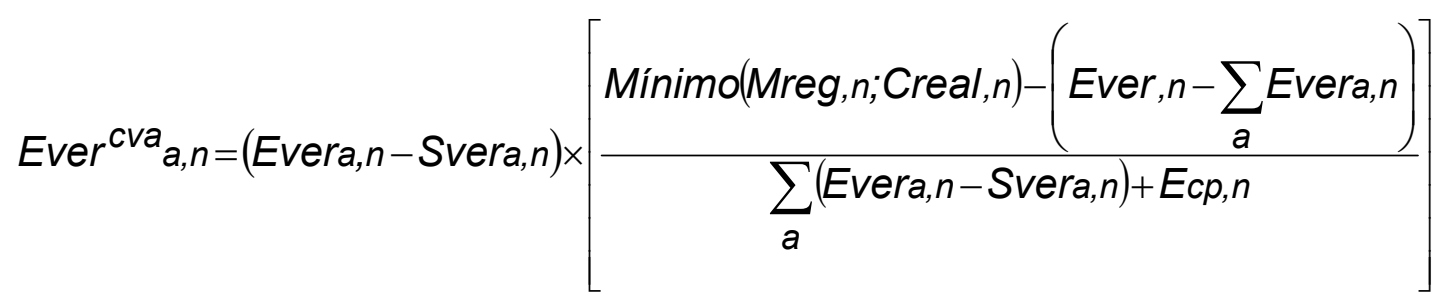

A Tabela 4.16 apresenta os resultados da aplicação da eq. (22) no exemplo.

\begin{tabular}{|c|c|c|c|c|c|c|}
\hline & & $\begin{array}{c}1^{\circ} T / 2006 \\
(n=3)\end{array}$ & $\begin{array}{c}2^{\circ} T / 2006 \\
(n=4)\end{array}$ & $\begin{array}{c}3^{\circ} T / 2006 \\
(n=5)\end{array}$ & $\begin{array}{c}4^{\circ} T / 2006 \\
(n=6)\end{array}$ & TOTAL \\
\hline $\operatorname{Ever}^{c v a} a, n$ & CCEAR Existente & 1.096 .406 & 1.036 .336 & 1.098 .874 & 1.131 .149 & 4.362 .765 \\
\hline $\operatorname{Ever}^{c v a} a, n$ & CCEAR Nova & - & - & - & - & - \\
\hline
\end{tabular}

Tabela 4.16 - Energia referente ao contrato "a" com ajuste para a CVAENERG (MWh) 
c) Montante total contratado verificado no mês " $n$ ", em MWh, para apuração da CVAENERG ( ), calculado conforme eq. (23) a seguir:

$$
\text { Ever }^{c v a}, n=\sum_{a}\left(E{ }^{c v e r}{ }_{a, n}\right)+\sum_{b}\left(E_{\text {verb }, n-S v e r b, n)}\right)+\text { Everltaipu, } n+\text { EverProinfa, } n
$$

A Tabela 4.17 apresenta os resultados da aplicação da eq. eq. (23) no exemplo.

Tabela 4.17 - Total contratado e verificado para apuração da CVAENERG (MWh)

\begin{tabular}{|c|c|c|c|c|c|c|}
\hline & \multirow{3}{*}{$\begin{array}{c}1^{\circ} \begin{array}{c}\mathbf{T} / 2006 \\
(\mathbf{n}=3)\end{array} \\
1.096 .406\end{array}$} & \multirow{2}{*}{$\begin{array}{c}2^{\circ} T / 2006 \\
(n=4)\end{array}$} & \multirow{2}{*}{$\begin{array}{c}3^{\circ} T / 2006 \\
(n=5)\end{array}$} & \multirow{2}{*}{$\begin{array}{c}4^{\circ} T / 2006 \\
(n=6)\end{array}$} & \multirow{3}{*}{\begin{tabular}{|c|} 
TOTAL \\
4.362 .765
\end{tabular}} \\
\hline & & & & & & \\
\hline Ever ${ }^{c v a} a, n$ & CCEAR Existente & & 1.036 .336 & 1.098 .874 & 1.131 .149 & \\
\hline Ever ${ }^{c v a} a, n$ & CCEAR Nova & - & - & - & - & - \\
\hline Ever $b, n$ & Bilaterais & 960.711 & 1.004 .845 & 999.518 & 996.030 & 3.961 .104 \\
\hline Ever Itaipu,n & Itaipu & 1.008 .116 & 1.023 .196 & 1.037 .178 & 1.037 .234 & 4.105 .722 \\
\hline Ever Proinfa, $n$ & Proinfa & 2.175 & 7.965 & 17.900 & 20.593 & 48.633 \\
\hline Ever $^{\text {cva }}, n$ & & 3.067 .407 & 3.072 .342 & 3.153 .469 & 3.185 .006 & 12.478 .224 \\
\hline
\end{tabular}

d) Custo total para o $E v e r{ }^{c v a}, n$ no mês " $n$ ", em R\$, $\left(C v e r^{c v a}, n\right)$, calculado conforme eq. (24) a seguir:

$$
\operatorname{Cver}^{c v a}{ }_{, n}=\sum_{a}\left(E{ }^{c v e r}{ }^{c v, n \times P a, n}\right)+\sum_{b}[P b, n \times(\text { Everb }, n-S v e r b, n)]+P \text { Itaipu, } n \times \text { Everltaipu, } n
$$

O Custo mensal com o total contratado e verificado para CVA Energia é calculado aplicando a eq. (24) aos volumes da Tabela 4.17 e aos preços verificados para cada contrato, conforme apresentado na Tabela 4.18 a seguir:

\begin{tabular}{|c|c|c|c|c|c|c|}
\hline & & $\begin{array}{c}1^{\circ} T / 2006 \\
(n=3)\end{array}$ & $\begin{array}{c}2^{\circ} T / 2006 \\
(n=4)\end{array}$ & $\begin{array}{c}3^{\circ} \mathrm{T} / 2006 \\
(n=5)\end{array}$ & $\begin{array}{c}4^{\circ} T / 2006 \\
(n=6)\end{array}$ & TOTAL \\
\hline$P a(R S / M W h)$ & CCEAR Existente & 61,27 & 61,27 & 65,61 & 65,76 & \\
\hline$P a(R \$ / M W h)$ & CCEAR Nova & - & - & - & - & \\
\hline$P b(R S / M W h)$ & Bilaterais & 131,56 & 131,67 & 132,85 & 132,69 & \\
\hline P Itaipu $(R \$ / M W$ & Itaipu & 83,35 & 82,89 & 86,09 & 85,88 & \\
\hline \multicolumn{2}{|c|}{ Cver ${ }^{c v a}, n$ (R\$mil) } & 277.600 & 280.619 & 294.176 & 295.616 & 1.148 .012 \\
\hline
\end{tabular}

Tabela 4.18 - Custos com o total contratado e verificado para apuração da CVAENERG

Finalmente, no cálculo da CVAENERG, neste trabalho é proposto considerar a diferença entre o custo total, em $\mathrm{R} \$$, verificado, no mês " $n$ ", com os contratados 
ajustados para o cálculo da CVAENERG $\left(\right.$ Cver $\left.^{c v a}, n\right)$ e o custo total, em $R \$$, considerado com a compra de energia na DRP para o mesmo mês " $m$ " $(C 100 \%, m)$, com $m=n$. O intuito aqui é capturar as reais variações, sem sobreposição dos custos de compra de energia repassados nas DRP, que observa, além dos meses " $n$ " do Período de Apuração, meses não pertinente ao processo estudado. Porém para que a CVAENERG capture apenas variações decorrentes de custos com a compra de energia é necessário que os volumes comparados sejam igualados. Com isso a CVAENERG, no mês " $n$ " (CVAENERG,n), é calculada conforme eq. (25) a seguir:

$$
\text { CVAENERG, } n=\text { Cver }^{\text {cva }}, n-C 100 \%, m+\left(E T^{100 \%}, m-E v e r^{\text {cva }}, n\right) \times \text { Tmédia, } n
$$

Finalmente para o cálculo do custo total com a CVAENERG na DRP, considera-se a eq. (26), conforme segue:

$$
\text { CVAENERG }=\sum_{n}(\text { CVAENERG }, n \times \text { SELICac })
$$

A Tabela 4.19 apresenta os resultados obtidos com o cálculo da CVA Energia para o exemplo. 
Tabela 4.19 - Custos com o CVAENERG na DPR 2007

\begin{tabular}{|c|c|c|c|c|c|}
\hline & \multicolumn{2}{|c|}{ DRP 2005} & \multicolumn{2}{|c|}{ DRP 2006} & \multirow[b]{2}{*}{ TOTAL } \\
\hline & $\begin{array}{c}1^{\circ} T / 2006 \\
(m=n=3)\end{array}$ & $\begin{array}{c}2^{\circ} T / 2006 \\
(m=n=4)\end{array}$ & $\begin{array}{c}3^{\circ} \mathrm{T} / 2006 \\
(m=n=5)\end{array}$ & $\begin{array}{c}4^{\circ} T / 2006 \\
(m=n=6)\end{array}$ & \\
\hline$C 100 \%, m$ & 285.062 & 291.340 & 301.387 & 300.218 & \\
\hline Tmédia, $n$ & 76,67 & 76,67 & 78,13 & 78,13 & \\
\hline CVA ENERG,$n$ & 30.398 & 36.271 & (1.463) & $(5.261)$ & 59.944 \\
\hline & $\begin{array}{c}1^{\circ} T / 2006 \\
(n=3)\end{array}$ & $\begin{array}{c}2^{\circ} T / 2006 \\
(n=4)\end{array}$ & $\begin{array}{c}3^{\circ} T / 2006 \\
(n=5)\end{array}$ & $\begin{array}{c}4^{\circ} T / 2006 \\
(n=6)\end{array}$ & TOTAL \\
\hline SELIC ac (até a DRP & $118,7 \%$ & $114,3 \%$ & $110,1 \%$ & $106,5 \%$ & \\
\hline SELIC ac (da DRP 2 & $112,0 \%$ & $112,0 \%$ & $112,0 \%$ & $112,0 \%$ & \\
\hline SELIC ac Total & $133,0 \%$ & $128,0 \%$ & $123,3 \%$ & $119,3 \%$ & \\
\hline Total (R\$ mil) & 40.424 & 46.426 & (1.804) & $(6.275)$ & CVAENERG $=78.770$ \\
\hline
\end{tabular}

\subsection{Tarifas da Compra de energia}

O objetivo principal deste item é propor metodologia (baseada em metodologia utilizada pela ANEEL no reajuste tarifário das distribuidoras) que traduz, através de equações, os valores calculados no item anterior (4.2) nas seguintes componentes da tarifa (conforme exposto no item 4.1.3):

1. Compra de Energia Elétrica para revenda ao consumidor cativo;

2. Perdas Técnicas na Distribuição;

3. Perdas na RB referente à Energia comprada para revenda;

4. Perdas Não Técnicas na Distribuição e;

5. Perdas na RB referente às Perdas na Distribuição.

E, a partir disso, definir as tarifas referentes aos custos com compra de energia elétrica pela distribuidora que serão aplicadas aos consumidores.

Para tanto, será utilizado como base o Índice de Reajuste Tarifário anual da distribuidora (IRT), ou seja, essas componentes serão calculadas na DRP (TITEM1) através da aplicação do IRTITEM (eq. (1)) em suas respectivas componentes calculadas na DRP anterior (TITEMo). A eq. (27) a seguir apresenta este cálculo. 
Como, o Valoro da eq. (1) é calculado multiplicando a TITEMo pela quantidade total de energia ou demanda faturada pela distribuidora de seus consumidores no Período de Referência (Mref), ao substituir este cálculo na eq. (1) obtém-se facilmente a eq. (28) a seguir:

$$
\text { IRTITEM }=\frac{\text { Valor } 1}{\text { TITEM0 } \times \text { Mref }}
$$

Conseqüentemente, substituindo o IRTITEM da eq. (28) na eq. (27), obtém-se a eq. (29), que servira como base para o cálculo das componentes da tarifa neste trabalho.

$$
\text { TITEM1 }=\frac{\text { Valor } 1}{\text { Mref }}
$$

Além disso, é necessário definir o seguinte:

a. Mercado de referência de energia do mercado cativo (MrefCat) - entendido como mercado faturado de energia pela distribuidora no período de 12 meses anteriores a DRP (Período de Referência), medido em MWh. Refere-se à energia consumida pelos consumidores cativos. Este item já foi definido e utilizado no cálculo da Creg na eq. (5);

b. Mercado de referência de energia do mercado livre (MrefLiv) - entendido como o mercado medido de energia, referente ao consumo dos consumidores livres no período de 12 meses anteriores a DRP e; 
c. Mercado de referência de demanda (MrefDem) - entendido como mercado faturado de demanda pela distribuidora de todos os consumidores ligados à sua rede de distribuição (consumidores cativos + livres) no período de 12 meses anteriores à DRP, medido em kW.

d. Perdas Totais (PTotal) ou Perdas Regulatória - entendidas como a energia comprada pela distribuidora para o consumo das perdas elétricas na distribuição, as quais se dividem em perdas técnicas e perdas comerciais, acrescidas das perdas na Rede básica (RB), sendo que seu cálculo segue a eq. (30) A seguir:

$$
\text { PTotal }=\text { iP Reg } \times \text { MrefCat }
$$

Onde:

iPreg Índice de Perdas Regulatória, conforme definido para eq. (5), estabelecido na revisão tarifária periódica de cada distribuidora pela Aneel.

Definidas as bases de cálculo, a seguir se apresenta, através de equações, a participação em energia (\%) de cada componente da tarifa em relação à energia total da distribuidora utilizada como base para repasse na DRP, ou seja, a Carga Regulatória (Creg) da distribuidora, conforme definida na eq. (5).

1. Compra de Energia Elétrica para revenda ao consumidor cativo.

A compra de energia elétrica para revenda (ECat) é dada na DRP pelo Mercado de Referência de energia do mercado cativo (MrefCat). Sendo assim, a participação da compra de energia elétrica para revenda é calculada diretamente conforme eq. (31) a seguir:

$$
\% \text { ECat }=\frac{\text { MrefCat }}{\text { Creg }}
$$

2. Perdas Técnicas na Distribuição. 
As perdas técnicas na distribuição $(P T e c)$ são calculadas através da aplicação do índice de perdas técnicas (iPTec), definido pela Aneel na revisão tarifária da distribuidora, ao mercado cativo da distribuidora (ECat), conforme definido anteriormente, somado ao Mercado livre da distribuidora (ELiv), que, por sua vez, é dado pelo Mercado de Referência de energia do mercado livre (MrefLiv). Com isso, a participação das perdas técnicas é calculada conforme eq. (32) a seguir:

$$
\% \text { PTec }=\frac{i P_{T e c} \times(\text { MrefCat }+ \text { MrefLiv })}{\text { Creg }}
$$

3. Perdas na RB referente à Energia comprada para revenda.

As perdas na RB referente à Energia comprada para revenda (PRBcat) é calculada através da aplicação do índice de perdas RB (iPRB), calculado pela CCEE, ao mercado cativo da distribuidora (ECat). Sendo assim, a participação das perdas na $\mathrm{RB}$ referente à Energia comprada para revenda é calculada conforme eq. (33) a seguir:

$$
\% P_{R B c a t}=\frac{i P_{R B} \times \text { MrefCat }}{\text { Creg }}
$$

4. Perdas Não Técnicas na Distribuição.

As Perdas Não Técnicas na Distribuição ou Perdas Comerciais (PCom) são apuradas, conforme definido no item 4.1.3.1, pela diferença entre as perdas totais e as perdas técnicas. Sendo assim, a participação das perdas não técnicas referente à Energia comprada para revenda é calculada conforme - a seguir: 


$$
\% \text { PCom }=\frac{\left(\text { PTotal }-P \text { Tec }-P_{\text {RBcat }}-P_{\text {RBPdis }}\right)}{\text { Creg }}
$$

5. Perdas na RB referente às Perdas na Distribuição.

As perdas na RB referente às Perdas na distribuição (PRBPdis) é calculada através da aplicação do índice de perdas RB (iPRB), calculado pela CCEE, as Perdas Técnicas $(P T e c)$ somada as Perdas não Técnicas da Distribuição (PCom) (eq. (33)).

$$
P R B P d i s=i P R B \times(P T e c+P C o m)
$$

Porém esta equação depende do resultado da das Perdas não Técnicas, que ao ser substituída na equação obtém-se a eq. (36) a seguir:

$$
\text { PRBPdis }=i_{R B} \times(P T e c+P \text { Total }-P T e c-P R B c a t-P R B P d i s)
$$

Reorganizando esta equação e dividindo pela Carga Regulatória (Creg), obtém-se a participação das perdas na RB referente às Perdas na distribuição, conforme eq. (37) a seguir:

$$
\% \text { PRBPdis }=\frac{\frac{i P_{R B}}{\left(1+i P_{R B}\right)} \times\left(\text { PTotal }^{-P R B c a t}\right)}{\text { Creg }}
$$

Logo, ao multiplicar cada participação calculada pelos custos repassáveis a tarifa e dividir o resultado por seu respectivo mercado de referência (mercado no qual a tarifa será destinada) obtêm-se a componente da tarifa que será aplicada ao consumidor. 
Porém, essa regra não se aplica aos custos referentes ao "Repasse de 100\%". Isto porque, quando apurado, o "Repasse de 100\%" leva em consideração, na energia total da carteira de contratos habilitada ao repasse, o montante referente à cota Proinfa que, por sua vez, é destinada exclusivamente à energia adquirida para atendimento dos consumidores cativos. Com isso, é proposto um ajuste na aplicação dessas proporções no "Custo de 100\%" de forma que, a Tarifa referente à Compra de Energia Elétrica para revenda ao consumidor cativo, que é destinada exclusivamente a este tipo de consumidor, absorva totalmente o benefício referente à Energia do Proinfa, dado que, no cálculo do "Custo de 100\%" a energia referente à cota Proinfa tem valor "zero" (Contratos de Proinfa, referente à cota da distribuidora, são cobrados do consumidor cativo via encargo, ou seja, esta cota é exclusiva do consumidor cativo).

Desta forma, a seguir são apresentadas, através de equações, as tarifas referentes à compra de energia que será aplicada ao consumidor final. Entretanto, vale ressaltar, que as equações são apenas sugestões para representação do repasse dos custos com a compra de energia elétrica ao consumidor, já que, não é considerada no cálculo das tarifas de fio $(\mathrm{R} \$ / \mathrm{kW})$ a estrutura tarifária da distribuidora, que se diferencia de acordo com nível de tensão e o tipo de consumidor ligado à rede de distribuição.

1. Tarifa da Compra de Energia Elétrica para revenda ao consumidor cativo em $\mathrm{R} \$ / \mathrm{MWh}$ (TECat), calculada conforme eq. (38) a seguir e destinada ao mercado de energia cativo da distribuidora.

$T E C a t=\frac{\left[\frac{(\% \text { ECat } \times \text { Creg })-\sum_{m} \text { EProinf } a, m}{C r e g-\sum_{m} E \text { Proinf a,m }}\right] \times C 100 \%+\% E C a t \times(C 3 \%+C A F+C V A E N E R G)}{\text { MrefCat }}$

Onde:

$m$

Mês pertencente ao Período Tarifário. 
2. Tarifa das Perdas Técnicas na Distribuição em $\mathrm{R} \$ / \mathrm{kW}$ (TPTec), calculada conforme eq. (39) a seguir e destinada ao mercado de demanda da distribuidora.

TPTec $=\frac{\left(\frac{\% P T e c \times C r e g}{\operatorname{Creg}-\sum_{m} E \text { Proinf } a, m}\right) \times C 100 \%+\% P T e c \times(C 3 \%+C A F+C V A E N E R G)}{\text { MrefDem }}$

3. Tarifa das Perdas na RB referente à Energia comprada para revenda em $\mathrm{R} \$ / \mathrm{MWh}$ (TPRBcat), calculada conforme eq. (40) a seguir e destinada ao mercado de energia cativo da distribuidora.

TPRBcat $=\frac{\left(\frac{\% P R B c a t \times C r e g}{\text { Creg }-\sum_{m} \text { EProinf } a, m}\right) \times C 100 \%+\% \text { PRBcat } \times(C 3 \%+C A F+C V A E N E R G)}{\text { MrefCat }}$

4. Tarifas das Perdas não Técnicas na Distribuição em $\mathrm{R} \$ / \mathrm{MWh}$ (TPCome) e em $\mathrm{R} \$ / \mathrm{kW}$ (TPComD), calculadas conforme eq. (41) e eq. (42) a seguir e destinadas ao mercado de energia total (cativo + livre) e mercado de demanda da distribuidora, respectivamente. 
$T P C o m D=\frac{\% R D \times\left[\left(\frac{\% P C o m \times \text { Creg }}{\text { Creg- } \sum_{m} E \text { Proinf }, m}\right) \times C 100 \%+\% \text { PCom } \times(C 3 \%+C A F+C V A E N E R G)\right]}{M r e f D e m}$

$T P$ ComE $=\frac{\% R E \times\left[\left(\frac{\% P C o m \times C r e g}{C r e g-\sum_{m} E P r o i n f a, m}\right) \times C 100 \%+\% P C o m \times(C 3 \%+C A F+C V A E N E R G)\right]}{(\text { MrefCat }+ \text { MrefLiv })}$

Onde:

\%RD Participação da Receita verificada da TUSD cobrada em R $\$ / \mathrm{kW}$ no Período de Referência em relação à Receita Total de TUSD verificada no mesmo período e;

\%RE Participação da Receita verificada da TUSD cobrada em R $\$ / M W h$ no Período de Referência em relação à Receita Total de TUSD verificada no mesmo período.

5. Tarifa das Perdas na RB referente às Perdas na Distribuição em $R \$ / k W$ (TPRBPdis), calculada conforme eq. (43) a seguir e destinada ao mercado de demanda da distribuidora. 


$$
T P_{\text {RBPdis }}=\frac{\left(\frac{\% P_{\text {RBPdis }} \times C r e g}{C r e g-\sum_{m} E_{\operatorname{Pr} o \text { inf } a, m}}\right) \times C 100 \%+\% P_{R B P d i s} \times(C 3 \%+C A F+C V A E N E R G)}{M r e f_{\text {Dem }}}
$$

\subsection{A Fatura dos Consumidores da Distribuidora}

Conforme já exposto, os consumidores conectados à rede de distribuição de energia elétrica são faturados mensalmente, por suas distribuidoras, montantes, em $\mathrm{R} \$$, correspondentes à utilização da rede elétrica $(\mathrm{kW})$ e à quantidade consumida de energia elétrica (MWh). Esse processo passa pela definição da tarifa de fornecimento de energia elétrica.

Logo, neste Item será apresentada, através de equações, a aplicação da tarifa no processo de faturamento dos consumidores. Porém, serão apenas apresentados os custos mensais ( $\mathrm{R} \$ /$ mês) referentes à compra de energia elétrica pela distribuidora.

No item anterior, apresentou-se o equacionamento das tarifas referentes a compras e que serão aplicadas aos consumidores. É possível observar que o processo de faturamento da energia é dividido em três blocos pela distribuidora, quais sejam:

$\checkmark$ Faturamento relacionado apenas à energia consumida por consumidores cativos da distribuidora (RECat,f), conforme eq.(44) a seguir;

$$
R E C a t, f=M C a t, f \times(T E C a t+T P R B c a t)
$$

Onde:

$f \quad$ Mês do faturamento; 
MCat, $\quad$ Mercado de Energia, em MWh, referente ao consumo de energia dos consumidores cativos da distribuidora no mês " $f$ ".

Faturamento relacionado à energia consumida por consumidores cativos mais livres da distribuidora (RECL,f), conforme eq.(45) a seguir e;

$$
R E C L, f=(M C a t, f+M L i v, f) \times T P C o m E
$$

Onde:

MLiv,f Mercado de Energia, em MWh, referente ao consumo de energia dos consumidores livres da distribuidora no mês " $f$ ".

$\checkmark$ Faturamento relacionado à demanda faturada dos consumidores conectados à rede de distribuição (REDem,f) conforme eq. (46) a seguir.

$$
R E_{D e m, f}=M_{D e m}, f \times\left(T P_{T e c}+T P_{C o m D}+T P_{R B P \text { dis }}\right)
$$

Onde:

MDem,f Mercado de Demanda, em $\mathrm{kW}$, referente à demanda faturada dos consumidores conectados à rede da distribuidora no mês " $f$ ".

Por fim, o ciclo da compra de energia, conforme apresentado no Capitulo 2, é encerrado com a receita total provinda do faturamento dos custos relacionado à Compra de energia elétrica no mês "f" (RETotal,f), dado em R\$/mês e calculado pela eq. (47) a seguir.

$$
R E T o t a l=R E C a t, f+R E C L, f+R E D e m, f
$$




\section{METODOLOGIA PARA REPRESENTAÇÃO DOS CUSTOS DE COMPRA DE ENERGIA ELÉTRICA NO FLUXO DE CAIXA DE UMA EMPRESA DISTRIBUIDORA}

Ao demonstrar os custos com a energia elétrica, destinada às empresas de distribuição, em fluxo de pagamentos aos fornecedores e recebimentos dos clientes, seu valor e seu gerenciamento financeiro devem ser ambos estabelecidos ponderando os desembolsos escalonados no tempo. Levar em conta tal visão de longo prazo significa considerar a atualização do valor do dinheiro no período de análise.

Neste trabalho, o cálculo do valor do dinheiro no tempo leva em consideração os desembolsos e recebimentos pela distribuidora dos custos relativos à compra de energia. Considera-se "desembolso" uma saída de caixa para pagar uma despesa, decorrente da compra de energia elétrica, e "recebimentos" uma entrada de caixa ou receita, decorrente dos pagamentos pelos clientes ligados à rede de distribuição, através da tarifa, dos custos referentes à energia fornecida para o atendimento de seus consumos.

O valor futuro e o valor presente consistem conceitos básicos do valor do dinheiro no tempo. Cálculos de valor futuro são necessários, por exemplo, para avaliar montantes futuros oriundos dos recebimentos antecipados dos custos com a compra de energia. São também úteis na determinação do valor em caixa no momento do desembolso para pagamento aos fornecedores da energia comprada pela distribuidora. Cálculos de valor presente são inversamente relacionados ao valor futuro. Eles são importantes, por exemplo, no cálculo da expectativa do resultado final do repasse com a compra de energia elétrica.

O conceito de um valor futuro, neste trabalho, envolve a aplicação de juros compostos sobre o resultado liquido do desembolso versus recebimentos em determinada data para obter o montante total acumulado futuro. Usando essa notação, pode-se formular uma equação geral (eq. (48)) para o valor futuro em determinada data futura " $F$ " do fluxo de pagamentos e recebimentos. 


$$
F C A, F=\sum_{f=1}^{F}\left[\left(R_{f}-D_{f}\right) \times(1+j)^{F-f}\right]
$$

Onde:

FCA, $F \quad$ Caixa acumulado futuro em $R \$$ na data futura " $F$ ";

j Taxa de juros em \%;

f Mês referente a um determinado desembolso e recebimento (faturamento);

Rf Receita referente aos recebimentos no mês "f";

Df Despesa referente ao desembolso no mês "f".

Por outro lado, o "valor presente" baseia-se na crença de que o valor do dinheiro depende do momento em que é recebido. O axioma implícito nesta crença é o de que $\mathrm{R} \$ 1$ (um real) hoje vale mais do que $\mathrm{R} \$ 1$ a ser recebido numa data futura. O valor presente depende muito das oportunidades rentáveis do recebedor e da época em que o dinheiro deverá ser recebido. $O$ valor presente de um montante futuro pode ser obtido matematicamente através da eq. (49) a seguir.

$$
V P=\frac{V F, F}{(1+k)^{F}}
$$

Onde:

VP Valor presente de um monte em determinada data futura " $F$ ", valor futuro $(V F, F)$, dado em $\mathrm{R} \$ \mathrm{e}$;

K Taxa de desconto em $\%$. 
Dado o exposto acima, neste tópico é apresentada metodologia para a construção de um fluxo de caixa específico para compra de energia elétrica, de forma a verificar o resultado líquido dos recebimentos versus o desembolso com a compra energia pela distribuidora. O objetivo principal é obter ferramenta que possibilite às empresas de distribuição, por exemplo, avaliar se o caixa gerado até determinada data é suficiente para honrar o desembolso com a compra na mesma data, ou ainda verificar se houve neutralidade dos custos com a compra de energia ao final do horizonte temporal do fluxo de caixa.

Metodologicamente, para a construção do modelo são considerados os seguintes pontos:

$\checkmark$ Vértice e Horizonte temporal do fluxo de caixa em estudo;

$\checkmark$ Desembolsos versus recebimentos e;

$\checkmark$ Tratamento dos resultados obtidos com o fluxo de caixa.

\subsection{Vértice e Horizonte temporal do fluxo de caixa em estudo}

Com relação aos vértices do fluxo de caixa (datas de interesse), é proposta a utilização de dados mensais, já que o consumidor final é faturado mensalmente pela distribuidora $(f)$.

Para definição do horizonte de estudo é proposto considerar o repasse dos custos com a compra de energia elétrica para suprimento das perdas e atendimento dos consumidores cativos no período de um ano civil (Período de Apuração), ou seja, determinar o horizonte de estudo consiste em determinar quando e quais das etapas de repasse ("Repasse de 100\%", "Repasse da Sobrecontratação", "Repasse do Ajuste Financeiro" e "CVA Energia") são referentes ao Período de Apuração.

Conforme exposto no decorrer do item 4.2, no cálculo do "Repasse de 100\%" são considerados os montantes contratados na DRP para o atendimento de doze meses subseqüentes, enquanto que, para o "Repasse da Sobrecontratação", 
"Repasse do Ajuste Financeiro" e "CVA Energia" são considerados no cálculo os custos com a compra do ano civil imediatamente anterior a DRP.

Logo, é no entendimento desse processo que se identifica o cronograma de repasse da compra de energia pela distribuidora, que considera as receitas e despesas referentes à compra de energia que atenda às necessidades da distribuidora no Período de Apuração. A Figura 5.1 ilustra este cronograma e conseqüentemente ajuda na identificação do horizonte de estudo.

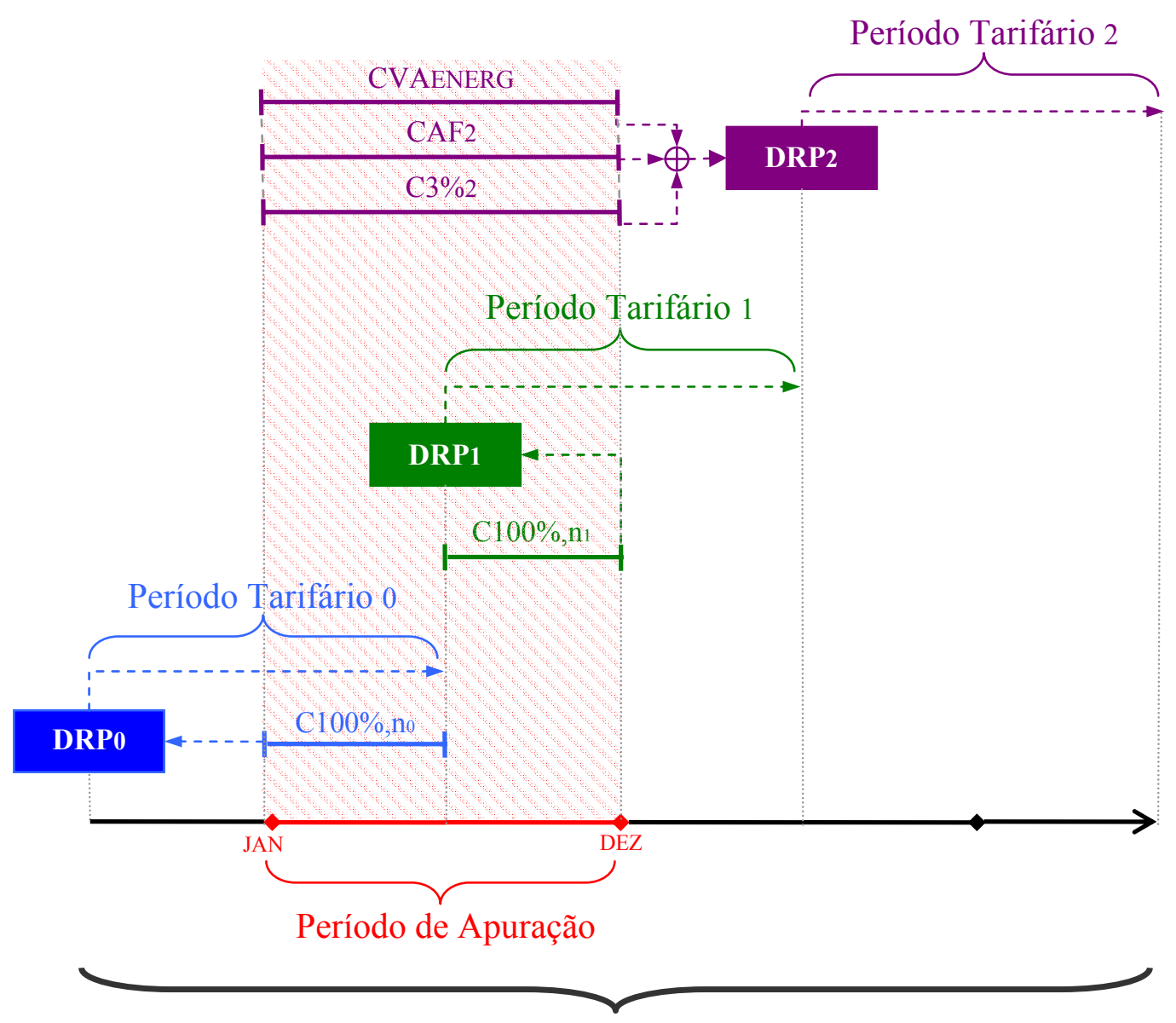

HORIZONTE DE ESTUDO

Figura 5.1 - Cronograma de Repasse dos Custos com Compra de Energia

Onde:

DRP0 Data de Reajuste em Processamento imediatamente anterior ao Período de Apuração; 
DRP1 Data de Reajuste em Processamento contida no Período de Apuração;

DRP2 Data de Reajuste em Processamento imediatamente posterior ao Período de Apuração.

Com isso, verifica-se que o repasse da compra à tarifa é realizado através de três DRP distintas, ou seja, o impacto temporal (Cronograma de Repasse) que a compra de energia do Período de Apuração tem no fluxo de caixa é de 36 meses, dado que, a receita calculada em cada DRP é recebida ao longo dos 12 meses subseqüentes (Período Tarifário).

\subsection{Desembolso versus recebimentos}

$\mathrm{O}$ desembolso com a compra de energia, em $\mathrm{R} \$$ mês, refere-se à despesa mensal da distribuidora com o pagamento dos montantes contratados com os fornecedores de energia elétrica para suprimento das perdas e atendimento do mercado cativo da distribuidora no mesmo mês. Conforme já exposto no capitulo 3 , o desembolso mensal com a compra de energia elétrica é considerado, neste trabalho, como conhecido e para fins de cálculo será representado mensalmente por "Df,f".

Para o cálculo dos recebimentos, relativo à compra de energia, utiliza-se da receita total provinda do faturamento dos custos relacionado à Compra de energia elétrica no mês "f' (RETotal,f), calculada conforme eq. (47) demonstrada no item 4.4 deste trabalho.

Entretanto algumas considerações devem ser tomadas para cada Período Tarifário, conforme ilustrado na Figura 5.1.

\section{Período Tarifário 0}

Entendido como sendo os doze meses subseqüentes à DRP0. Considerando o Horizonte de Estudo, compreende a receita obtida apenas com o "Repasse de $100 \%$ " dos custos com os montantes contratados habilitados para o repasse de janeiro do Período de Apuração ao mês imediatamente anterior a DRP1, ou seja, a 
receita mensal nesse período é obtida através da eq. (47) calculada na DRP0, dado que:

1. $C 100 \%=\sum_{m} C 100 \%, m$, conforme eq. (9), para janeiro $\leq m<m e ̂ s(D R P 1)$. Onde janeiro corresponde ao primeiro mês do Período de Apuração e;

2. $C 3 \%=C F A=C V A E N E R G=0$ (zero).

\section{Período Tarifário 1}

Entendido como sendo os doze meses subseqüentes à DRP1. Considerando o Horizonte de Estudo, compreende a receita obtida apenas com o "Repasse de 100\%" dos custos com os montantes contratados habilitados para o repasse do mês da DRP1 a dezembro do Período de Apuração, ou seja, a receita mensal nesse período é obtida através da eq. (47) calculada na DRP1, dado que:

1. $C 100 \%=\sum_{m} C 100 \%, m$, conforme eq. (9), para mês $(D R P 1) \leq m \leq$ dezembro. Onde dezembro corresponde ao último mês do Período de Apuração e;

2. $C 3 \%=C F A=C V A E N E R G=0$ (zero).

\section{Período Tarifário 2}

Entendido como sendo os doze meses subseqüentes à DRP2. Considerando o Horizonte de Estudo, compreende a receita obtida com os custos calculados para o "Repasse da Sobrecontratação", "Repasse do Ajuste Financeiro" e "CVA Energia" para o Período de Apuração, ou seja, a receita mensal nesse período é obtida através da eq. (47) calculada a partir e considerando a DRP2, dado que:

1. $\mathrm{C} 100 \%=0$.

\subsection{Resultado Líquido do Fluxo de Caixa}

O tratamento proposto para o fluxo de caixa é o de calcular o valor acumulado em caixa ao longo do tempo, ou seja, para cada vértice do fluxo de caixa somam-se 
os resultados liquido de cada vértice até a data do vértice em estudo. Porém, é necessário levar o resultado líquido de cada vértice a valor futuro e, só depois, calcular o valor em caixa $(R \$)$. Para isso, basta substituir os valores calculados de "RETotal, $f$ " conforme eq. (47) para cada mês " $f$ ", (considerando é claro, as regras para cada Período Tarifário, conforme exposto no Item 5.2) e os desembolsos "Df,f" do mesmo mês "f" na eq. (48).

O caixa acumulado $(F C A, F)$ poder assumir valores positivos ou negativos ao longo do tempo, dependendo de como foi considerado no repasse dos custos com a compra de energia à tarifa. Considerando que quando positivo os recursos em caixa estão aplicados em investimentos de curto prazo e quando negativo exista a necessidade de captação de recursos ao custo de capital da empresa ou mesmo em financiamentos de curto prazo, conclui-se que a taxa de juros " $j$ " pode ser diferente ao logo do tempo. Portanto, é proposto tratamento diferenciado das taxas para as diferentes condições de caixa. A Figura 5.2 exemplifica tal situação.

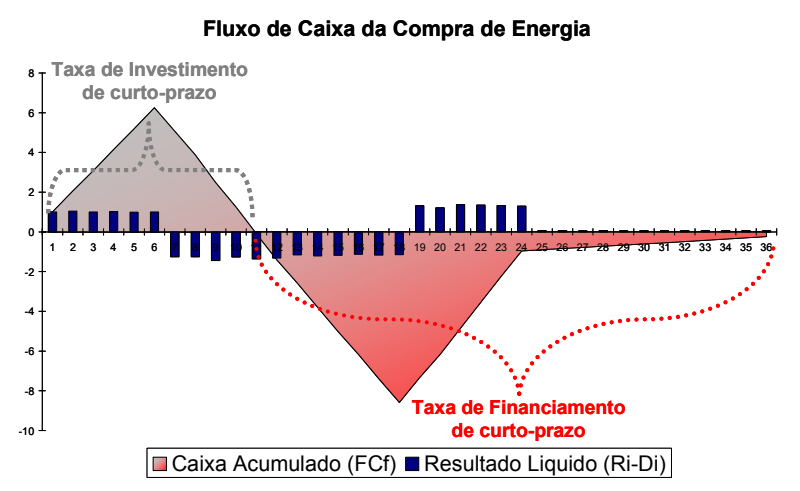

Figura 5.2 - Fluxo de Caixa da Compra de Energia

Por fim, como também está ilustrado na Figura 5.2, é possível identificar através do caixa acumulado até o final do horizonte temporal do fluxo, se houve realmente o repasse integral dos custos com a compra de energia, ou seja, $F C 36=0$, ou mesmo, quais foram os ganhos ou perdas em valor presente (eq. (49)) que a distribuidora obteve relacionado a, por exemplo, resultados do gerenciamento 
financeiro do fluxo de caixa e aos resultados da diferença entre perda real e regulatória, conforme definido anteriormente.

Aplicando o exposto nos itens 4.3 e 4.4 e no capitulo 5 ao exemplo proposto no item 4.2 obtém-se os resultados das Tabela 5.1 e Tabela 5.2 a seguir.

Tabela 5.1 - Cálculo da Tarifa Utilizada no repasse dos custos com contratação do ano de 2006

\begin{tabular}{|c|c|c|c|c|c|}
\hline & & & DRP 2005 & DRP 2006 & DRP 2007 \\
\hline MUWh & MrefCat & Faturado & 10.762 .448 & 10.467 .550 & 10.572 .799 \\
\hline MIVVII & Mref Liv & Faturado & 1.233 .801 & 1.957 .410 & 2.324 .983 \\
\hline MW & Mref Dem & Faturado & 27.440 & 28.021 & 29.092 \\
\hline & $i$ Preg & Definido pela Aneel & $18,57 \%$ & $19,72 \%$ & $21,10 \%$ \\
\hline & iP Tec & Definido pela Aneel & $6,0 \%$ & $6,0 \%$ & $4,8 \%$ \\
\hline & $i P_{R B}$ & Calculada pela CCEE & $2,72 \%$ & $2,42 \%$ & $2,31 \%$ \\
\hline MWh & $P$ Total & eq. (30) & 1.998 .587 & 2.064 .201 & 2.230 .860 \\
\hline & Creg & eq. (5) & 12.761 .035 & 12.531 .751 & 12.803 .659 \\
\hline & $\%$ E Cat & eq. (31) & $84,3 \%$ & $83,5 \%$ & $82,6 \%$ \\
\hline & $\% P \mathrm{Tec}$ & eq. (32) & $5,6 \%$ & $5,9 \%$ & $4,8 \%$ \\
\hline & $\%$ PBcat & eq. (33) & $2,3 \%$ & $2,0 \%$ & $1,9 \%$ \\
\hline & $\% P R B$ Pdis & eq. (37) & $0,4 \%$ & $0,3 \%$ & $0,4 \%$ \\
\hline & $\%$ P Com & eq. (34) & $7,4 \%$ & $8,2 \%$ & $10,3 \%$ \\
\hline & $C 100 \%$ & Tabela 4.6 e Tabela 4.7 & 576.403 & 601.605 & - \\
\hline R\$ mil & $C 3 \%$ & Tabela 4.11 & & & $(1.660)$ \\
\hline $\begin{array}{l}\text { (referente } \\
\text { s a 2006) }\end{array}$ & $C A F$ & Tabela 4.14 & & & $(2.302)$ \\
\hline & CVA ENERG & Tabela 4.19 & & & 78.770 \\
\hline$\overline{M W h}$ & $\overline{\Sigma E \text { Proinfa, } m}$ & Tabela 4.2 e Tabela 4.3 & - & 259.863 & $\mathrm{~N} / \mathrm{A}$ \\
\hline & $\% R D$ & Calculado na DRP & $84 \%$ & $78 \%$ & $82 \%$ \\
\hline & $\% R E$ & Calculado na DRP & $16 \%$ & $22 \%$ & $18 \%$ \\
\hline $\mathrm{R} \$ / \mathrm{MWh}$ & TE Cat & eq. (38) & 45,17 & 47,81 & 5,84 \\
\hline $\mathrm{R} \$ / \mathrm{kW}$ & $T P T e c$ & eq. (39) & 1,18 & 1,30 & 0,12 \\
\hline $\mathrm{R} \$ / \mathrm{MWh}$ & TP RBcat & eq. (40) & 1,23 & 1,19 & 0,13 \\
\hline $\mathrm{R} \$ / \mathrm{kW}$ & $T P \operatorname{Com} D$ & eq. (41) & 1,30 & 1,39 & 0,22 \\
\hline $\mathrm{R} \$ / \mathrm{MWh}$ & TP Com E & eq. (42) & 0,57 & 0,91 & 0,11 \\
\hline $\mathrm{R} \$ / \mathrm{kW}$ & $T P$ RB Pdis & eq. (43) & 0,07 & 0,07 & 0,01 \\
\hline
\end{tabular}


Tabela 5.2 - Fluxo de Caixa da compra de energia para suprimento do mercado de uma distribuidora hipotética no ano de 2006

\begin{tabular}{|c|c|c|c|c|c|c|c|c|c|c|c|c|c|}
\hline & \multirow{2}{*}{\multicolumn{4}{|c|}{ RECEITA PELA TARIFA DA DRP 2005}} & \multirow{2}{*}{\multicolumn{4}{|c|}{ RECEITA PELA TARIFA DA DRP 2006}} & \multirow{2}{*}{\multicolumn{4}{|c|}{ RECEITA PELA TARIFA DA DRP 2007}} \\
\hline & & & & & & & & & & & & & \\
\hline & & $\begin{array}{c}3^{\circ} \text { T } 2005 \\
(f=1)\end{array}$ & $\begin{array}{c}4^{\circ} \quad 2005 \\
(f=2)\end{array}$ & $\begin{array}{c}1^{\circ} T 2006 \\
(f=3)\end{array}$ & $\begin{array}{c}2^{\circ} \text { T } 2006 \\
(f=4)\end{array}$ & $\begin{array}{c}3^{\circ} \text { T } 2006 \\
(f=5)\end{array}$ & $\begin{array}{c}4^{\circ} \quad 2006 \\
(f=6)\end{array}$ & $\begin{array}{c}1^{\circ} T 2007 \\
(f=7)\end{array}$ & $\begin{array}{c}2^{\circ} \text { T } 2007 \\
(f=8)\end{array}$ & $\begin{array}{c}3^{\circ} \text { T } 2007 \\
(f=9)\end{array}$ & $\begin{array}{c}4^{\circ} \text { T } 2007 \\
(f=10)\end{array}$ & $\begin{array}{c}1^{\circ} T 2008 \\
(f=11)\end{array}$ & $\begin{array}{c}2^{\circ} T 2008 \\
(f=12)\end{array}$ \\
\hline$\overline{\mathrm{Cat}}$ & & 2.615 .820 & 2.627 .410 & 2.594 .497 & 2.629 .823 & 2.584 .041 & 2.694 .973 & 2.583 .158 & 2.710 .626 & 2.702 .209 & 2.780 .580 & 2.688 .023 & 2.768 .376 \\
\hline MLiv, & & 437.375 & 68.965 & 499.845 & 51.225 & 552.507 & 571.971 & 70.969 & 629.537 & 628.756 & 636.283 & 623.593 & 226.658 \\
\hline MDen & & 6.890 & 933 & 7.061 & 7.136 & 6.966 & 7.152 & 7.097 & 7.239 & 7.103 & 7.288 & 8.604 & 8.746 \\
\hline$R E C a$ & & 121.368 & 1.905 & 20.378 & 122.017 & 126.598 & 132.033 & 26.555 & 132.800 & 16.153 & 16.621 & 6.068 & 16.548 \\
\hline$R E C$ & 5) & 1.738 & 1.762 & 1.761 & 1.810 & 2.841 & 2.960 & 2.857 & 3.026 & 366 & 375 & 363 & 329 \\
\hline RE Dem,f (R\$ mil) & eq. (46) & 17.634 & 17.743 & 18.072 & 18.263 & 19.270 & 19.787 & 19.634 & 20.028 & 2.488 & 2.553 & 3.014 & 3.064 \\
\hline RE Total,f(R\$ mil) & 7. (47) & 140.739 & 41.410 & 140.211 & 142.091 & 148.710 & 154.779 & 49.046 & 55.853 & 19.007 & 19.550 & 9.446 & 19.941 \\
\hline$\overline{D f, f}$ & Desembolso & - & - & 282.037 & 286.240 & 308.618 & 307.860 & - & - & - & - & - & - \\
\hline RE Tot & & 140.739 & $\$ 1.410$ & 141.826) & 144.149) & 159.909) & 153.080) & 49.046 & 55.853 & 19.007 & 9.550 & 9.446 & 19.941 \\
\hline j(inve & & $2,4 \%$ & $2,4 \%$ & $2,4 \%$ & $2,4 \%$ & $2,4 \%$ & $2,4 \%$ & $2,4 \%$ & $2,4 \%$ & $2,4 \%$ & $2,4 \%$ & $2,4 \%$ & 2,4 \\
\hline$j($ financiamento) & & $3,0 \%$ & $3,0 \%$ & $3,0 \%$ & $3,0 \%$ & $3,0 \%$ & $3,0 \%$ & $3,0 \%$ & $3,0 \%$ & $3,0 \%$ & $3,0 \%$ & $3,0 \%$ & $3,0 \%$ \\
\hline$F C A, F(R \$$ mil) & eq. (48) & 140.739 & 285.543 & 150.602 & 10.085 & $(149.580)$ & $(307.193)$ & $(167.455)$ & $(16.676)$ & 1.826 & 21.419 & 41.382 & 62.320 \\
\hline
\end{tabular}




\section{UM MODELO EMPÍRICO DE ANÁLISE DE RISCO PARA FLUXO DE CAIXA DA COMPRA DE ENERGIA (CASHFLOW- AT-RISK)}

Nos capítulos anteriores, foram apresentadas e desenvolvidas equações com o intuito de representar as despesas e receitas, provindas da compra de energia elétrica que atendam às necessidades de consumo da distribuidora no decorrer de um ano civil, permitindo a montagem do respectivo fluxo de caixa. Contudo, a metodologia apresentada concentra-se principalmente em variáveis de uma única resposta numérica, ou seja, os resultados obtidos com o fluxo de caixa são baseados em valores determinísticos. Este tipo de abordagem é bastante útil, por exemplo, quando o objetivo da distribuidora é o de aferição, como na verificação de repasse integral dos custos com a compra energia, ao consumidor, no final do horizonte de estudo.

Entretanto, quando o objetivo da distribuidora passa a ser o de planejar e, conseqüentemente, há a necessidade de prever o fluxo de caixa da compra, a abordagem determinística mostra-se pouco eficaz, dado a existência de inúmeras incertezas pertinentes ao processo.

Nesse sentido, este capítulo traz como objetivo principal desenvolver um modelo empírico para gerenciamento dos riscos provindos de perturbações ou desvios inerentes às previsões das variáveis que compõem a formulação desenvolvida para o fluxo de caixa da compra de energia.

Para tanto, é utilizado como métrica de risco o "fluxo de caixa em risco" Cashflow-at-Risk - (Perobelli, 2004), entendido aqui como a probabilidade da distribuidora não dispor de recursos para honrar seus compromissos com os contratos de energia elétrica em determinadas datas futuras (vértices do fluxo).

Para tratar as variáveis que compõem o fluxo de caixa considerando seu comportamento probabilístico, utilizam-se modelos de regressão linear múltipla e os resultados obtidos através de simulações no modelo NEWAVE. O propósito da análise de regressão é o desenvolvimento de modelo estatístico que possa ser 
utilizado para prever os valores de uma variável resposta, com base nos valores de variáveis explicativas.

Dado o exposto, a metodologia adotada na construção do modelo de fluxo de caixa em risco, necessita:

1. Definir as variáveis de estudo, subdividindo-as em variáveis de interesse e dependentes, variáveis independentes e as variáveis explicativas.

2. Definir o Período de Apuração e conseqüentemente o horizonte de estudo observado do fluxo de caixa em risco.

3. Identificar os fatores de risco relevantes via a estimação da relação estatística existente entre algumas variáveis independentes e as variáveis explicativas (fatores de risco macroeconômicos e próprios do negócio) e sugerir um tratamento para previsão dos fatores de risco macroeconômicos.

4. Montar distribuição simulada das variáveis de interesse e efetivar a análise estatística de tal distribuição.

\subsection{Variáveis do modelo de risco}

Para determinar as variáveis do modelo de risco é utilizado como base o diagrama ilustrado na Figura 6.1, onde estão representadas as variáveis utilizadas na formulação das equações que formam o fluxo de caixa da compra de energia bem como suas respectivas relações.

Com o intuito de identificar a função de cada variável no processo de cálculo do fluxo de caixa da compra, no diagrama, as variáveis estão divididas em: variáveis independentes; variáveis dependentes e; variáveis de interesse. 


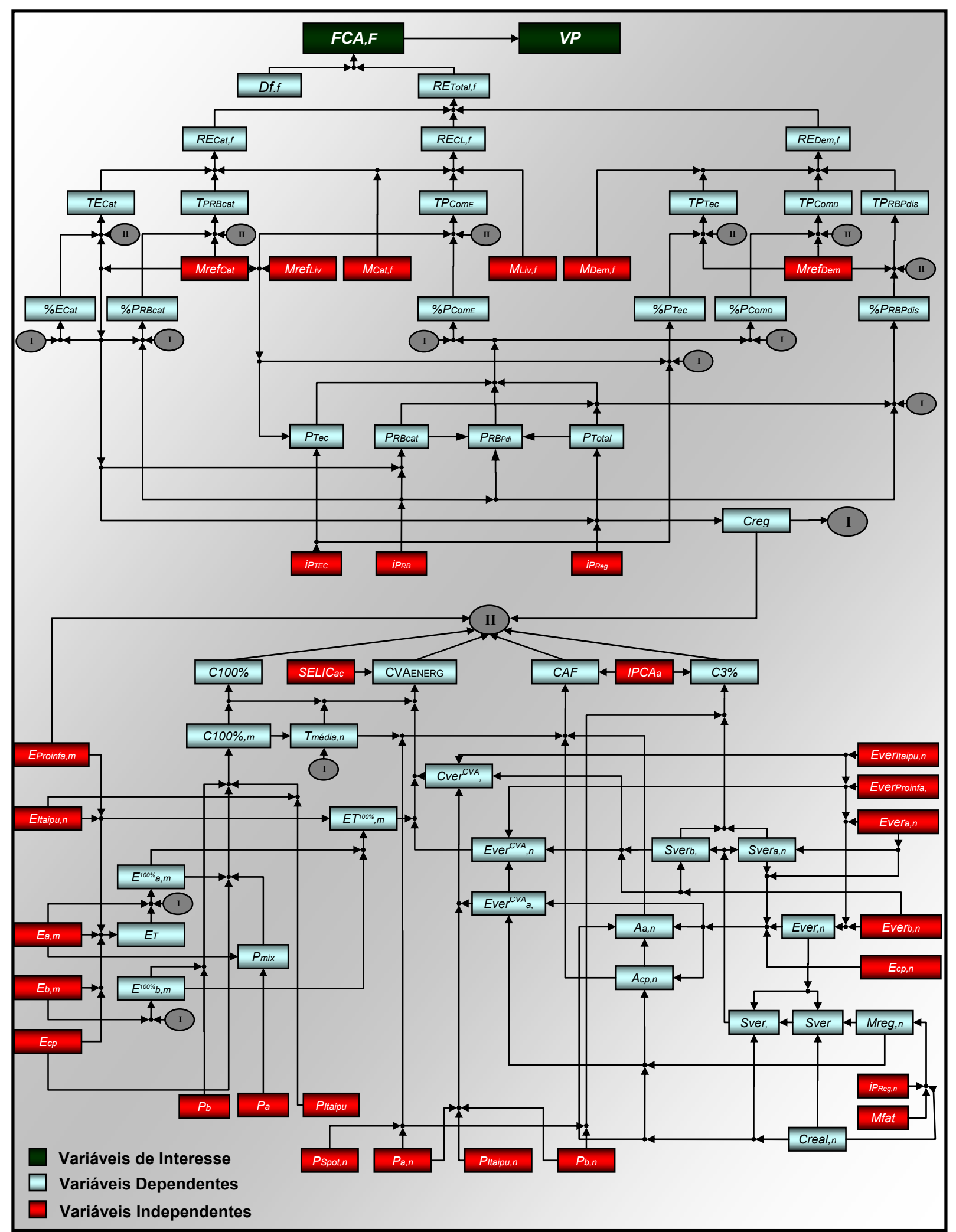

Figura 6.1 - Diagrama de relação entre as variáveis que compõem o Fluxo de Caixa da Compra de Energia 


\subsubsection{A escolha das Variáveis Independentes}

Neste trabalho, as variáveis independentes são entendidas como variáveis que não sofrem oscilações decorrentes de variações nos valores de qualquer outra variável que componha o fluxo de caixa da compra, ou seja, alterações em seus valores apenas serão provocadas por fenômenos exógenos ao processo de cálculo do fluxo de caixa (produção nacional, temperatura, inflação, fatores comportamentais, etc.). Por outro lado, a variação do valor de qualquer uma dessas variáveis implica na variação de valores das variáveis relacionadas a elas, portanto, as variáveis independentes são as candidatas a fatores de risco do modelo.

No diagrama, ilustrado na Figura 6.1, pode-se observar que as variáveis independentes estão subdivididas em:

1. Variáveis de mercado - consumo de energia e demanda;

2. Variáveis de Preço;

3. Variáveis de montantes de energia contratados;

4. Variáveis de índices e;

5. Variáveis macroeconômicas.

Dentre as variáveis citadas, foram escolhidas para análise de suas previsões e, conseqüentemente, compor os fatores de risco do modelo, as variáveis relacionadas ao consumo do mercado cativo, a variável de preço de curto prazo (PLD) e as variáveis macroeconômicas. Para as demais variáveis, um conjunto de premissas é adotado para suas previsões, porém, os valores atribuídos a elas serão apresentados de forma determinística.

\subsubsection{Variáveis de Interesse e Dependentes}

Considerando-se que o modelo para gerenciamento de risco proposto baseiase na mensuração do fluxo de caixa em risco, a variável de interesse neste trabalho é o caixa acumulado em determinada data futura $(F C A, f)$, calculado através da eq. 
(48). Tanto a variável $F C A, f$, como as variáveis resultantes das equações apresentadas nos capítulos anteriores, são denominadas, aqui, como variáveis dependentes e seus valores são calculados de maneira estocástica através da substituição dos prováveis valores calculados para os fatores de risco nas equações que as relacionam.

\subsection{Período de Apuração e Horizonte de Estudo}

Para desenvolvimento do modelo empírico de análise de risco do fluxo de caixa da compra de energia, simula-se, neste trabalho, o desembolso com a compra de energia para atendimento da carga, de uma distribuidora de energia elétrica situada na região sudeste, no período de janeiro a dezembro de 2006 (Período de Apuração).

Para tanto, supõe-se que as informações que a distribuidora detém são referentes a dezembro 2005, ou seja, equivale a se dizer que o modelo está sendo desenvolvido pela distribuidora ao final do ano de 2005.

Com isso, de acordo com o apresentado na Figura 5.1 - Cronograma de Repasse dos Custos com Compra de Energia e suposição adotada para este trabalho, o Horizonte de Estudo do modelo de risco, compreende o período entre julho de 2005 a junho de 2008.

\subsection{Elaboração de metodologia de Previsão para os fatores de risco}

Conforme exposto no item anterior, as variáveis escolhidas como fatores de risco do modelo de fluxo de caixa em risco da compra são:

$\checkmark$ Variáveis relacionadas ao consumo do mercado cativo;

$\checkmark$ Variável de preço de curto prazo (PLD) e;

$\checkmark$ Variáveis Macroeconômicas. 
A seguir, serão propostos modelos de previsão para cada uma dessas variáveis, bem como, tratamento probabilístico das mesmas.

\subsubsection{Variáveis de Mercado Cativo}

As variáveis de mercado cativo são: MrefCat, MCat,f e Mfat. Sendo a primeira variável referente ao mercado cativo faturado pela distribuidora no Período de Referência (12 meses anteriores a DRP), a segunda refere-se ao mercado cativo mensal faturado pela distribuidora durante o Horizonte de Estudo (Período do Fluxo de Caixa) e a última refere-se ao mercado cativo faturado pela distribuidora durante o Período de Apuração (ano civil referente à compra de energia estudada). Como se pode observar, todas estas variáveis podem ser derivadas do mercado cativo mensal da distribuidora.

Portanto, neste item, será elaborado um modelo empírico para a previsão do mercado cativo mensal de uma distribuidora, no qual serão utilizadas informações mensais de histórico de consumo de uma distribuidora de energia elétrica situada na região sudeste, conforme já exposto no item anterior. Para tanto, a seguintes suposições são consideradas:

$\checkmark$ Para não expor os dados fornecidos e conseqüentemente a empresa de distribuição é aplicado um fator $\mathrm{K}$ aos valores disponibilizados;

$\checkmark$ Histórico mensal de carga medida nos pontos de medição de fronteira da distribuidora (Cdist), ou seja, nos limites entre o sistema de transmissão e de distribuição de energia da distribuidora de janeiro de 2002 a dezembro de 2005;

$\checkmark$ Histórico mensal de consumo de clientes livres de janeiro de 2003 a dezembro de 2005;

$\checkmark$ Índice de perdas Regulatória, utilizado pela ANEEL no reajuste tarifário da distribuidora em 2005; 
$\checkmark$ Índice de glosa regulatória (iGlosa) - diferença entre a Carga Real e o Carga Regulatória - calculado com base nas informações das cargas utilizadas pela ANEEL no reajuste da distribuidora em 2005 através da eq. (50) a seguir:

$$
i G l o s a=\frac{\sum_{m} \text { Creal,m-Creg }}{\text { Preg }}
$$

Onde:

$m$

Refere-se ao mês pertencente ao Período de Referência da DRP de 2005 da distribuidora;

Creal, $m \quad$ Carga real da distribuidora medida no CG para o mês " $m$ ";

Creg Carga regulatória da distribuidora para o período de referência da DRP de 2005, calculada conforme eq. (5).

Preg Perda regulatória ou Perda Total (PTotal) da distribuidora para o período de referência da DRP de 2005, calculada conforme eq. (30).

Além disso, pode-se dizer, o mercado cativo, faturado pela distribuidora no mês " $f$ ", é dado pela energia requerida pela distribuidora no CG, no mês " $f$ ", subtraída das perdas na RB e das perdas da distribuição, todas no mesmo mês " $f$ ". Porém, nem todos esses valores são obtidos diretamente, para tanto, os seguintes ajustes são propostos:
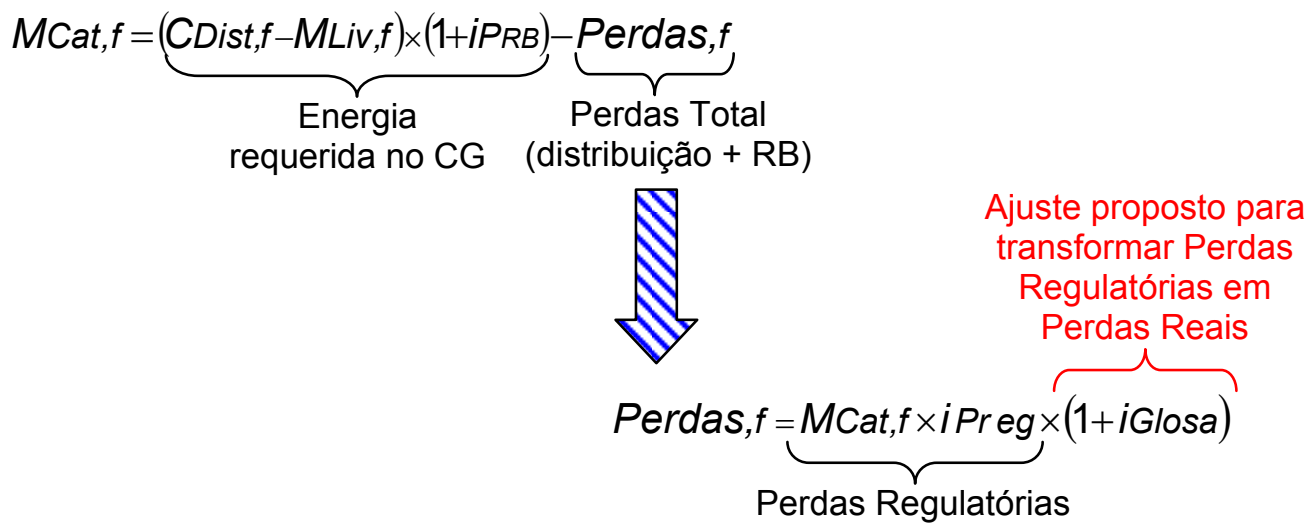
Rearranjando as equações, obtém-se a eq. (51) para o cálculo mercado cativo mensal da distribuidora.

$$
M C a t, f=\frac{(C D i s t, f-M L i v, f) \times(1+i P R B)}{[1+i \operatorname{Preg} \times(1+i G l o s a)]}
$$

Portanto, as variáveis a projetar são:

$\checkmark$ A carga da distribuidora referente à medição no ponto de conexão para o mês " $f$ ' (CDist,, );

$\checkmark$ Mercado dos consumidores livres no mês " $f$ ' (MLiv,f); e

$\checkmark$ Índice de Perdas na Rede Básica para o mês " $f$ '.

O motivo da escolha dessas variáveis e não diretamente a utilização da variável de mercado cativo, decorre do fato de que estas têm seus dados históricos baseados em valores de medição, ou seja, é possível identificar exatamente a qual mês pertence o dado, enquanto que o histórico do mercado cativo está baseado em informações de faturamento de clientes, o que torna praticamente impossível relacionar a energia faturada a um determinado mês fechado (primeiro a ultimo dia do mês).

\section{Modelo Empírico de Previsão da Carga Mensal da Distribuidora (CDIST,F)}

Para construção do modelo de previsão da carga mensal da distribuidora, utilizou-se de métodos de regressão, decompondo as observações históricas num modelo de três componentes não-observáveis: tendência, sazonalidade e uma componente aleatória de média zero e variância constante. O modelo proposto é baseado no modelo de série temporal de "Sazonalidade determinística - método de regressão" apresentado por Morettin e Toloi (2006, p. 66). Segundo os autores os métodos de regressão são ótimos para séries que apresentam sazonalidade 
determinística, ou seja, que pode ser prevista perfeitamente a partir de meses anteriores.

No tratamento da tendência é proposta a utilização da variável explicativa PIB nacional $(P I B, f)$, já que o crescimento de consumo de energia elétrica está fortemente associado ao desempenho da economia nacional, que, por sua vez, pode ser mensurado através da evolução do PIB (apud Cyrino e Campos, 2005).

Já para a sazonalidade, é proposta a utilização de variáveis simbólicas “dummies".

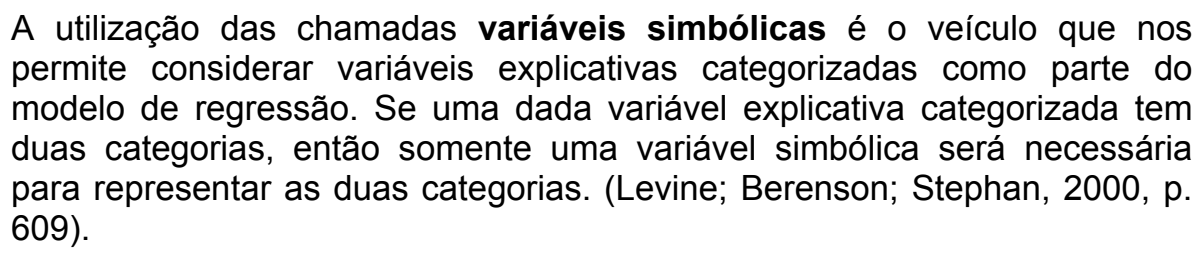

No modelo de sazonalidade da carga, as dummies são definidas como:

$D_{j f}=\left\{\begin{array}{l}1, \text { se o período } f \text { corresponde ao mês } j ; \\ -1, \text { se o período } f \text { corresponde ao mês } 12 \\ 0, \text { caso contrário, } j=1, \ldots, 11\end{array}\right.$

Onde, $j=1$ corresponde ao mês de janeiro, $j=2$ ao mês de fevereiro e assim sucessivamente.

Sendo assim, a equação geral (eq. (52)) que representa o modelo da "CDist,f", é a seguinte:

$$
C D i s t, f=\beta o+\beta 1 \times P I B, f+\sum_{j=1}^{11} \alpha j \times D j f+\Delta f
$$

Onde: 
$\beta$ e $\alpha \quad$ Coeficientes de regressão da equação e;

$\Delta f \quad$ Componente aleatória do modelo, suposta normalmente distribuída de média zero e variância constante $\sigma^{2}-\mathrm{N}(0, \sigma)$.

Este modelo apresenta diversas variáveis explicativas com relação linear entre cada variável explicativa e a variável resposta (CDist,f). Este tipo de representação é conhecido como Modelo de Regressão Linear Múltipla. Para estimar os coeficientes deste tipo de regressão é possível utilizar-se do Método dos Mínimos Quadrados - MMQ (ver Levine; Berenson; Stephan, 2000, p. 520). Este método baseia-se no encontrar a linha reta que melhor se ajusta aos dados reais através da minimização das diferenças entre os valores reais e os valores que seriam estimados pela linha ajustada.

Aplicando o modelo proposto aos dados de carga da distribuidora analisada, bem como aos valores de PIB mensal, conforme apresentado na Tabela 6.1, bem como utilizando-se de um software de regressão (EViews) para resolver a eq. (52) e, conseqüentemente, estimar os coeficientes da regressão, obteve-se a eq. (53) que representa o modelo empírico de projeção para a carga da distribuidora analisada.

Tabela 6.1 - Dados de carga da distribuidora em estudo e do PIB mensal.

\begin{tabular}{|c|c|c|c|c|c|c|c|c|c|c|c|c|c|c|c|c|c|c|c|c|c|c|c|c|c|c|c|}
\hline Data & Carga & D1 & D2 & D3 & D4 & D5 & D6 & D7 & D8 & D9 & D10 & D11 & PIB_MÊS & Data & Carga & D1 & D2 & D3 & D4 & D5 & D6 & D7 & D8 & D9 & D10 & D11 & PIB_MÊS \\
\hline jan/02 & 1.440 & 1 & 0 & 0 & 0 & 0 & 0 & $\overline{0}$ & 0 & 0 & 0 & 0 & 112,7 & $\mathrm{jan} / 04$ & 1.624 & 1 & 0 & 0 & 0 & 0 & 0 & 0 & 0 & 0 & 0 & 0 & 120,2 \\
\hline fev/02 & 1.353 & 0 & 1 & 0 & 0 & 0 & 0 & 0 & 0 & 0 & 0 & 0 & 113,0 & fev/04 & 1.573 & 0 & 1 & 0 & 0 & 0 & 0 & 0 & 0 & 0 & 0 & 0 & 120,8 \\
\hline $\mathrm{mar} / 02$ & 1.591 & 0 & 0 & 1 & 0 & 0 & 0 & 0 & 0 & 0 & 0 & 0 & 113,3 & $\mathrm{mar} / 04$ & 1.752 & 0 & 0 & 1 & 0 & 0 & 0 & 0 & 0 & 0 & 0 & 0 & 121,2 \\
\hline abr/02 & 1.593 & 0 & 0 & 0 & 1 & 0 & 0 & 0 & 0 & 0 & 0 & 0 & 113,8 & abr/04 & 1.669 & 0 & 0 & 0 & 1 & 0 & 0 & 0 & 0 & 0 & 0 & 0 & 121,6 \\
\hline mai/02 & 1.587 & 0 & 0 & 0 & 0 & 1 & 0 & 0 & 0 & 0 & 0 & 0 & 114,4 & mai/04 & 1.710 & 0 & 0 & 0 & 0 & 1 & 0 & 0 & 0 & 0 & 0 & 0 & 122,1 \\
\hline jun/02 & 1.532 & 0 & 0 & 0 & 0 & 0 & 1 & 0 & 0 & 0 & 0 & 0 & 114,8 & jun/04 & 1.676 & 0 & 0 & 0 & 0 & 0 & 1 & 0 & 0 & 0 & 0 & 0 & 122,6 \\
\hline $\mathrm{jul} / 02$ & 1.561 & 0 & 0 & 0 & 0 & 0 & 0 & 1 & 0 & 0 & 0 & 0 & 115,1 & jul/04 & 1.716 & 0 & 0 & 0 & 0 & 0 & 0 & 1 & 0 & 0 & 0 & 0 & 123,0 \\
\hline ago/02 & 1.600 & 0 & 0 & 0 & 0 & 0 & 0 & 0 & 1 & 0 & 0 & 0 & 115,3 & ag & 1.749 & 0 & 0 & 0 & 0 & 0 & 0 & 0 & 1 & 0 & 0 & 0 & 123,3 \\
\hline set/02 & 1.553 & 0 & 0 & 0 & 0 & 0 & 0 & 0 & 0 & 1 & 0 & 0 & 115,5 & 04 & 1.720 & 0 & 0 & 0 & 0 & 0 & 0 & 0 & 0 & 1 & 0 & 0 & 123,6 \\
\hline out/02 & 1.703 & 0 & 0 & 0 & 0 & 0 & 0 & 0 & 0 & 0 & 1 & 0 & 115,7 & ut/04 & 1.741 & 0 & 0 & 0 & 0 & 0 & 0 & 0 & 0 & 0 & 1 & 0 & 124,0 \\
\hline nov/02 & 1.610 & 0 & 0 & 0 & 0 & 0 & 0 & 0 & 0 & 0 & 0 & 1 & 115,8 & nov/04 & 1.706 & 0 & 0 & 0 & 0 & 0 & 0 & 0 & 0 & 0 & 0 & 1 & 124,3 \\
\hline dez/02 & 1.611 & -1 & -1 & -1 & \begin{tabular}{l|}
-1 \\
\end{tabular} & \begin{tabular}{l|}
-1 \\
\end{tabular} & -1 & -1 & -1 & \begin{tabular}{|l|}
-1 \\
\end{tabular} & -1 & -1 & 115,9 & dez/04 & 1.723 & -1 & -1 & \begin{tabular}{|l|}
-1 \\
\end{tabular} & -1 & \begin{tabular}{|l|}
-1 \\
\end{tabular} & \begin{tabular}{|l|}
-1 \\
\end{tabular} & -1 & -1 & -1 & -1 & -1 & 124,5 \\
\hline jan/03 & 1.600 & 1 & 0 & 0 & 0 & 0 & 0 & 0 & 0 & 0 & 0 & 0 & 115,7 & jan/05 & 1.702 & 1 & 0 & 0 & 0 & 0 & 0 & 0 & 0 & 0 & 0 & 0 & 124,6 \\
\hline fev/03 & 1.555 & 0 & 1 & 0 & 0 & 0 & 0 & 0 & 0 & 0 & 0 & 0 & 115,5 & fev/05 & 1.588 & 0 & 1 & 0 & 0 & 0 & 0 & 0 & 0 & 0 & 0 & 0 & 124,9 \\
\hline $\mathrm{mar} / 03$ & 1.637 & 0 & 0 & 1 & 0 & 0 & 0 & 0 & 0 & 0 & 0 & 0 & 115,7 & $\mathrm{mar} / 05$ & 1.827 & 0 & 0 & 1 & 0 & 0 & 0 & 0 & 0 & 0 & 0 & 0 & 125,3 \\
\hline abr/03 & 1.600 & 0 & 0 & 0 & 1 & 0 & 0 & 0 & 0 & 0 & 0 & 0 & 116,0 & abr/05 & 1.770 & 0 & 0 & 0 & 1 & 0 & 0 & 0 & 0 & 0 & 0 & 0 & 125,7 \\
\hline mai/03 & 1.635 & 0 & 0 & 0 & 0 & 1 & 0 & 0 & 0 & 0 & 0 & 0 & 115,9 & ai/05 & 1.779 & 0 & 0 & 0 & 0 & 1 & 0 & 0 & 0 & 0 & 0 & 0 & 126,0 \\
\hline jun/03 & 1.569 & 0 & 0 & 0 & 0 & 0 & 1 & 0 & 0 & 0 & 0 & 0 & 116,0 & jun/05 & 1.750 & 0 & 0 & 0 & 0 & 0 & 1 & 0 & 0 & 0 & 0 & 0 & 126,3 \\
\hline $\mathrm{jul} / 03$ & 1.621 & 0 & 0 & 0 & 0 & 0 & 0 & 1 & 0 & 0 & 0 & 0 & 116,5 & jul/05 & 1.745 & 0 & 0 & 0 & 0 & 0 & 0 & 1 & 0 & 0 & 0 & 0 & 126,6 \\
\hline ago/03 & 1.638 & 0 & 0 & 0 & 0 & 0 & 0 & 0 & 1 & 0 & 0 & 0 & 116,9 & ago/05 & 1.820 & 0 & 0 & 0 & 0 & 0 & 0 & 0 & 1 & 0 & 0 & 0 & 127,1 \\
\hline set/03 & 1.638 & 0 & 0 & 0 & 0 & 0 & 0 & 0 & 0 & 1 & 0 & 0 & 117,3 & set/05 & 1.746 & 0 & 0 & 0 & 0 & 0 & 0 & 0 & 0 & 1 & 0 & 0 & 127,5 \\
\hline out/03 & 1.708 & 0 & 0 & 0 & 0 & 0 & 0 & 0 & 0 & 0 & 1 & 0 & 117,9 & out/05 & 1.814 & 0 & 0 & 0 & 0 & 0 & 0 & 0 & 0 & 0 & 1 & 0 & 127,7 \\
\hline nov/03 & 1.641 & 0 & 0 & 0 & 0 & 0 & 0 & 0 & 0 & 0 & 0 & I & 118,5 & nov/05 & 1.756 & 0 & 0 & 0 & 0 & 0 & 0 & 0 & 0 & 0 & 0 & 1 & 127,8 \\
\hline dez/03 & 1.648 & -1 & -1 & -1 & -1 & -1 & -1 & -1 & -1 & -1 & -1 & -1 & 119,4 & dez/05 & 1.771 & -1 & -1 & -1 & -1 & -1 & \begin{tabular}{|l|}
-1 \\
\end{tabular} & -1 & -1 & -1 & -1 & -1 & 128,0 \\
\hline
\end{tabular}


Definido o modelo de previsão da carga, agora é necessário definir a componente aleatória do modelo $(\Delta f)$. Para mensurar esta, é utilizado como base o Erro Padrão da Previsão (Previsão_se,f) para cada período futuro " $f$ " (EViews...,2005,p.552), conforme eq.(54) a seguir:

$$
\text { Previsão_se, } f=s \times \sqrt{1+X^{\prime} f \times\left(X^{\prime} \times X\right)^{-1} \times X f}
$$

Onde:

Xf é o vetor com os valores das variáveis explicativas para determinada data "f" futura.

$X f^{\prime} \quad$ é o vetor transposto de $x f$

X é a matriz $T \times k$ dos valores das variáveis observadas, sendo a primeira variável igual a 1 , ou seja, índice que multiplica o primeiro coeficiente do modelo de regressão. Para exemplificar, a seguir é apresentada a primeira e última linha da matriz, com base na Tabela 6.1.

$$
\left[\begin{array}{ccccccccccccc}
1 & 112,7 & 1 & 0 & 0 & 0 & 0 & 0 & 0 & 0 & 0 & 0 & 0 \\
\cdot & \cdot & \cdot & \cdot & \cdot & \cdot & \cdot & \cdot & \cdot & \cdot & \cdot & \cdot & \cdot \\
1 & 128,0 & -1 & -1 & -1 & -1 & -1 & -1 & -1 & -1 & -1 & -1 & -1
\end{array}\right]_{48 \times 13}
$$

$X^{\prime} \quad$ é a matriz transposta de $X$;

É o erro padrão da regressão calculado conforme eq. (55) a seguir (EViews...,2005,p.452): 


$$
S=\sqrt{\frac{\sum_{i=1}^{T}\left(y i-y i^{\prime}\right)^{2}}{T-k}}
$$

Onde:

yi Corresponde ao valor observado de carga para uma determinada data "i" do histórico analisado (CDist,i), exemplo dezembro de 2002 CDist, dez/2002 = $1.611 \mathrm{GWh}$;

yi' $\quad$ Corresponde ao calculado de carga para uma determinada data " $i$ " do

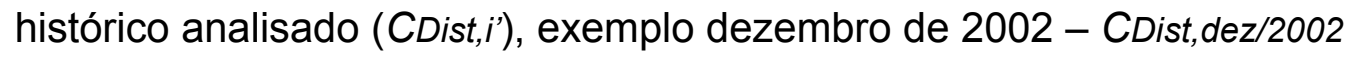
$=1.594 \mathrm{GWh}$;

$T$ Corresponde ao número de observações do histórico, neste caso $\mathrm{T}=$ 48 e;

K Corresponde ao número de Coeficientes do Modelo, neste caso $\mathrm{k}=13$.

Para os dados da Tabela 6.1 e o modelo da eq. (53) tem-se que $s=32,1$.

Dado o exposto, a componente aleatória para determinada data futura " $f$ " é dada pela eq. (56), ou seja, distribuição normal de média zero e desvio padrão igual ao erro padrão da previsão.

$$
\Delta f=N(0 ; \text { Previsão_se,f })
$$

Modelo de PREVISÃo PARA O MERCADO dOS CONSUMIDORES LIVRES NO MÊS "F" (MLIV,F)

Conforme já exposto, para projetar a variável de consumo de mercado livre, bem como algumas outras variáveis independentes do modelo de fluxo de caixa, utiliza-se neste trabalho um modelo determinístico de previsão. 
Especificamente, para projetar o crescimento de clientes livres da distribuidora analisada é utilizada a Função Tendência para Análise de Regressão do assistente gráfico do Microsoft Excel (ver Levine; Berenson; Stephan, 2000, p. 520) aplicada ao histórico de dados de janeiro de 2003 a dezembro de 2005. O gráfico da Figura 6.2 ilustra a linha de tendência bem como sua equação.

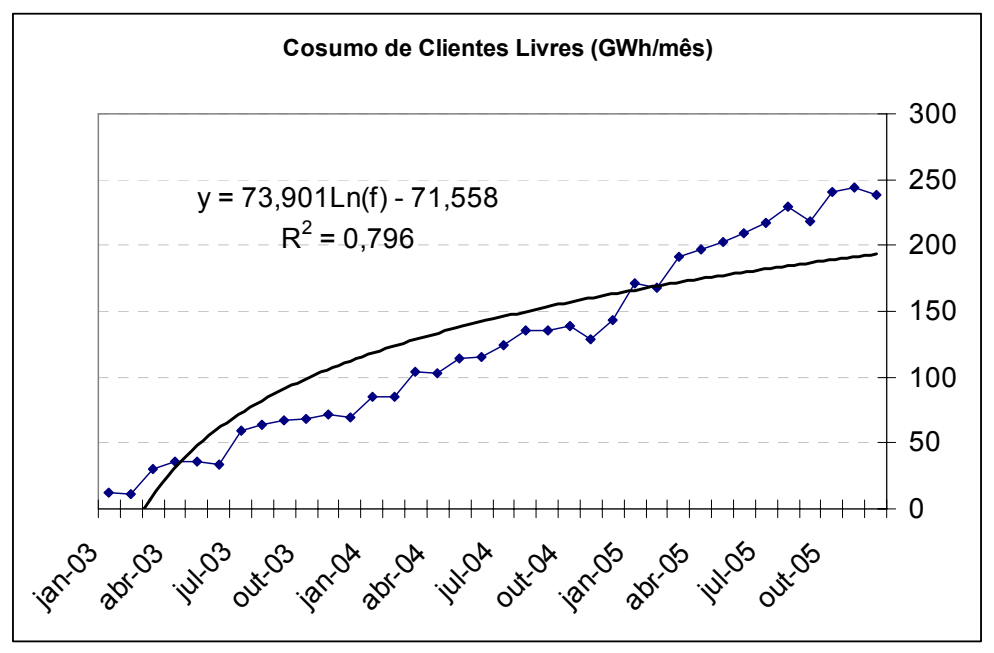

Figura 6.2 - Gráfico da evolução histórica de Consumo dos Clientes Livres (jan/2003 a dez/2005)

Desta forma a eq. (57) representa o modelo de previsão do consumo de clientes livres para a distribuidora analisada.

$$
M \operatorname{Liv}, x=73,901 \times \operatorname{Ln}(x)-71,558
$$

Onde:

$x \quad$ Corresponde ao mês que se deseja projetar, dado que: $x=1$ corresponde ao mês de janeiro de 2003; $x=2$ corresponde ao mês de fevereiro de 2003 e assim sucessivamente. 
O modelo de previsão do índice de perdas na RB será tratado da mesma forma como foi construído o modelo de previsão de consumo dos clientes livres, ou seja, utilizando-se da Função Tendência para Análise de Regressão do assistente gráfico do Microsoft Excel, aplicado ao histórico de dados também de janeiro de 2003 a dezembro de 2005. O gráfico da Figura 6.3 ilustra a linha de tendência bem como sua equação.

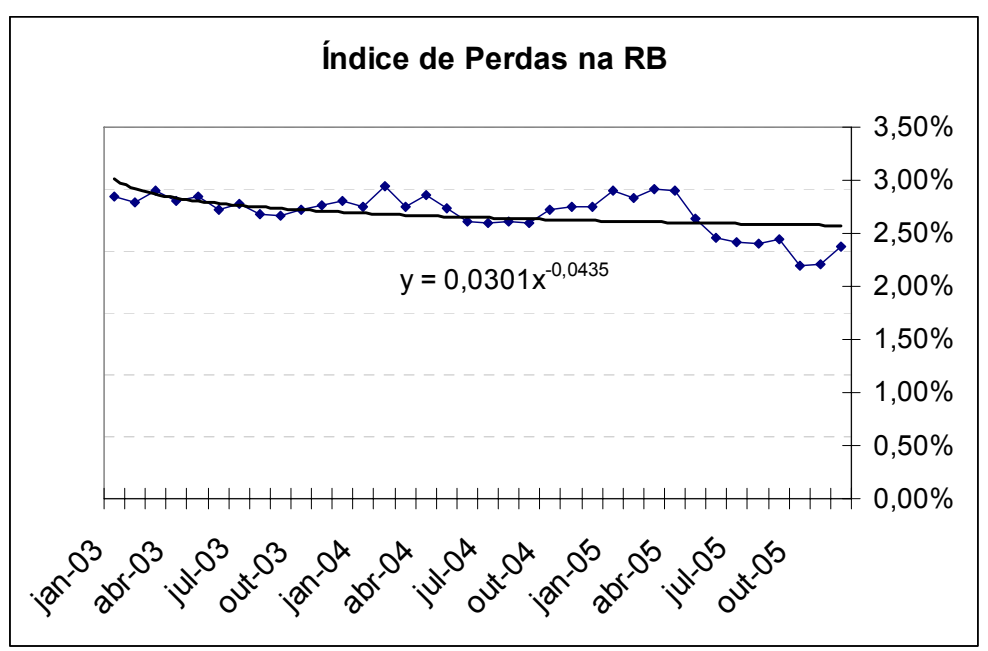

Figura 6.3 - Gráfico da evolução histórica do Índice de Perdas na RB (jan/2003 a dez/2005)

Desta forma a eq. (58) representa o modelo de previsão do consumo de clientes livres para a distribuidora analisada.

$$
i_{R B}=0,0301 \times X-0,0435
$$

Onde:

$x \quad$ Conforme definido anteriormente.

Definida as equações de previsão, basta substituí-las na eq. (51), obtendo assim o modelo empírico para a previsão do mercado cativo mensal da distribuidora analisada. 


\title{
6.3.2. Variável de preço de curto prazo (PLD)
}

As principais variáveis de risco de preço, no mercado de energia elétrica brasileiro, são relacionadas ao Preço de Liquidação das Diferenças (PLD), que determina como são liquidadas as diferenças da compra de energia elétrica no mercado de curto prazo.

O processo de cálculo do PLD baseia-se na utilização dos modelos computacionais NEWAVE e DECOMP ${ }^{20}$.

\begin{abstract}
O NEWAVE consiste em um modelo de otimização para o planejamento de médio prazo (até cinco anos), com discretização mensal e representação a sistema equivalente, considerando todas as usinas de um submercado agregadas em um único reservatório. Seu objetivo é determinar a estratégia de geração hidráulica e térmica em cada mês dentro do período de estudo, que minimiza o valor esperado do custo de operação para todo o período de planejamento. (Visão..., 2006, p.37)
\end{abstract}

Um dos principais resultados obtidos com o NEWAVE é a produção de duas mil séries, com igual probabilidade de ocorrência, de preço futuro ( $R / M W h)$ do Custo Marginal de Operação ${ }^{21}(\mathrm{CMO})$, representadas mensalmente para um período de até 5 anos.

Neste trabalho, considera-se que os valores de previsão estocástica do PLD são iguais aos CMO das saídas do NEWAVE limitados por um preço mínimo e máximo definido pela Aneel e vigente para o período de apuração.

${ }^{20}$ DECOMP: modelo de otimização para o horizonte de Curto Prazo (até 12 meses), que representa o primeiro mês em base semanal e vazões previstas, a aleatoriedade das vazões do restante do período através de uma árvore de possibilidades (cenário de vazões) e o parque gerador individualizado (usinas hidráulicas e térmicas por subsistema). Seu objetivo é determinar o despacho de geração das usinas hidráulicas e térmicas que minimiza o valor esperado do custo de operação no primeiro estágio (primeira semana), dado o conjunto de informações disponíveis (carga, vazões, disponibilidade, limites de transmissão entre subsistema, função de custo futuro do NEWAVE,...). CCEE, Regras Algébricas de Mercado, MÓDULO - Preço de Liquidação de Diferenças, p. 6.

${ }^{21}$ Custo Marginal de Operação: Custo por unidade de energia produzida na qual se incorre para atender a um acréscimo de carga no sistema. Procedimentos de Rede do NOS, Submódulo 20.1 Definição e Glossário, item 7.191, p. 19. 
Para ilustrar a aplicação do modelo de risco na distribuidora analisada, utilizam-se as saídas do NEWAVE em simulação com dados de entrada baseados na elaboração do Programa Mensal de Operação $(\mathrm{PMO})^{22}$, para o mês de janeiro de 2006.

A Figura 6.4 ilustra o gráfico com a curva de previsão de PLD de forma estocástica, para os meses de janeiro de 2006 a junho de 2008.

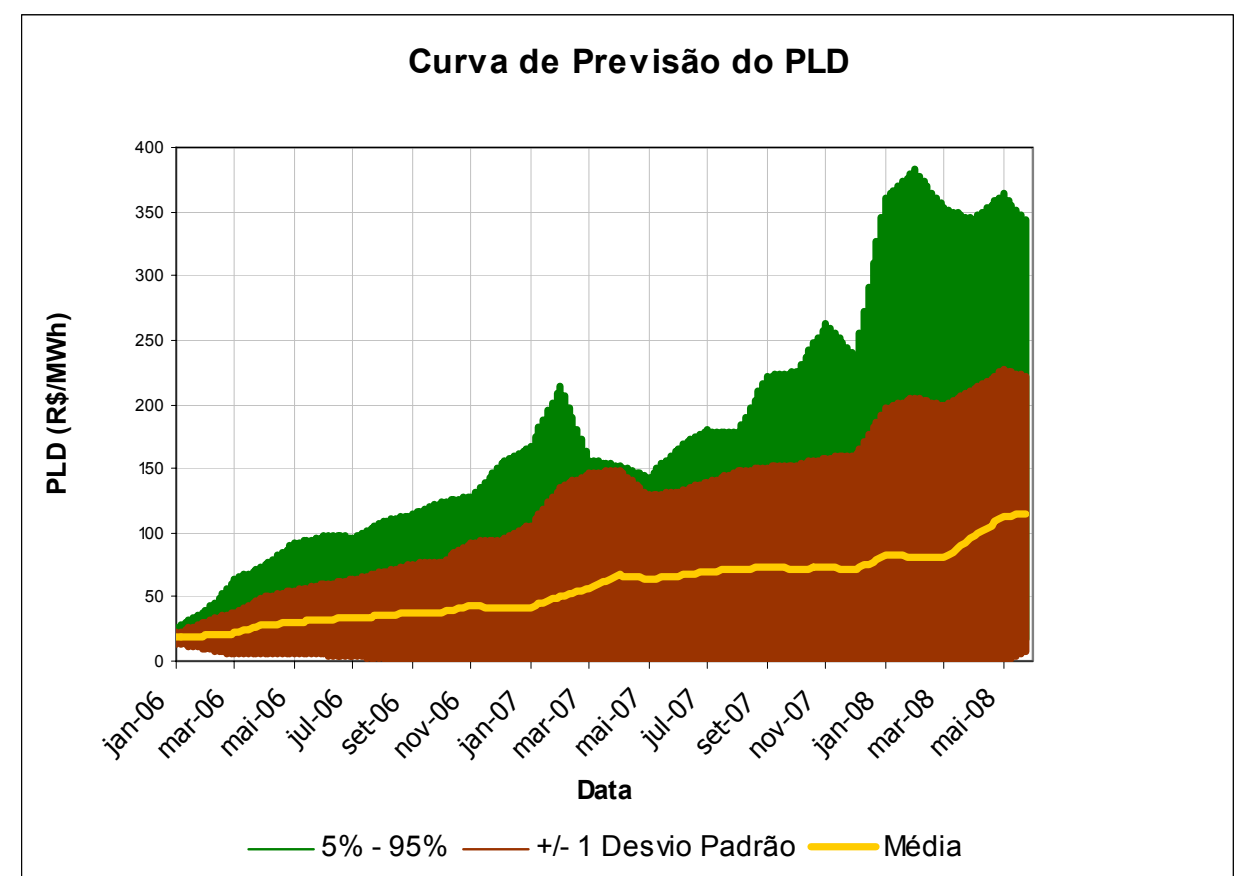

Figura 6.4 - Curva de Previsão estocástica do PLD de janeiro de 2006 a dezembro de 2007

\subsubsection{Tratamento para previsão dos fatores de risco macroeconômicos}

Conforme ilustrado na Figura 6.1 e no item que trata da previsão de consumo do mercado, os principais fatores de risco macroeconômicos do modelo de previsão do fluxo de caixa são: a Taxa Selic, o IPCA e o PIB.

22 Programa Mensal de Operação Eletroenergética (PMO), para o mês de janeiro de 2006, estabelecendo as diretrizes eletroenergéticas de curto prazo, de modo a otimizar a utilização dos recursos de geração e transmissão do sistema interligado nacional - SIN, segundos procedimentos e critérios consubstanciados nos Procedimentos de Rede, homologados pela ANEEL. São também consideradas as restrições físico-operativas de cada empreendimento de geração e transmissão, bem como as restrições relativas aos outros usos da água, estabelecido pela Agência Nacional de Águas - ANA. ONS. 
O tratamento proposto para a estimação dos valores futuros dos fatores de risco macroeconômico está baseado em informações obtidas, através do site do Banco Central (www.bcb.gov.br), de expectativa futura da média e do desvio padrão. A Tabela 6.2 apresenta a expectativa de mercado para cada uma desses fatores macroeconômicos em 30 de dezembro de 2005.

\begin{tabular}{|c|c|c|c|c|c|c|}
\hline & \multicolumn{2}{|c|}{ SELIC } & \multicolumn{2}{|c|}{ IPCA } & \multicolumn{2}{|c|}{ TAXA PIB } \\
\hline & MÉDIA & $\begin{array}{l}\text { DESVIO } \\
\text { PADRÃOO }\end{array}$ & MÉDIA & $\begin{array}{l}\text { DESVIO } \\
\text { PADRÃOO }\end{array}$ & MÉDIA & $\begin{array}{l}\text { DESVIO } \\
\text { PADRÃO }\end{array}$ \\
\hline 2006 & $16,0 \%$ & $0,4 \%$ & $4,6 \%$ & $0,3 \%$ & $3,5 \%$ & $0,4 \%$ \\
\hline 2007 & $14,5 \%$ & $0,7 \%$ & $4,5 \%$ & $0,4 \%$ & $3,6 \%$ & $0,5 \%$ \\
\hline 2008 & $13,2 \%$ & $0,9 \%$ & $4,4 \%$ & $0,4 \%$ & $3,8 \%$ & $0,6 \%$ \\
\hline
\end{tabular}

Para tratar os índices macroeconômicos em risco supõe-se aceitável, para efeito dos objetivos em mente, uma aproximação desses valores por uma normal, de média e desvio padrão dados pela Tabela 6.2 (ver Levine; Berenson; Stephan, 2000, p. 217). Por exemplo, a taxa de crescimento para o PIB em 2007 apresenta distribuição normal de média $3,6 \%$ e desvio padrão $0,5 \%$, ou seja, $N(3,6 \% ; 0,5 \%)$.

Porém, como observadas na tabela, as informações apresentadas estão configuradas em base anual, o que difere do modelo de previsão do fluxo de caixa, que está em base mensal.

Para resolver este problema é proposto tratar o IPCA e a Taxa SELIC com índices mensais iguais, calculados através da eq. (59) a seguir:

$$
M \operatorname{Liv}, x=73,901 \times \operatorname{Ln}(x)-71,558
$$

Onde:

im Distribuição de Probabilidade do índice mensal de taxa SELIC ou IPCA; 
ia Distribuição de Probabilidade do índice anual de taxa SELIC ou IPCA, obtido através de valores divulgados pelo Banco Central de expectativa de mercado.

Porém, não é possível dar o mesmo tratamento à taxa de crescimento do PIB. Isto por que, a taxa é aplicada diretamente ao PIB total do ano anterior, ou seja, se o PIB do ano de 2007 fosse, por exemplo, de 2,5 trilhões de reais e o de dezembro de 2007 fosse de 200 bilhões de reais, ao aplicar a taxa de crescimento anual do PIB de 3,8\% ao PIB anual de 2007, obteríamos um PIB para 2008 de aproximadamente 2,6 trilhões de reais. Por outro lado, se aplicarmos a eq. (59) na taxa de crescimento anual do PIB, obtendo uma taxa mensal de 0,31\% e aplicando-a ao PIB mensal de dezembro e assim sucessivamente até obter o PIB de dezembro de 2008, o PIB anual para 2008 seria de 2,4 trilhões, o que não corresponderia ao crescimento de PIB de 3,8\% para 2008 em relação a 2007, ou seja, a aplicação da eq. (59) não se aplica a taxa de crescimento do PIB.

Logo, o tratamento proposto para a previsão do PIB de um determinado mês, é o de aplicar a taxa anual do PIB ao PIB do mês correspondente do ano anterior, ou seja, se o PIB que se deseja calcular é o referente a fevereiro de 2008 , basta aplicar a taxa do PIB de 2008 ao PIB do mês de fevereiro de 2007 e assim sucessivamente para todo horizonte de estudo.

\subsubsection{Outras Variáveis do Modelo de Previsão}

Para as variáveis de Mercado, variáveis de preço e variáveis de montante mensal de energia contratado, não tratadas nos itens anteriores, são utilizadas na previsão os valores contidos no "Modelo de Previsão de Orçamento" da própria distribuidora analisada. Novamente, convém ressaltar que estes dados referem-se aos utilizados pela empresa no final do ano de 2005.

Destaca-se que o objetivo do tratamento proposto para os fatores de risco não é acertar pontualmente os valores para as variáveis, mas apenas acessar sua provável distribuição futura e utilizar tal informação para construção da distribuição futura da variável de interesse. 
Ao contrário do que ocorre com previsões pontuais, aqui o mais relevante é encontrar uma medida de desvio (risco) e não uma estimativa pontual da variável de interesse.

\subsection{Montar distribuição simulada das variáveis de interesse e determinar o fluxo de caixa em risco (Cashflow-at-Risk)}

Definidas as equações de previsão das variáveis independentes e os fatores de risco relevantes (variáveis aleatórias), o próximo passo, na construção do modelo de risco, é o de imputar essas informações nas equações que as relacionam ao Fluxo de caixa Acumulado da compra de energia em determinada data de interesse $(F C A, f)$. Com isso, cria-se um modelo onde ao inserir valores das variáveis de entrada (variáveis independentes e variáveis explicativas) obtêm-se os resultados buscados (variáveis de interesse).

Estressando os valores dos fatores de risco pela consideração de $M$ possíveis "choques aleatórios" ${ }^{23}$, através do Método de Monte Carlo - MMC, encontra-se, dessa forma, uma distribuição empírica para Fluxo de caixa Acumulado da compra de energia em determinada data de interesse (FCA,f), ou seja, com a Simulação de Monte Carlo, tem-se, a cada sorteio, um vetor $(F \times 1)$ de novos valores de variáveis de interesse em todas as datas de interesse e ao fim de $M$ sorteios, a distribuição empírica dos fluxos de caixa.

A partir desta distribuição, é possível calcular a área sob $F C A, f<0$, em cada data futura de interesse. Tal área é igual à probabilidade da empresa, em cada data de interesse, não dispor de recursos para honrar, por si só, seus compromissos, o que ocorre quando seu fluxo de caixa é negativo.

Para simular este modelo, com os dados da distribuidora analisada, foram introduzidas as equações, apresentadas e desenvolvidas neste trabalho, a uma

${ }^{23}$ Para o PLD considerou-se que cada um dos dois mil valores resultantes do modelo Newave possuem igual probabilidade de ocorrência, com isso, a cada interação foi sorteado um desses valores de PLD de forma aleatória. 
planilha do Microsoft Excel e, em seguida, foram imputados os dados de entrada. Como resultado, obteve-se (aplicando o fator $\mathrm{K}$ que preserva os reais dados da empresa), por exemplo, um Caixa Acumulado ao final do Horizonte de Estudo (FCA,junho2008), trazido ao valor presente (lembrando que o valor presente, neste caso, é representado na data de dezembro de 2005) de, aproximadamente, 19 milhões de reais negativo (menos dezenove milhões). Comparando este valor ao total desembolsado, também trazido a valor presente, verifica-se que este montante representa, aproximadamente, $1,3 \%$ do total gasto com energia elétrica pela distribuidora no ano de 2006.

Uma provável explicação para o valor negativo do Caixa Acumulado é o fato da distribuidora analisada possuir, para o Período de Apuração, Carga Regulatória menor que a Carga Real, sendo esta diferença de, aproximadamente, $1 \%$ da energia da Carga Real. De acordo com as regras vigentes, os custos com a energia comprada referentes a esta diferença não é repassada ao consumidor final.

Para mensurar o risco, estressando as vaiáveis através do Método de Monte Carlo, foi utilizado o software “@ Risk" da Palisade, através do qual foram simuladas 10.000 (dez mil) interações (sorteios). Com isso, obteve-se o resultado, para o Fluxo de Caixa Acumulado em todas as datas de interesse, ilustrado na Figura 6.5 a seguir.

É possível observar, entre outras coisas, que o Fluxo de Caixa Acumulado apresentou baixa sensibilidade a variações dos fatores de risco, sugerindo a indicação de uma robustez no modelo de repasse. Porém, isto também pode ser explicado pela data que foi escolhida para aplicação do modelo de risco (dezembro de 2005), que, por sua vez, é bastante próxima ao Período de Apuração, ou seja, as variações decorrentes das incertezas são reduzidas devido à proximidade de tempo. 


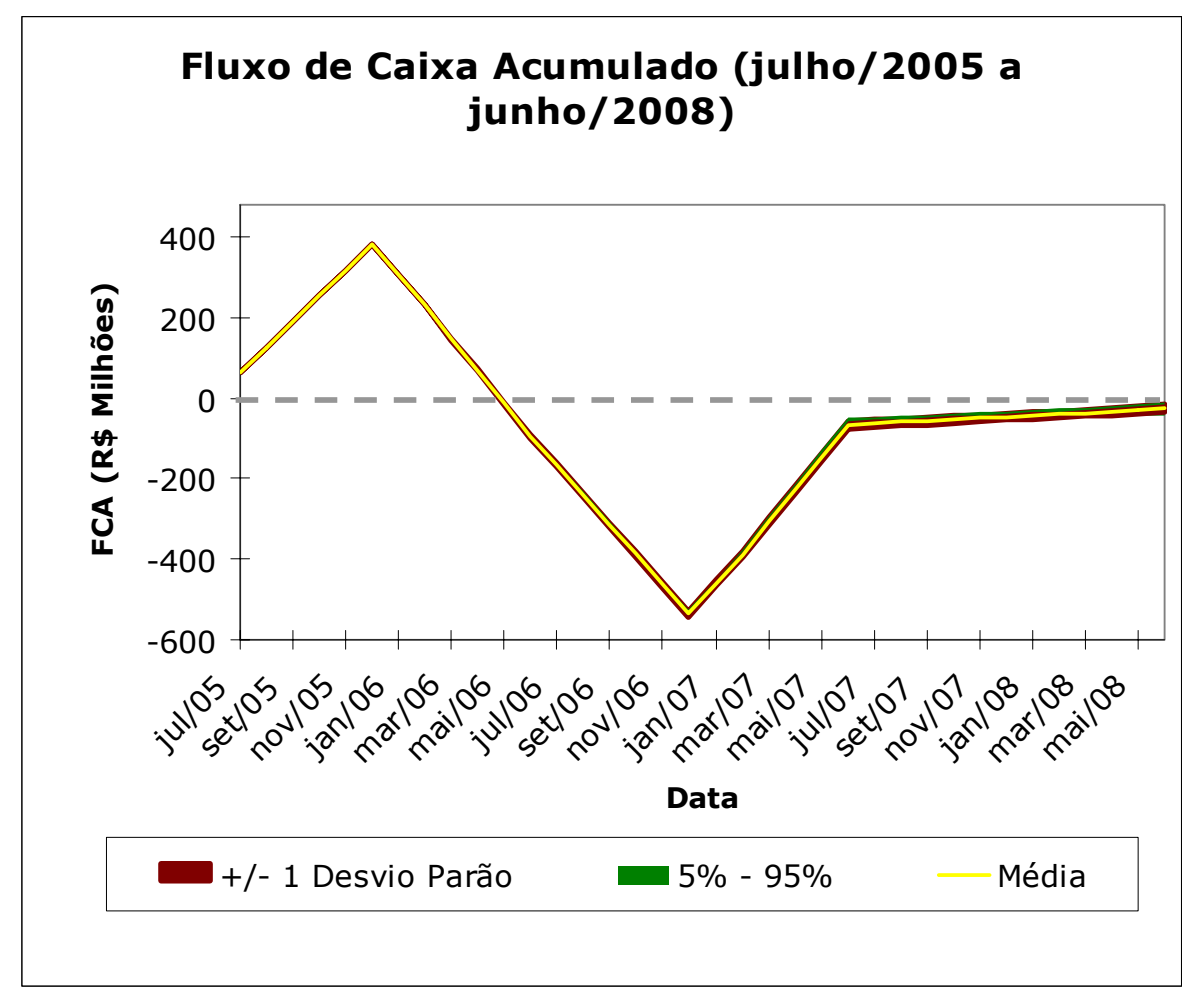

Figura 6.5 - Fluxo de Caixa Acumulado em Risco da Compra de Energia

Outro Resultado obtido com a simulação, é a probabilidade do Fluxo de Caixa acumulado em risco ao final do Horizonte de Estudo (FCA,junho/2008) ser negativo (Cashflow-at-Risk), que foi de, aproximadamente, 99\%, conforme ilustrado na Figura 6.6. Baseado nesta informação, pode-se dizer que, mesmo a distribuidora analisada apresentando valores a serem glosados, devido à diferença entre a Carga Real e Regulatória, existe uma mínima possibilidade de não haver glosas financeiras, aproximadamente $1 \%$. 


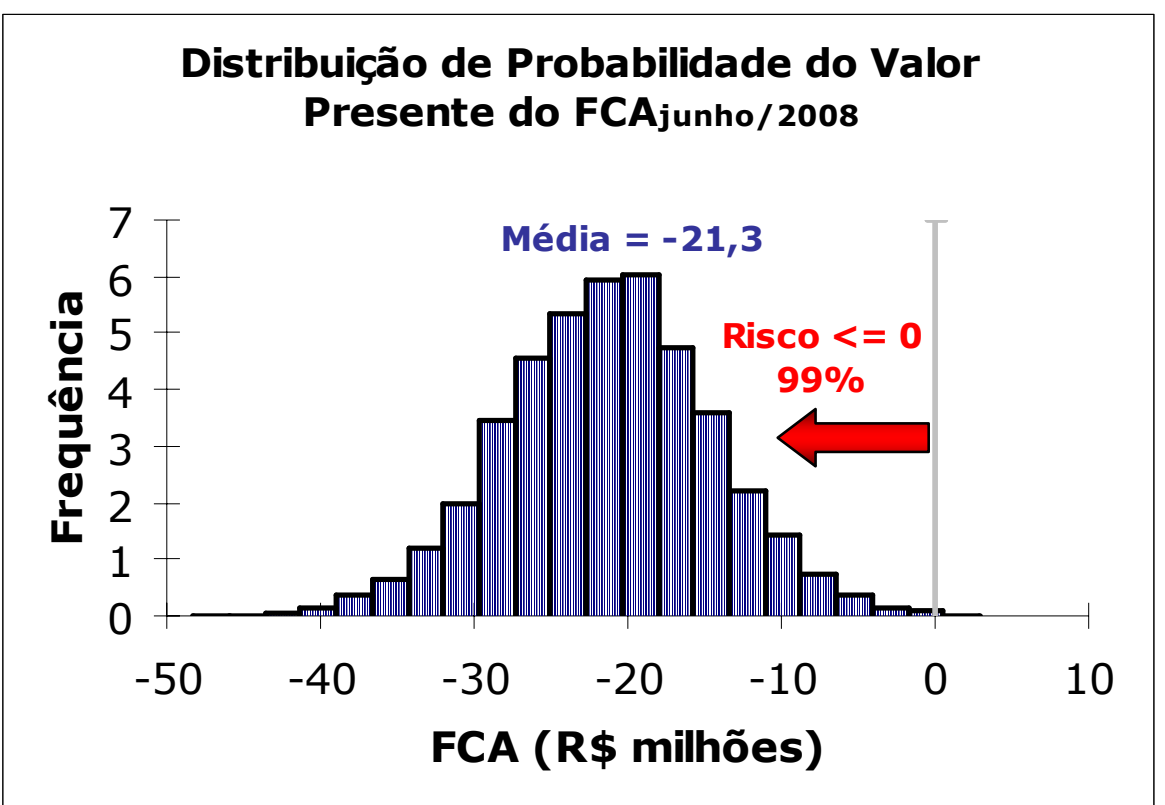

Figura 6.6 - Distribuição de Probabilidade do valor presente do Fluxo de Caixa Acumulado de junho de 2008 


\section{CONCLUSÕES}

O objetivo da Pesquisa centrou-se na proposição de metodologia e ferramental de suporte para auxiliar empresas distribuidoras no entendimento e gerenciamento do repasse dos custos de compra de energia e, com isso, assegurar um planejamento acurado dos recursos necessários considerando o aspecto de alocação no tempo, bem como auxiliar na aferição de resultados obtidos. Nessa perspectiva, ao longo deste trabalho foi apresentada metodologia com intuito de representar custos de aquisição de energia no fluxo de caixa da distribuidora, assim como um modelo para gerenciamento dos riscos associados aos desvios das variáveis que compõem o processo de aquisição e repasse dos custos de energia elétrica.

Logo, a metodologia aqui proposta demonstra ser um mecanismo importante na gestão do capital de giro da compra de energia elétrica de uma empresa de distribuição, visualizando os resultados líquidos dos desembolsos versus recebimentos provindos da compra de energia elétrica. Além disso, o instrumental desenvolvido permite a determinação da melhor sazonalidade para os contratos de energia, ou ainda, a aferição da premissa de repasse integral de todos os custos com a compra foram todos repassados ao consumidor, via tarifa, no final do horizonte de estudo.

É importante salientar ainda que o modelo de risco aqui apresentado demonstra ser útil aos gestores para avaliar o comportamento futuro de seus fatores de risco e, principalmente, o reflexo de tal comportamento sobre o fluxo de caixa projetado.

Visando servir da ferramenta, a metodologia aqui apresentada foi aplicada a uma distribuidora de energia da região Sudeste. Dentre as conclusões obtidas podese destacar que: a metodologia pode ser considerada estável, devido à baixa sensibilidade do Fluxo de Caixa Acumulado às variações dos fatores de risco e; o resultado, ao final do Horizonte de Estudo, está de acordo com o esperado para a distribuidora analisada, ou seja, caixa acumulado negativo. Isto por que, a 
distribuidora analisada possui, no Período de Apuração, Carga Real maior que Carga Regulatória.

Entretanto, é importante reconhecer as limitações da metodologia. De maneira geral, ressalta-se o fato de o presente modelo ser apenas uma primeira abordagem de uma pesquisa mais ampla. Dessa forma, serão necessários mais testes, com outras especificações de cunho econométrico, considerando um maior número possível de fatores de risco e uma adequada previsão desses fatores, ponderando sua relação com as variáveis que compõe o cálculo do Fluxo de Caixa da compra, além da aplicação em outras empresas.

Adicionalmente, destaca-se que a metodologia de repasse à tarifa adotada pela Aneel, no momento que é escrito este trabalho, ainda não é a definitiva, dado que, discussões a cerca do assunto ainda estão sendo realizadas e, conseqüentemente, a metodologia apresentada neste trabalho pode estar baseada em metodologia não definitiva.

No que se refere à eficácia do modelo em horizontes de previsão longos, deve-se mencionar que os modelos econométricos utilizados para a previsão dos fatores de risco são fortemente baseados em informações passadas, sendo incapazes de detectar choques inéditos sobre o comportamento de tais fatores. $O$ modelo proposto, contudo, não exclui a possibilidade de que cenários de estresse sejam imputados pelos gestores.

Finalmente, vale mencionar, no mesmo diapasão que caracteriza as previsões, que ainda que $\circ$ conjunto de variáveis independentes seja cuidadosamente escolhido e estimado, não há garantias de que é sempre possível estimar seu comportamento futuro. 


\section{REFERÊNCIAS BIBLIOGRÁFICAS}

ALMEIDA, D. R. Acumulação, crescimento e crise do setor de energia elétrica brasileira: a perspectiva da empresa pública e do planejamento de longo prazo. 1993. Tese de Doutorado - Instituto de Economia Industrial - Universidade Federal do Rio de Janeiro. Rio de Janeiro, 1993.

BARTRAM, S. M. Corporate Risk Management as a Lever for Shareholder Value Creation. [ca. 2000]. (Estudo Técnico).

BITU, R.; BORN, P. Tarifas de Energia Elétrica: Aspectos Conceituais e Metodológicos. São Paulo: MM Editora Ltda. 1993.

BLANARU, A.; TELES, E. Estudo sobre a avaliação de empresas diante das condições de incerteza das premissas: análise probabilística gerada por simulação de Monte Carlo como auxílio ao processo decisório. [ca. 2003]. (Estudo Técnico).

BRASÍLIA. Decreto 774, de 18 de março de 1993. Regulamenta a Lei 8.631 de 04.03.1993 que dispõe sobre a fixação dos níveis das tarifas para Serviço Público de Energia Elétrica, extingue o Regime de Remuneração Garantida e dá outras providências. Diário Oficial, Brasília, 19/03/1993. Seção 01, 3289 p.

BRASÍLIA. Lei $n^{\circ}$ 8.631, de 4 de março de 1993. Dispõe sobre a fixação dos níveis das tarifas para o serviço público de energia elétrica, extingue o regime de remuneração garantida e dá outras providências. Diário Oficial, Brasília, 05/03/93. Seção 01, 2597 p.

BRASÍLIA. Lei $n^{\circ}$ 8.987, de 13 de fevereiro de 1995. Dispõe sobre o regime de concessão e permissão da prestação de serviços públicos previstos no art. 175 da Constituição Federal, e dá outras providências. Disponível em <http://www.aneel.gov.br>. Acesso em: 2007.

BRASÍLIA. Lei n 9.074, de 7 de julho de 1995. Estabelece normas para a outorga e prorrogações das concessões e permissões de serviços públicos e dá outras providências. Diário Oficial, Brasília, 08/07/95. Seção 01, p 10125.

BRASÍLIA. Lei ${ }^{\circ} 10.848$, de 15 de março de 2004. Dispõe sobre a comercialização de energia elétrica, altera as Leis 5.655 de 20.05.1971, 8.631 de 04.03.1993, 9.074 de 07.07.1995, 9.427 de 26.12.1996, 9.478 de 06.08.1997, 9.648 de 27.05.1998, 9.991 de 24.07.2000, 10.438 de 26.04.2002, e dá outras providências. Diário Oficial, Brasília, 16/03/2004, Seção 01, Volume 141, Número 51, p 2. 
CAMÂRA DE COMERCIALIZAÇÃO DE ENERGIA ELÉTRICA. Visão Geral das Operações na CCEE. 2006.

CASTRO, A. Gerenciamento do Risco de Mercado para Produtos e Commodites no Brasil. 2002. Dissertação de Mestrado - Escola de Administração de Empresas de São Paulo, Fundação Getulio Vargas. São Paulo, 2002.

CROUHY, M.; GALAI, D; MARK, R. Gerenciamento de Risco: Abordagem Conceitual e Prática. Rio de Janeiro: Qualitymark; São Paulo: SERASA, 2004.

CYRINO, R. CAMPOS, C. Gerenciamento de Risco da Compra de Energia no Novo Modelo do Setor Elétrico. Monografia MBA em Energia - Escola Politécnica, Universidade de São Paulo. São Paulo, 2005.

DOMICIANO, J. A. Um Modelo de definição de tarifa de energia elétrica baseada no custo marginal: Estudo de caso na Ceron. 2002. Dissertação de Mestrado Universidade Federal de Santa Catarina. Florianópolis, 2002.

ELÉTRICA, Agência Nacional de Energia. Cadernos Temáticos ANEEL 4 - Tarifas de Fornecimento de Energia Elétrica. Disponível em http://www.aneel.gov.br. Acesso em 2007.

ELÉTRICA, Agência Nacional de Energia. Estabelece Tratamento regulatório das perdas de energia nas tarifas dos sistemas de distribuição de energia elétrica. Nota Técnica 02623 de maio de 2006. Disponível em <http://www.aneel.gov.br>. Acesso em: 2008.

ELÉTRICA, Agência Nacional de Energia. Estabelece Segunda revisão tarifária periódica da concessionária de distribuição de energia elétrica ELETROPAULO. Nota Técnica 184 de 27 de junho de 2007. Disponível em <http://www.aneel.gov.br>. Acesso em: 2008.

ELÉTRICA, Agência Nacional de Energia. Estabelece Regras de Comercialização referente ao repasse do custo de sobrecontratação de energia elétrica. Nota Técnica 085 de 05 de março de 2008. Disponível em <http://www.aneel.gov.br>. Acesso em: 2008.

ELÉTRICA, Agência Nacional de Energia. Estabelece as disposições atualizadas e consolidadas, relativas as Condições Gerais de Fornecimento de Energia Elétrica, a serem observadas na prestação e utilização do serviço público de energia elétrica, 
tanto pelas concessionárias e permissionárias quanto pelos consumidores. Resolução 456 de 29/11/2000. Diário Oficial, Brasília, 30/11/2000. Seção 01, Volume 138, Número 230-E, p. 35.

ELÉTRICA, Agência Nacional de Energia. Estabelece os procedimentos para a determinação das tarifas de energia elétrica de concessionária ou permissionária de serviço público de distribuição, para o fim de substituição dos contratos atuais de fornecimento dos consumidores do grupo $A$, e altera os arts. $7^{\circ}$, $9^{\circ}$ e 10 da Resolução ANEEL 249 de 06.05.2002. Resolução 666 de 29 de novembro de 2002. Diário Oficial, Brasília, 02/12/2002, Seção 01, Volume 139, Número 232, p 58.

ELÉTRICA, Agência Nacional de Energia. Estabelece a metodologia para o cálculo do reajuste das tarifas de uso dos sistemas de distribuição de energia elétrica, aplicáveis às concessionárias ou permissionárias de distribuição, bem como adota termos e conceitos. Resolução 790 de 24 de dezembro de 2002. Diário Oficial, Brasília, 27/12/2002, Seção 01, Volume 139, Número 250, p 361.

ELÉTRICA, Agência Nacional de Energia. Estabelece as disposições consolidadas relativas ao cálculo da tarifa de uso dos sistemas de distribuição - TUSD e da tarifa de energia elétrica - TE, bem como altera e revoga as Resoluções Normativas ANEEL especificadas. Resolução 166 de 10 de outubro de 2005. Diário Oficial, Brasília, 27/12/2002, Seção 01, Volume 142, Número 196, p 61.

ELÉTRICA, Agência Nacional de Energia. Estabelece os conceitos gerais, as metodologias aplicáveis e os procedimentos iniciais para realização do segundo ciclo de revisão tarifária periódica das concessionárias de serviço público de distribuição de energia elétrica. Resolução 234 de 31 de outubro de 2006. Diário Oficial, Brasília, 08/11/2006, Seção 01, Volume 143, Número 214, p 111.

ELÉTRICA, Agência Nacional de Energia. Estabelece as condições para a comercialização de energia elétrica, oriunda de empreendimentos de geração que utilizem fontes primárias incentivadas, com unidade ou conjunto de unidades consumidoras cuja carga seja maior ou igual a $500 \mathrm{~kW}$, no âmbito do Sistema Interligado Nacional - SIN. Resolução 247 de 21 de dezembro de 2006. Diário Oficial, Brasília, 26/12/2006, Seção 01, Volume 143, Número 246, p 271.

ELETROPAULO METROPOLITANA ELETRICIDADE DE SÃO PAULO S.A. Prospecto do Programa de Distribuição Pública de Debêntures da Eletropaulo. 2005. 596 p.

FERREIRA, I. R. Earnings at Risk para as Instituições não Financeiras e as Exigências da Lei Americana Sarbanes-Oxley. 2005. Dissertação de Mestrado Escola de Pós-Graduação em Economia, Fundação Getulio Vargas. Rio de Janeiro, 2005. 
GITMAN, L. Princípios da Administração Financeira. $3^{\circ}$ Ed. São Paulo: Harbra Ltda, 1987.

JORION, P. Value at Risk: A nova Fonte de Referência para a Gestão do Risco Financeiro. $2^{\circ}$ ed. São Paulo: Bolsa de Mercadorias \& Futuros, 2003.

KAISER ASSOCIATES LATIN AMERICA, Situação do Mercado Brasileiro de Energia Elétrica. São Paulo, 2006.

LAROQUE, E. LOWENKRON, A. AMADEO, E. JENSEN, J. Cenários Probabilísticos: Conjugando análise de riscos e projeções macroeconômicas. Documento Técnico, 2003. Lista de riscos disponível em $<$ http://www.listaderiscos.com.br>.

LEITE, H. P. Contabilidade para Administradores. $3^{\circ}$ ed. São Paulo: Atlas, 1993.

LEVINE, D. M.; BARENSON, L. M.; STEPHAN, D. Estatística: Teoria e Aplicação, $1^{\circ}$ ed. Rio de Janeiro: Livros Técnicos e Científicos, 2008.

LOWENKRON, A. LAROQUE, E. COSTA, C. AMADEO, E. JENSEN, J. Risco Macroeconômico: Projeções probabilísticas para 2005. Documento Técnico, 2005. Lista de riscos disponível em <http://www.listaderiscos.com.br>.

MARQUES, L. D. Modelos Dinâmicos com Dados em Painel: revisão de literatura, 2000.

MARTIN, P. A.; TOLOI, C. M. C. Análise de Séries Temporais, $2^{\circ}$ ed. São Paulo: Edgard Blucher, 2006.

MINISTÉRIO DE MINAS E ENERGIA. Cartilha O Novo Modelo do Setor Elétrico. Brasília, 2003. Disponível em http://www.mme.gov.br. Acesso em 2007.

NETO, A. A.; SILVA, C. A. T. Administração do Capital de Giro. $3^{\circ}$ ed., $7^{\circ}$ reimpr. São Paulo: Atlas, 2007.

NETO, J. F. C.; MOURA, H. J.; FORTE, S. H. C. A. Modelo prático de previsão de fluxo de caixa operacional para empresas comerciais considerando os efeitos do risco, através do método de Monte Carlo. . [ca. 2000]. (Estudo Técnico). Universidade de Fortaleza - UNIFOR. 
NETO, J. M. V. Determinação do Valor em Risco em Empresas não financeiras: Estudo de Caso de Empresa Geradora de Energia. 2005. Dissertação de Mestrado - Faculdade de Economia, Administração, Contabilidade e Atuária, Pontifícia Universidade Católica de São Paulo. São Paulo, 2005.

PEROBELLI, F. F. C. Um Modelo para Gerenciamento de Riscos em Instituições não Financeiras: Aplicação ao setor de Distribuição de Energia Elétrica no Brasil. 2004. Tese de Doutorado - Faculdade de Economia, Administração e Contabilidade, Universidade de São Paulo. São Paulo, 2004.

RISKMETRICS GROUP. Corporete Metrics Technical Document, 1999. Disponível em <http://www.riskmetrics.com>.

SAITO, R. O uso de derivativos e gerenciamento de riscos em empresas brasileiras não financeiras. 2005. 34 p. (Relatório Técnico). FGVEAESP/GVPESQUISA.

SECURATO, J. R. Decisões Financeiras em Condições de Risco. São Paulo: Atlas, 1996.

SILVA, E. L. Formação de Preços em Mercado de Energia Elétrica. Porto Alegre: Saga Luzzatto, 2001.

SUSTERÁS. G. L. Aplicação de Algoritmos Genéticos para Previsão do Comportamento das Distribuidoras como apoio à estratégia de Comercialização de Energia de Agentes Geradoras. 2006. Dissertação de Mestrado - Escola Politécnica, Universidade de São Paulo. São Paulo, 2006. 